DE93 002039

\title{
SAFETY REQUIREMENTS, FACILITY USER NEEDS, AND REACTOR CONCEPTS FOR A NEW BROAD APPLICATION TEST REACTOR
}

Edited by J. M. Ryskamp

Authors Are Listed On The Next Page

Idaho National Engineering Laboratory

EG\&G Idaho, Inc.

P. 0. Box 1625

Idaho Falls, ID 83415-1575

July 1992

Work performed under the auspices of the U. S. Department of Energy Assistant Secretary for Nuclear Energy

Under Contract No. DE-AC07-76ID01570. 
Project Manager and Report Editor

J. M. Ryskamp

Reactor Design Process Team

Leader: J. M. Ryskamp

Members: R. G. Bennett, J. A. Lake, R. D. Struthers, D. H. Stevensen, D. M. Woodall

Safety Requirements Team

Leader: J. L. Liebenthal

Members: E. C. Anderson, C. H. Cooper, J. C. Haire, W. G. Lussie

Facility User Needs Team

Leader: A. B. Denison

Members: R. A. Anderl, D. L. Batt, D. W. Constable, J. R. Fincke,

R. C. Greenwood, M. L. Griebenow, Y. D. Harker, B. J. Herrera,

J. E Herring, J. L. Jones, C. G. Motloch, D. W. Nigg,

E. H. Ottewitte, D. A. Petti, J. H. Ramsthaler, J. M. Ryskamp,

M. B. Sattison, F. Y. Tsang

Reactor Concept Team

Leader: C. D. Fletcher

Members: R. G. Ambrosek, I. M. Blasch, R. L. Drexler, F. G. Farmer,

J. A. Hong, S. N. Jahshan, C. F. Leyse, L. B. Lundberg,

R. W. Marshall, Jr., C. G. Motloch, S. M. Modro, R. L. Moore,

J. M. Ryskamp, R. C. Thayer, G. L. Thinnes, R. P. Wadkins

Strategy Assistance

C. G. Motloch, J. S. Martinell 


\begin{abstract}
This report describes the EG\&G Laboratory Directed Research and Development Program (LDRD) Broad Application Test Reactor (BATR) Project that was conducted in fiscai year 1991. The scope of this project was divided into three phases: a project process definition phase, a requirements development phase, and a preconceptual reactor design and evaluation phase. Multidisciplinary teams of experts conducted each phase. This report presents the need for a new test reactor, the project process definition, a set of current and projected regulatory compliance and safety requirements, a set of facility user needs for a broad range of projected testing missions, and descriptions of reactor concepts capable of meeting these requirements. This information can be applied to strategic planning to provide the Department of Energy with management options.
\end{abstract}




\section{SUMMARY}

For a variety of reasons, including (1) the increasing demands of the 1990's regulatory environment, (2) limited existing test capacity and capability to satisfy projected future testing missions, and (3) an expected increasing need for nuclear information to support development of advanced reactors, there is a need to develop a set of requirements and preliminary concepts for a new Broad Application Test Reactor (BATR). These requirements must include consideration not only for a broad range of projected testing missions, but also for current and projected regulatory compliance and safety requirements. The requirements will form the basis for development and assessment of preconceptual reactor designs and lead to the identification of key technologies to support the government's long-term strategic and programmatic planning.

This report outlines the need for a new Broad Application Test Reactor and suggests a few preliminary reactor concepts that can meet that need. A comprehensive set of safety requirements and facility user needs was developed before starting the conceptual design process. Multidisciplinary teams of experts developed this broad set of potential test reactor requirements. These requirements were then ranked to guide the subsequent development and evaluation of candidate reactor concepts. The reactor concepts were also assessed against broad applicability and flexibility criteria, the capability to meet the wide variety of mission requirements, and the potential to meet changes in regulatory and safety requirements.

The safety requirements in this report have been derived primarily from INSAG-3 ${ }^{1}$, with additional requirements regarding licensing. INSAG-3 contains principles for ensuring a high level of safety. Additional specific safety requirements will evolve as the reactor design progresses. The reactor must be licensable according to national and international standards in force at the time of construction 
and continue over its operating lifetime. Siting issues are included to provide guideline assistance in the design process. The Department of Energy (DOE) Orders must be followed, and DOE or Nuclear Regulatory Commission safety goals should be adopted (DOE goals were issued in a draft policy September 9, 1991). The implementation of these requirements should lead to a safe and effective reactor design.

Many different test reactor missions were explored. A steady-state high flux reactor can achieve the following missions (ranked in order of the perceived experimental need): fuels and materials irradiation testing, isotope production, space testing, medical research, fusion testing, intense positron facility, and transmutation doping. Table 1 summarizes the facility user needs for the missions stated above, and includes other design drivers. The most clear and consistent need is for a high neutron flux over a large sample volume. A neutron flux greater than $10^{15} \mathrm{~cm}^{-2} \mathrm{~s}^{-1}$ over a large volume (tens of liters) is considered both essential and feasible. A spectrum of neutron energies is needed, but the majority of the work can be accomplished with thermal neutrons. Multiple in-core loops and rabbit tubes are mandatory features. The core should be modular, reconformable, and flexible with easy access for loops, beam tubes, and rabbit tubes in order to adapt to a variety of different missions over the 30-50 year reactor life. Development risk should be reduced by using evolutionary rather than revolutionary technology. Such a reactor will be needed in the next decade.

Several existing and new reactor concepts (or neutron sources) were evaluated. These include conventional high flux reactor concepts (with metallic fuel plates and light or heavy water coolant and reflectors), pebble bed reactors, particle bed reactors, reactors with rotating fuel rings, cermet-fueled liquid-metal-cooled reactors, TRIGA reactors, and accelerator-driven spallation neutron sources. Advantages and disadvantages of each of these concepts are shown in Table 2 (partly derived from Reference 2). Based on this information, we determined that conventional concepts are the most likely to achieve the safety requirements and to meet facility user needs. After additional 
Table 1. Facility user needs and other design drivers

Priority

User Needs/Design Drivers

Essential Must meet all applicable safety requirements

Must be licensable

High flux $\left(>10^{15} \mathrm{~cm}^{-2} \mathrm{~s}^{-1}\right)$, large sample volume, steady-state reactor

Multiple in-core loops required (variable dimensions)

Modular type core (reconformable, flexible)

Flexible core to accommodate changing missions

In-core rabbit tubes

Easy access to loops, rabbit tubes, neutron beams, etc.

High availability/capacity factor

Primarily thermal neutron flux spectrum, but some positions with fast and epithermal spectra

Isotope production capability and handling

Minimum operational cost

Minimum waste stream effluents/environmental impact

Desirable Minimum development risk (want evolutionary, not revolutionary, technology)

Neutron beam tubes in reflector

Cold source in reflector

Powered axial locator mechanism

Minimum impact of control system on the fluxes at loop/beam/target locations

On-1 ine experiment changes

On-line and/or easy refueling capability

On-line and/or easy maintenance/inspectability

Long operational lifetime 
Table 1. (Continued)

Priority

User Needs/Design Drivers

Beneficial Want participation from several outside users (DOE, DOD, Navy, NASA, universities, and industry, etc.)

Low-enrichment fuel to limit security issues

Design with loop and other target dimensions consistent with existing test reactors for phase-in of missions

Maximum power level of $500 \mathrm{MW}$

Minimum capital cost

Use of system heat to offset operations costs

Use of a standard fuel type to minimize operations costs

Core components and support structures that are easily replaced to respond to radiation embrittlement concerns

Size of containment hatches adequate for removal of any component 
Table 2. Comparison of neutron source concepts for a BATR

\begin{tabular}{|c|c|c|}
\hline Concept & Advantages for BATR & Disadvantages for BATR \\
\hline Conventional & $\begin{array}{l}\text { Existing operating and } \\
\text { experimental experience } \\
\text { base, BATR flux can be } \\
\text { achieved with current } \\
\text { technology, licensability }\end{array}$ & $\begin{array}{l}\text { Aluminum (low melting } \\
\text { temperature, low strength, } \\
\text { low thermal-conductivity } \\
\text { oxide, steam explosion } \\
\text { potential, chemical } \\
\text { reactions) }\end{array}$ \\
\hline $\begin{array}{l}\text { Packed Particle } \\
\text { Bed }\end{array}$ & Very high flux & Moderate development risk \\
\hline Pebble Bed & $\begin{array}{l}\text { Existing experience base, } \\
\text { geometric flexibility, } \\
\text { neutron spectra flexibility, } \\
\text { minimum reactivity } \\
\text { insertion risk }\end{array}$ & $\begin{array}{l}\text { Low flux with existing } \\
\text { technology, fuel } \\
\text { development risk }\end{array}$ \\
\hline Rotating Rings & $\begin{array}{l}\text { Very high flux, but over } \\
\text { a limited volume. }\end{array}$ & $\begin{array}{l}\text { Substantial development } \\
\text { risk, safety concerns with } \\
\text { rotating fivel masses }\end{array}$ \\
\hline $\begin{array}{l}\text { Cermet-Fueled } \\
\text { Liquid-Metal } \\
\text { Cooled }\end{array}$ & High flux & $\begin{array}{l}\text { Significant safety risk } \\
\text { from coolant interactions } \\
\text { with in-core loop water }\end{array}$ \\
\hline TRIGA & $\begin{array}{l}\text { Existing experience } \\
\text { base, enhanced safety for } \\
\text { reactivity insertion events }\end{array}$ & $\begin{array}{l}\text { Suitable for pulsed, not } \\
\text { steady, operation, low } \\
\text { flux with existing } \\
\text { technology }\end{array}$ \\
\hline $\begin{array}{l}\text { Accelerator- } \\
\text { Driven } \\
\text { Spallation } \\
\text { Neutron Source }\end{array}$ & $\begin{array}{l}\text { Extremely high flux, but } \\
\text { over a small volume }\end{array}$ & $\begin{array}{l}\text { Cost, significant } \\
\text { development risk, unique } \\
\text { problems for shielding } \\
\text { experimenters }\end{array}$ \\
\hline
\end{tabular}


brainstorming and evaluation of conventional concepts, we selected the two most promising candidates: a multiple-annular configuration and a modular-hexagonal configuration, as shown in Figure 1. Both of these designs contain plate-type fuel (arcuate, involute, or concentric), light water coolant, and a heavy water reflector. The advantages and disadvantages of these concepts are compared with an upgraded Advanced Test Reactor (ATR) in this report. The flexibility of the two proposed concepts exceeds that of the upgraded ATR.

In summary, this report states the need for a new broad application test reactor and suggests a few reactor concepts that can meet that need. This report contains information supporting strategic planning that provides the Department of Energy with management options that could reduce risks. The Idaho National Engineering Laboratory should assist the Department of Energy in organizing a new initiative to provide the United States with a comprehensive Broad Application Test Reactor early in the next century. 

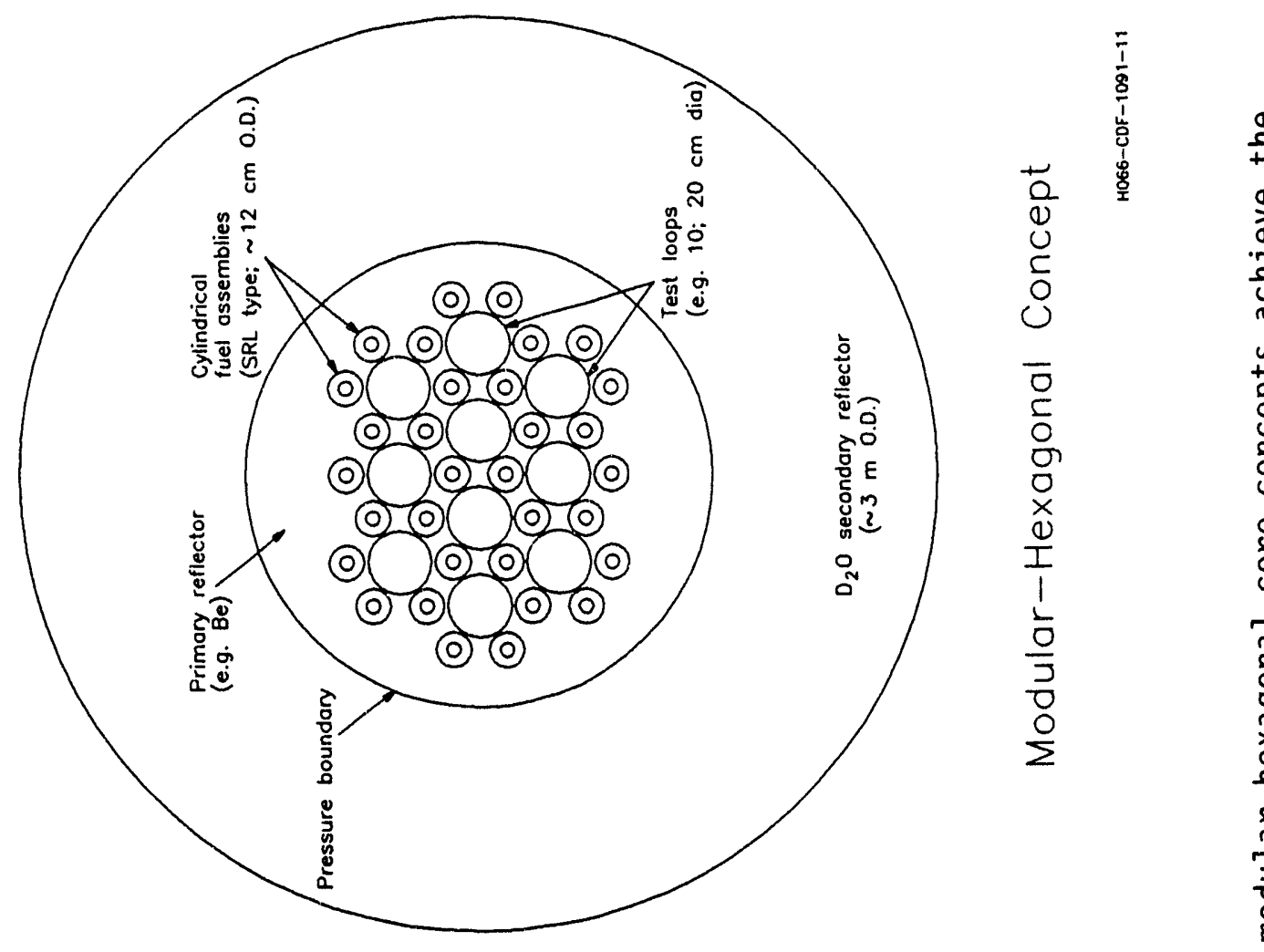

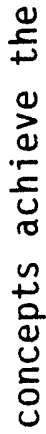

$\frac{0}{\frac{0}{0}}$

守

음

ช

Фे

息:

可

을

몽

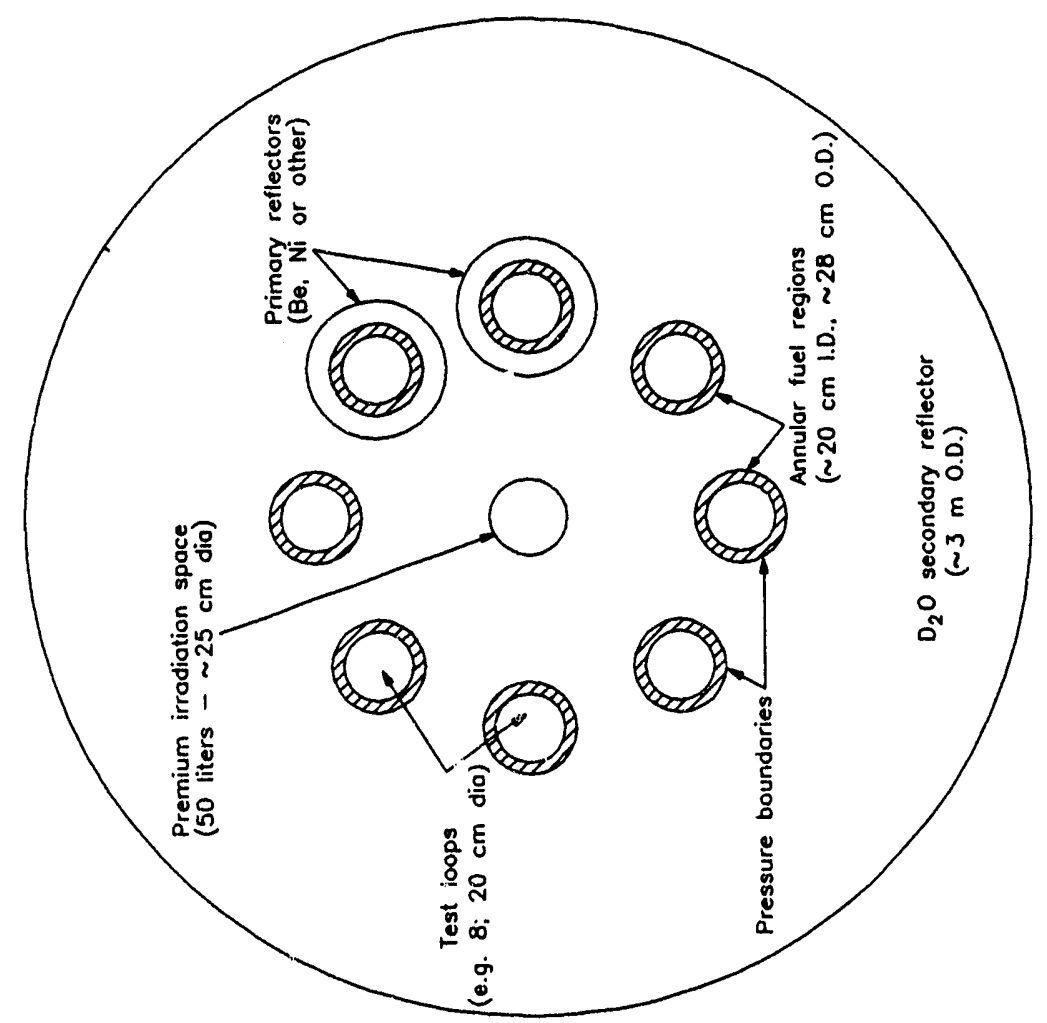

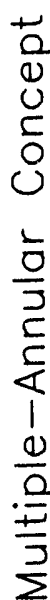

ปั

멍

$+8$

i

$\therefore$

is

它

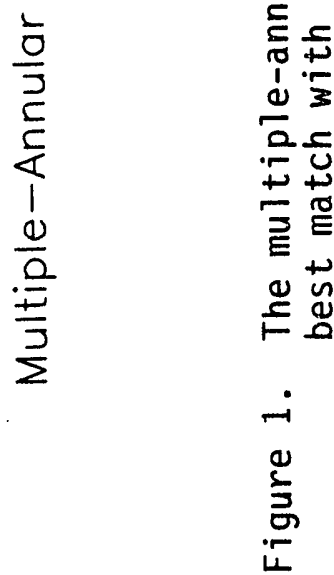




\section{CONTENTS}

Page

REPORT AUTHORS AND PROJECT TEAMS ................. . .

ABSTRACT ....................................

SUMMARY. . . . . . . . . . . . . . . . . . . . . . iv

1. INTRODUCTION . . . . . . . . . . . . . . . . . . 1

1.1 Need for a BATR . . . . . . . . . . . . . . . . 1

1.2 Project Process Definition. . . . . . . . . . . . 8

2. SAFETY REQUIREMENTS. . . . . . . . . . . . . . . . . 11

2.1 Licensing Requirements. . . . . . . . . . . . . 12

2.2 General Principles................ 13

2.2.1 Design Management Principles........... 13

2.2.2 Process Control Principles .............. 14

2.2.3 Barrier and Mitigation Principles. . . . . . . . . . 15

2.2.4 Safety System Principles ... . . . . . . . . 16

2.2.5 Siting Principles. . . . . . . . . . . . 17

2.3 Design Specific Requirements. . . . . . . . . . . . 18

2.3.1 Nuclear Regulatory Commission Safety Goals . . . . . 18

2.3.2 Proposed Safety Goals. . . . . . . . . . . . . 18

2.3.3 Probabilistic Risk Assessment as a Design Tool. . . . 18

2.3.4 Sponsoring Agency Safety Rules . . . . . . . . . 18

2.4 Design Specific Safety Requirements . . . . . . . . . . 19

2.4.1 Reactivity Coefficients. . . . . . . . . . 19

2.4.2 Stability. ................. 19

2.4.3 Probabilistic Requirement. . . . . . . . . . 19

2.4.4 Passive Cooling. . . . . . . . . . . . . . 19

2.4.5 Walk-Away Safety .................. 19

2.4.6 Containment/Confinement. . . . . . . . . . 20

2.5 Safety Considerations............... 20

3. FACILITY USER NEEDS. . . . . . . . . . . . . . . . 20

3.1 Fuels and Material Irradiation Testing . . . . . . . . 20

3.2 Isotope Production. . . . . . . . . . . . . . . 27

3.3 Space Applications Testing. . . . . . . . . . . . . . 27

3.4 Medical Research. . . . . . . . . . . . . . . . 28

3.5 Fusion Testing. . . . . . . . . . . . . . . . . . . 29

3.6 Intense Positron Facility . . . . . . . . . . . . 29

3.7 Transmutation Doping. . . . . . . . . . . . . . 30

3.8 Summary of Facility User Needs. . . . . . . . . . . . 31 


\section{CONTENTS (CONTINUED)}

4. REACTOR CONCEPT EVALUATION AND CONFIGURATION DEVELOPMENT . . . . 31

4.1 Neutron Source Concept Evaluations. . . . . . . . . . . 31

4.1.1 Conventional Reactor ............... 33

4.1.2 Packed Particle Bed Reactor. . . . . . . . . . . . . . 34

4.1.3 Pebble Bed Reactor . . . . . . . . . . . . . . . . 34

4.1.4 Reactor with Rotating Fuel Rings ............ . 35

4.1.5 Cermet-Fueled Liquid-Metal-Cooled Reactor. . . . . . . 35

4.1.6 TRIGA Reactor. ................... . 36

4.1.7 Accelerator-Driven Spallation Neutron Source . . . . . 36

4.1.8 Comparison of Neutron Source Concepts. . . . . . . . 37

4.2 Conventional Reactor General Considerations . . . . . . . 39

4.2.1 Design/Performance Topics . . . . . . . . . . . 39

4.2.2 Safety Topics... . . . . . . . . . . . . . . . . 44

4.2.3 Operational/Flexibility Topics............ 46

4.2.4 Reactor Control Topics................. 48

4.3 Conventional Reactor Configuration Development. . . . . . 49

4.3.1 Multiple-Annular Configuration ........... 49

4.3.2 Modular-Hexagonal Configuration. . . . . . . . . . 52

4.3.3 Upgraded ATR Configuration ............. 55

4.4 Comparison of Conventional Reactor Configurations . . . . . 58

4.5 Summary of Findings and Recommendations . . . . . . . . . 59

5. CONCLUSIONS AND RECOMMENDATIONS. . . . . . . . . . . . . 60

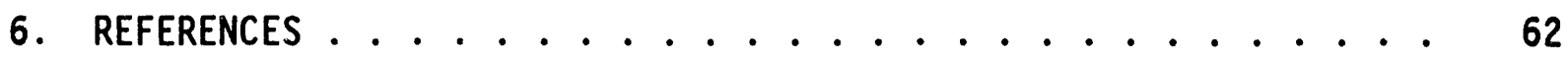

APPENDIX A - FUEL ASSEMBLY STRUCTURAL STUDIES. . . . . . . . . . . 64

APPENDIX B - FUEL STUDIES. . . . . . . . . . . . . . . . 73

APPENDIX C - THERMAL-HYDRAULIC STUDIES . . . . . . . . . . . . . 84

APPENDIX D - REACTOR PHYSICS STUDIES . . . . . . . . . . . . . 90

APPENDIX E - MECHANICAL DESIGN STUDIES . . . . . . . . . . . 105

TABLES

1. Facility User Needs and Other Design Drivers . . . . . . . . . vi

2. Comparison of Neutron Source Concepts for a BATR . . . . . . . viii 
CONTENTS (CONTINUED)

3. Research Reactors over 5 MW that have Begun Operation Since 1980................... 3

4. Retirement and Start-Up Dates for Comparable-Mission DOE Reactors................... 7

5. The Resctor Design Process............... 10

6. Basic Facility User Requirements by Discipline for a Steady-State Reactor. ............... 21

7. Essential User Needs. . . . . . . . . . . . . 23

8. Facility User Needs and Other Design Drivers. . . . . . . . 24

9. Comparison of Neutron Source Concepts for a BATR. . . . . . 38

10. Comparison of Reactor Configuration Flexibility . . . . . . 59

A-1 Mechanical and Physical Material Properties ......... 67

B-1 BATR fuel Candidates. . . . . . . . . . . . 76

C-1 Assumptions and Results for the Plate Material Thermal Limit Study ................. 86

C-2 Time to Reach Fuel Plate Solidus Temperature at Full Reactor Power .................. 87

D-1 Dependence of Single Module Multiplication Factor on Primary Reflector Substitutions............. 96

D-2 Dependence of Peak and Average Neutron Flux $\left(\mathrm{cm}^{-2} \mathrm{~s}^{-1}\right)$ in the Outer Reflector on Primary Reflector Substitution in the Single Module Model. . . . . . . . . . . . . 97

D-3 Dependence of Peak and Average Neutron Flux $\left(\mathrm{cm}^{-2} \mathrm{~s}^{-1}\right)$ in the Fueled Regions of Primary Reflector Substitutions in the Single Module Model. . . . . . . . . . . . . .

D-4 Dependence of Peak and Average Neutron Flux $\left(\mathrm{cm}^{-2} \mathrm{~s}^{-1}\right)$ in the Central Region of Inner Reflector on Primary Substitutions in the Single Module Model. . . . . . . . . .

D-5 Variation in the Multiplication Factor and the Peak Thermal Flux with the Two Module Separation ........ 100 


\section{CONTENTS (CONTINUED)}

\section{FIGURES}

1. The Multiple-Annular Distributed Core and Hexagonal Close-Packed Core Concepts Achieve the Best Match

with the Safety Requirements and Facility User Needs. . . . . . $x$

2. The Worldwide Age Distribution of Research Reactors Shows that a Large Fraction of the Reactors are

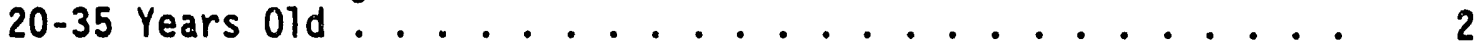

3. A Possible Schedule for the Broad Application Test Reactor. . . 6

4. Fuel Configurations Considered for BATR .......... 42

5. Multiple-Annular Conventional Reactor Configuration ..... 50

6. Modular-Hexagonal Conventional Reactor Configuration. ..... 53

7. A Two-Layer Checkerboard Reactor Configuration. . . . . . . 56

8. Upgraded Advanced Test Reactor Configuration. . . . . . . . 57

A-1 Segmented Involute Fuel Assembly. . . . . . . . . . 69

A-2 Involute Side Plate Spacing Based on Maximum Curvature (1 largest radius of Curve of ATR Plates is $13.325 \mathrm{~cm}$ ). . . . 72

D-1 BATR Single Base Module and Dimensions. . . . . . . . 9.4

D-2 Six Modules in a Circular Layout Core. The Intermodule Separation is 2D, Twice the Diameter of the Fuel Side Plate of a Module ................ 102

D-3 Hexagonal Layout of $4 \times 4$ Modules. The Intermodule Separation is 2D, Twice the Outer Fuel Side Plate Diameter of a Module. . . . . . . . . . . . . .

D-4 Rectangular Layout of $4 \times 4$ Modules. The Intermodule Separation is $2 D$. Twice the Outer Fuel Side Plate Diameter of a Module. 


\section{INTRODUCTION}

This report describes the EG\&G Laboratory Directed Research and Development Program (LDRD) Broad Application Test Reactor (BATR) Project that was conducted in fiscal year 1991 (FY-91). This report identifies the need for a new test reactor and outlines the project process definition, a set of current and projected regulatory compliance and safety requirements, a set of facility user needs for a broad range of projected testing missions, and a set of reactor concepts that meets these requirements.

\subsection{Need for a BATR}

For a variety of reasons, including (1) mandates of the 1990 s regulatory environment, (2) limited existing test capacity and capability to satisfy projected future testing missions, and (3) an increasing need for nuclear effects information to support development of advanced reactors, there is a need to develop a set of requirements and preliminary reactor concepts for a new broad application test reactor. These requirements must include consideration of a broad range of projected testing missions, as well as current and projected regulatory safety requirements.

The capacity to satisfy future testing missions is precarious because research reactors throughout the world are aging, as shown in Figure 2.3 A large fraction of the reactors are 20-35 years 01d, and few reactors are being built to replace them. Most test reactors will be over 40 years old by the year 2005, and many will have reached their lifetime limits and will have been shut down. Table 3 lists the world's research reactors with thermal powers over 5 MW that have begun operation since 1980. None of these newer reactors are located in the United States. Because the needs for fuels and materials testing and isotope production are expected to grow, the U.S. will certainly have a shortage of irradiation capacity, unless new high-flux reactors become available early in the next century. 


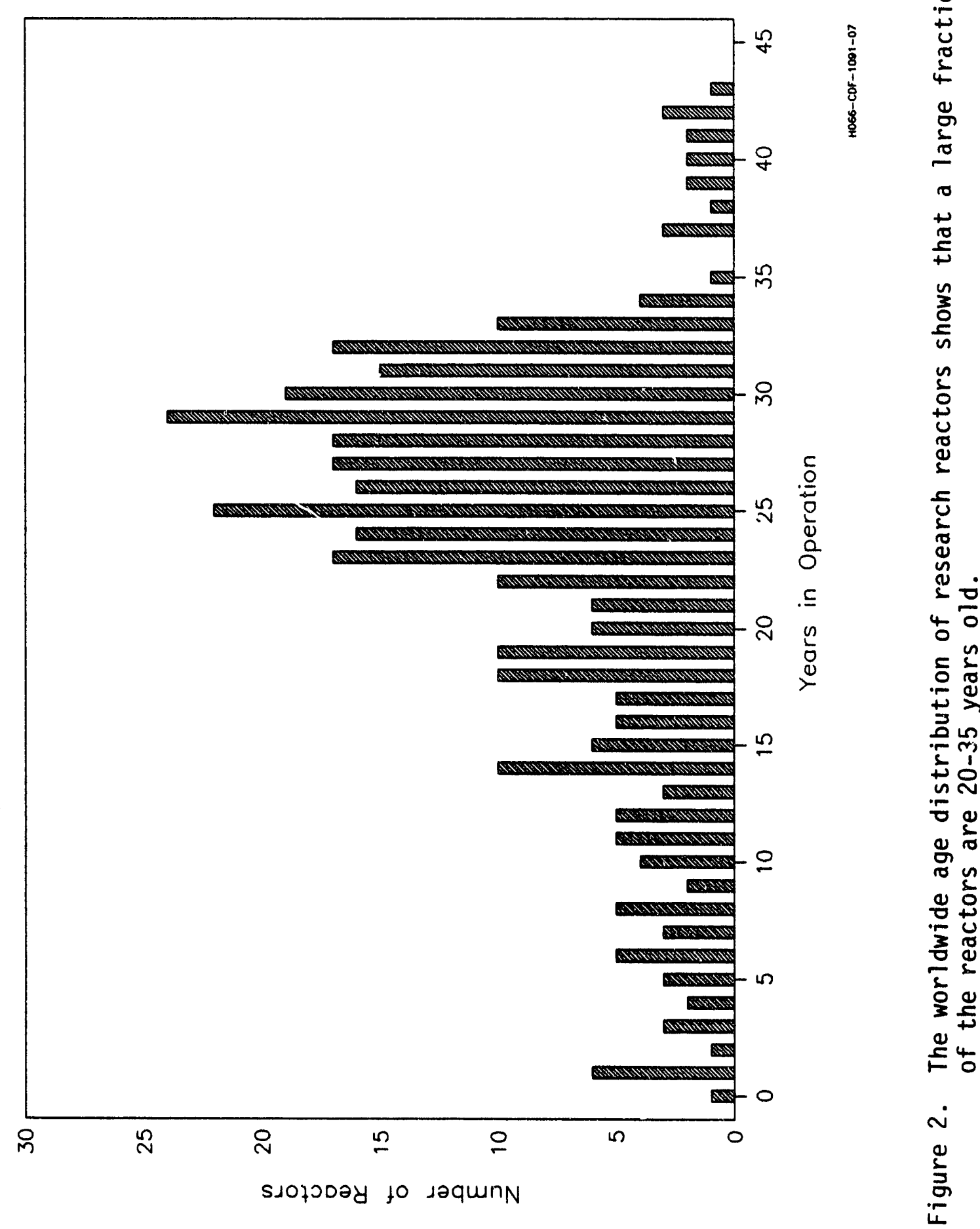


Table 3. Research reactors over 5 MW that have begun operation since 1980

\begin{tabular}{|c|c|c|c|}
\hline Country & Name & $\begin{array}{l}\text { Year } \\
\text { Critical }\end{array}$ & Power (MW) \\
\hline France & Scarabee $\mathrm{N}$ & 1982 & 100 \\
\hline India & Drhuva & 1985 & 100 \\
\hline India & FBTR & 1985 & 40 \\
\hline Iriúonesia & RSG-GAS-30 & 1987 & 30 \\
\hline Chile & Lo Aquirre Rech-2 & 1989 & 10 \\
\hline Libya & IRT-1 & 1983 & 10 \\
\hline Peru & $R P-10$ & 1988 & 10 \\
\hline USSR & $R B T-10 / 1$ & 1983 & 10 \\
\hline USSR & RBT-10/2 & 1984 & 10 \\
\hline Turkey & TR-2, Turkish Reactor & 1981 & 5 \\
\hline
\end{tabular}

An Advanced Neutron Source (ANS) with a peak unperturbed thermal neutron flux of about $8 \times 10^{15} \mathrm{~cm}^{-2} \mathrm{~s}^{-1}$ is being designed for condensed matter physics, materials science, isotope production, and fundamental physics research. ${ }^{4}$ The ANS is a new reacior-based research facility being planned by Oak Ridge National Laboratory (ORNL) to meet the need for an intense steady-state source of neutroris. The design is currently in the conceptual phase, and the reactor could begin operation in the year 2000. However, an ORNL report states: ${ }^{5}$

\footnotetext{
"It is generally agreed that the ANS cannot be the sole neutron source upon which a national irradiation-effects program is based; indeed, its usage should be confined to those experiments for which it is best suited. The problem is that the future mix of available facilities is ill-defined for the year 2000, owing to the recent or planned shutdown of existing reactors that will be or could be useful for materials testing at that time. For example, under present
} 
planning, the High Flux Isotope Reactor (HFIR) at ORNL will be phased out as the ANS comes on-line, but there may be good reason to consider an upgrading of the HFIR following the lead of the Europeans and the Japanese (e.g., Studsvik RZ Reactor, Petten HFR, Julich FRJ-2, JAERI JRR-3) in the latter part of the last decade. In fact, if the United States does not take some action of this sort, then it must be assumed that our national strategy is to use overseas facilities when the time comes to develop advanced power reactors, perform studies underlying the life extension or existing power reactors, and/or move more aggressively ahead in the fusion power field." "Regardless of the extent to which the ANS design is ultimately responsive to the radiation-effects community, it will not suffice as the only materials testing and basic irradiation effects neutron source in the U.S. It is not possible to meet the needs of all programs in a single reactor."

It is clear from this statement, which is a consensus of participants in a workshop held under the auspices of the U.S. Department of Energy (DOE), that the United States should take action. One such action is the design and construction of a Broad Application Test Reactor. The Idaho National Engineering Laboratory (INEL) therefore should assist the Department of Energy in organizing a new initiative to provide the United States with a comprehensive materials testing facility for the next century.

The current fleet of operating DOE test reactors, including the Advanced Test Reactor (ATR) at INEL, the HFIR at ORNL, the High Flux Beam Reactor (HFBR) at Brookhaven National Laboratory (BNL), and others were constructed and commissioned in the 1960s and 1970s. These reactors provide invaluable materials irradiation testing capability, limited isotope production, fundamental research, and weapons irradiation effects testing to support government defense and civilian missions. A number of future reactor testing needs are envisioned, which cannot be accommodated in the current test reactors either because of insufficient irradiation 
capacity or capability limitations. These include large volume, high power density space reactor fuels testing, (such as that required to qualify fuel assemblies for the particle bed reactor concept), large burst transient testing, high flux materials research using neutron beams (a mission assigned to the Advanced Neutron Source project at ORNL) and others. Many testing needs and materials irradiation capabilities are not simultaneously met by any single existing facility. Furthermore, all current test reactors are experiencing some form of challenge (and substantially increased costs) resulting from operating 1960s technology in the 1990s regulatory environment. It is possible that the government may decide at somo noint in time not to make additional investments in the upgrade of current test reactors to the technology that would be required to remain in compliance with current and future regulations (this is especially true if a cost effective alternative exists).

As a result, there is a need to examine the potential programmatic, compliance, and safety requirements for the next generation DOE test reactor that can fulfill the government defense and civilian testing needs in the early 2000s. It is importani to evaluate these requirements in terms of preliminary reactor concepts and technological capabilities to support the government's long-term strategic planning.

A possible schedule for the BATR design and construction is shown in Figure 3. The following acronyms are used in the figure: Probability Risk Assessment (PRA), Notice of Intent (NOI), Draft Environmental Impact Statement (DEIS), Final Environmental Impact Statement (FEIS), Preliminary Safety Analysis Report (PSAR), and Final Safety Analysis Report (FSAR). The reactor could begin operation in the year 2007. This schedule is aggressive and is patterned after the ANS schedule. Typically, it takes at least 15 years to design and build a unique high flux reactor for the Department of Energy. 


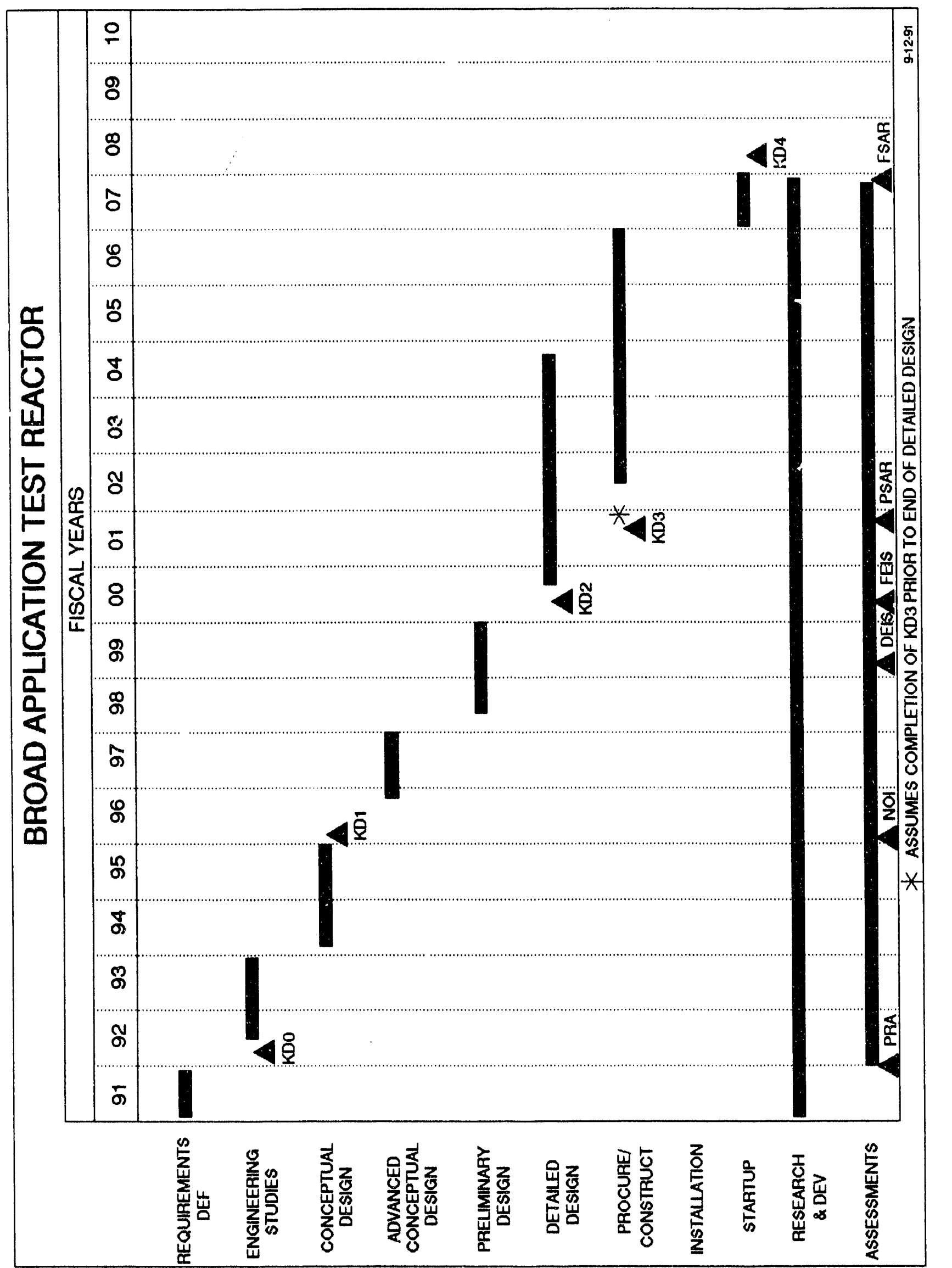

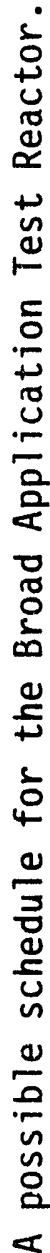


Table 4 presents retirement and start-up dates for comparable-mission DOE reactors. The ANS can take up much of the work presently being conducted at HFIR and HFBR. Only the BATR has the potential to continue the in-core loop experiments being conducted currently at ATR. The ANS design does not include experiment loops, thus the BATR complements the ANS mission; both reactors are needed.

A multipurpose, flexible facility is needed to accommodate the changing market and regulatory environment. The BATR will be much more flexible than the ATR and will be capable of a much broader variety of missions. However, we propose that the BATR design should be capable of continuing the current ATR missions. Thus, as the ATR ages, its work can be phased into the BATR. The BATR will give the DOE the flexibility it needs to achieve its goals. The ATR and the BATR could operate simultaneously for ten years with complementary missions, or the BATR could take over the ATR mission if radiation-induced pressure vessel embrittlement, or some other safety issue, causes ATR to be shut down.

Table 4. Retirement and start-up dates for comparable-mission DOE reactors

\begin{tabular}{|c|c|c|c|}
\hline & & $\mathrm{Ye}$ & \\
\hline Reactor & Main Mission & Retirement & Start-up \\
\hline $\begin{array}{l}\text { Advanced Test } \\
\text { Reactor (ATR) }\end{array}$ & $\begin{array}{l}\text { Materials Irradiation in Loops } \\
\text { (initial start-up 1967) }\end{array}$ & $?$ & \\
\hline $\begin{array}{l}\text { Fast Flux Test } \\
\text { Facility (FFTF) }\end{array}$ & $\begin{array}{l}\text { Limited Materials Testing (fast), } \\
\text { Limited Isotope Production (fast) }\end{array}$ & $?$ & \\
\hline $\begin{array}{l}\text { High Flux Beam } \\
\text { Reactor (HFBR) }\end{array}$ & Beam Research, Neutron Scattering & 2000 & \\
\hline $\begin{array}{l}\text { High Flux Isotope } \\
\text { Reactor (HFIR) }\end{array}$ & Isotope Production & 2000 & \\
\hline $\begin{array}{l}\text { Advanced Neutron } \\
\text { Source (ANS) }\end{array}$ & $\begin{array}{l}\text { Neutron Scattering, } \\
\text { Isotope Production }\end{array}$ & & 2000 \\
\hline $\begin{array}{l}\text { Broad Application } \\
\text { Test Reactor } \\
\text { (BATR) }\end{array}$ & $\begin{array}{l}\text { Broad Application, Test Loop } \\
\text { Irradiation, Beam Research, } \\
\text { Isotope Ploduction }\end{array}$ & & 2007 \\
\hline
\end{tabular}


Irradiation-induced embrittlement has shut down the Institut Laue-Langevin High Flux Reactor in Grenoble, France. This shutdown of the world's highest flux reactor was unexpected, leaving 1800 annual users without a . sufficient neutron source. Knowing that a BATR exists as a backup, the ATR missions should give sponsors a vision of continuity in their projects.

Strategic planning provides management options that could reduce risks. Planning ahead for a Broad Applications Test Reactor will give the Department of Energy the flexibility it needs to keep pace in a changing regulatory and programmatic environment. The BATR study is intended to help organize a new initiative for providing the United States with a comprehensive materials-testing facility for the next century.

\subsection{Project Process Definition}

In October 1990, the BATR project duties were divided among three teams, with a total of nearly 50 participants. Although a large number of personnel were involved, funding resources were limited, and as such the methodology employed was predominantly qualitative. However, this approach led to a successful analysis effort and could be applied generically to other reactor development projects.

The scope of the project effort was divided into three phases: a project process definition phase, a requirements development phase, and a preconceptual reactor design and evaluation phase. A multidisciplinary team of experts was assembled from personnel in reactor design, reactor safety, and programs dealing with reactor testing needs to develop a broad-based set of potential test reactor requirements. These requirements were then ranked to guide the subsequent development and evaluation of candidate reactor design concepts. The reactor design concepts were assessed and evaluated against broad applicability and flexibility criteria, and capability to meet a wide variety of mission 
requirements and to respond to changes in regulatory and safety requirements. The test reactor requirements and preliminary reactor concepts are documented in this report, which can subsequently be used in strategic planning discussions with DOE.

The Reactor Design Process Team spent the first quarter of FY-91 defining the deliverable and developing the process to be followed to produce that deliverable. The deliverable is this technical report, which states the need and requirements for a new broad application test reactor and suggests a few preliminary reactor concepts that can meet the need and requirements. The reactor design process also follows quality methods by defining a comprehensive set of requirements before the design process begins. Table 5 presents the generic reactor design process. Some additional items were added for the BATR project.

The Safety Requirements Team and the Facility User Needs Team spent the second quarter of FY-91 defining their requirements. These requirements are documented in Sections 2 and 3 of this report, respectively.

The Reactor Concept Team brainstormed concepts and performed trade-off studies. The BATR concept Team has documented their findings in Section 4 of this report.

In terms of organization, each of the individual teams met several times, and all teams met as a unit five times. The purposes of this organization were to ensure strength in each of the diverse disciplines contributing to the project and to provide necessary interdisciplinary communication among the teamis. 
Table 5. The reactor design process

1. Obtain resources for preliminary reactor design

2. Determine customer and define strategy

3. Define deliverable product (report, paper)

4. Define reactor design process (inputs, outputs)

5. Assemble appropriate teams (process, requirements, concept)

6. Define requirements
a. User needs/performance
b. Safety
c. Cost
d. Development risk

7. Rank requirements (musts/wants)

8. Assign weighting factors

9. Brainstorm reactor concepts

10. Survey existing concepts

11. Analyze concepts

12. Evaluate concepts against the requirements

13. Rank the concepts

14. Combine best features of concepts

15. Brainstorm ideas for improving concept

16. Analyze the best concept

17. Perform trade-off studies

18. Select preferred preliminary reactor concept

19. Calculate characteristics of design

20. Document entire effort

21. Prepare proposal for conceptual design

22. Conduct conceptual design

23. Conduct preliminary design

24. Conduct final design 


\section{SAFETY REQUIREMENTS}

This section presents general safety design requirements and siting issues for the BATR. These requirements and issues were used in conjunction with the facility user needs statement by both the Reactor Concept Team and the Reactor Design Process Team in the implementation of their phases of the BATR project.

The requirements set forth herein are designated as "shoulds" or "musts" as specified. They constitute baseline requirements that must be configuration controlled throughout the concept selection, design, and subsequent phases of the project. This means that they must not be changed or waived without concurrence of the BATR management team, and there must be a written record of how each of the requirements is dispositioned, especially in the design process. They are the statement of customer safety needs and cannot be unilaterally altered.

The general safety requirements below have been derived primarily from the INSAG-3 document. 1 Requirements regarding licensing and licensability are also included. The INSAG-3 document presents basic safety principles. They were developed by authors who compiled a listing of principles for ensuring a high level of safety and presented them in the subject report as one means of assuring compliance with these basic safety principles. They were not published as requirements but as principles, the implementation of which would lead to safe and effective reactor plants. The principles were studied by the Safety Requirements Team, and those that were directly relevant to the reactor plant design process were selected and presented here as requirements for the BATR. The first two requirements, regarding licensing, were developed by the Safety Requirements Team.

There are four categories of requirements or issues:

(1) Licensing requirements, which delineate the expected process of licensing that the design must be capable of passing, 
(2) General requirements, which are design and siting related principles that this reactor must meet to achieve safety comparable to other well designed reactors,

(3) Design requirements, which are specific to the expected design and are firm safety-related reactor characteristics, and

(4) Design considerations, which are those issues that the Safety Requirements Team considered to be less-than-firm requirements, because they may not be fully achievable, but nevertheless highly desirable.

The public safety risk from a reactor facility resulting from design basis events depends greatly on the facility design and site. The siting issues (Section 2.2.5) are included to provide guideline assistance in the design process. Most of these siting issues were derived from INSAG principles but they do not constitute design requirements per se. They constitute issues that can have an impact on the design and on various design decisions, but are envisioned more as constraints rather than requirements.

\subsection{Licensing Requirements}

1. The reactor must be licensable according to national and international standards in force at the time of construction.

2. The reactor design must be flexible such that future safety improvements can be incorporated to meet the changing national and international standards over its operating lifetime.

3. The principles of INSAG-3 shall be followed except where they apply strictly to power reactors. 


\subsection{General Principles}

General safety principles are described in a concise manner here. The numbers appearing in parentheses refer to the INSAG report ${ }^{1}$ general safety principles.

\subsubsection{Design Management Principles}

2.2.1.1 Proven Technoingy. Technologies incorporated into the design should have been proven by experience and testing. Significant new design features or new reactor types are introduced only after thorough research and prototype testing at the component, system, or plant level, as appropriate. (4.2.1.2)

\subsubsection{Probabilistic Risk Assessment (PRA) Based Conservative Design} Margin. A nuclear power plant is designed to cope with a set of events including normal conditions, anticipated operational occurrences, extreme external events, and accident conditions. For this purpose, conservative rules and criteria incorporating PRA-based safety margins enhance the design requirements. Comprehensive analyses are performed to evaluate the safety performance or capability of the various components and systems in the plant. $(4 \cdot 2 \cdot 1.3)$

2.2.1.3 Reliability. Reliability targets are assigned to safety systems or functions. The targets are established on the basis of the safety objectives and are consistent with the roles of the systems or functions in different accident sequences. Provision is made for testing and inspection of components and systems for which reliability targets have been set. $(4.2 .2 .3)$

2.2.1.4 Redundancy and Diversity. Diverse and redundant design provisions seek to prevent the loss of safety functions due to damage to several components, systems, or structures resulting from a common cause. $(4.2 .2 .4)$ 
2.2.1.5 Qualification. Safety components and systems are chosen that are qualified for the environmental conditions that would prevail if they were required to function. The effects of aging on normal and abnormal functionality are considered in design and qualification to ensure that all components and systems can achieve the required system/facility design life. (4.2.2.5)

2.2.1.6 As Low As Reasonably Achievable (ALARA) in Design. At the design stage, radiation protection features are incorporated to protect plant personnel from radiation exposure and to keep emissions of radioactive effluent within ALARA prescribed limits. (4.2.2.7)

\subsubsection{Process Control Principles}

2.2.2.1 Process Control System. Normal operation and anticipated operational occurrences are controlled so that plant and system variables remain within their operating ranges. This reduces the frequency of demands on the safety systems. $(4 \cdot 2.2 .1)$

2.2.2.2 Normal Heat Removal. Heat transport systems are designed for highly reliable heat removal during normal operation. They would also provide means for the removal of heat from the reactor core during anticipated operational occurrences and during most types of accidents that might occur. $(4.2 .3 .4)$

\subsubsection{Monitor the Plant Safety Status. Parameters to be} monitorad in the control room are selected, and their displays are arranged, to ensure that operators have clear and unambiguous indications of the status of plant conditions important for safety, especially for the purpose of identifying and diagnosing the iutomatic actuation and operation of a safety system or the degradation of defense in depth. $(4.2 .3 .9)$ 
2.2.2.4 Preserve Control Capability. The control room is designed to remain habitable under normal operating conditions, anticipated abnormal occurrences, and accidents considered in the design. Independent monitoring and the essential capability for control needed to maintain ultimate cooling, shutdown, and confinements are provided remote from the main control room for circumstances in which the main control room may be uninhabitable or damaged. $(4.2 .3 .10)$

\subsubsection{Barrier and Mitigation Principles}

2.2.3.1 Reactor Core Integrity. The core is designed to have mechanical stability. It is designed to tolerate an appropriate range of anticipated variations in operational parameters. The core design is such that the expected core distortion or movement during an accident within the design basis would not impair the effectiveness of the reactivity control or the safety shutdown systems or prevent cooling of the fuel. (4.2.3.2)

2.2.3.2 Reactor Coolant System Integrity. Codes and standards for nuclear vessels and piping are supplemented by additional measures to prevent conditions arising that could lead to a rupture of the primary coolant system boundary at any time during the operational life of the plant. (4.2.3.6)

2.2.3.3 Station Blackout. Nuclear plants are designed so that the simultaneous loss of normal on-site and off-site $A C$ electrical power (a station blackout) will not soon lead to fuel damage. (4.2.3.11) 


\subsubsection{Safety System Principles}

2.2.4.1 Automatic Safety System. Automatic systems are provided that would safely terminate the chain reaction, maintain coolability of the reactor, and limit any release of fission products from the fuel, if operating conditions were to exceed predetermined set-points. (4.2.2.2)

2.2.4.2 Reactivity Accidents. The reactor is designed so that reactivity-induced accidents are protected against, with a conservative margin of safety, i.e., the consequences of accidents will not involve violation of safety barriers. (4.2.3.1)

2.2.4.3 Shutdown. Rapidly responding and highly reliable reactivity reduction for safety purposes is designed to be independent of the equipment and processes used to control the reactor power. Safety shutdown actions are available at all times whenever steps to achieve a self-sustaining chain reaction are being intentionally taken or whenever a chain reaction might be accidently initiated. $(4.2 .3 .3)$

2.2.4.4 Emergency Heat Removal. Provision is made for alternative means to restore and maintain fuel cooling under accident conditions, even if normal heat removal fails or if the integrity of the primary cooling system boundary is lost. $(4.2 .3 .5)$

2.2.4.5 Confinement. The $p l a n t$ is designed to be capable of retaining the bulk of the radioactive material that might be released from fuel for the entire range of accidents considered in the design. (4.2.3.7)

\subsubsection{Protection of Confinement. If specific and inherent}

features of a nuclear power $p l$ ant would not prevent detrimental effects on the confinement structure in a severe accident, special protection against the effects of such accidents is provided, to the extent needed to meet the general safety objective. (4.2.3.8) 
2.2.4.7 Control of Accidents. Provisions are made at the design stage for the control of accidents within the design basis, including the specification of information and instrumentation needed by the plant staff for following and intervening during the courses of accidents. (4.2.3.12)

2.2.4.8 Inspectability. Safety related components, systems, and structures are designed and constructed so that they can be inspected throughout their operating lives to verify their continued acceptability for service with an adequate safety margin. (4.2.2.6)

\subsubsection{Siting Principles}

2.2.5.1 Local Factors. The choice of site takes into account the results of investigations of local factors that could adversely affect the safety of the plant. (4.1.1)

2.2.5.2 Total Hazard. Sites are investigated from the standpoint of the total hazard/risk impact of the plant in normal operation and in accident conditions. (4.1.2)

2.2.5.3 Countermeasure Compatibility. The site is selected to minimize, and be compatible with, the off-site countermeasures that may be necessary to limit the effects of all accidental hazardous occurrences, and is expected to remain compatible with such measures. (4.1.3)

2.2.5.4 Reliable Long-Term Heat Sink. The site has a reliable, preferably passive, long-term heat sink that can remove energy generated in the plant after shutdown, both immediately and long after shutdown. (4.1.4)

2.2.5.5 Seismic Zone. The designation of the specific seismic zone and safe shutdown earthquake, and measures to obviate an operating basis earthquake if feasible, will present a design constraint for the overall design approach. (no INSAG reference) 


\subsection{Design Specific Requirements}

\subsubsection{Nuclear Requlatory Commission (NRC) Safety Goals}

These criteria should be adopted as living requirements, that is, the design should be capable of meeting these goals, even if they change in the future.

\subsubsection{Proposed Safety Goals}

Proposed NRC safety goals are stated for core melt and large release. As a design specific requirement prior to the adoption of NRC goals, a core damage goal of $10^{-6}$ per year is adopted in Section 2.4 .3 below.

\subsubsection{Probabilistic Risk Assessment (PRA) as a Design Tool}

PRA must be employed as a means of demonstrating compliance with the NRC Safety Goals and reducing risks in the design. Use of PRA should not exclude the traditional design basis approach to safety evaluation.

\subsubsection{Sponsoring Agency Safety Rules}

Again, these rules should be treated as living requirements. Sponsoring agency rules for comment should be treated as appropriate in accord with the living requirement principle for sponsor agency safety rules. The current sponsoring agency safety rules are the DOE Orders and these should be followed. 


\subsection{Design Specific Safety Requirements}

\subsubsection{Reactivity Coefficients}

Reactivity coefficients should be strongly negative overall, al though carefully limited local regions having a positive coefficient may be allowable, if necessary. Redundant and diverse shutdown systems should be employed; fluid poisons or a "reactor fuse" are possibilities for achieving this. The reactivity coefficients must be sufficiently negative to override a large positive step reactivity pulse. The goal is no core damage.

\subsubsection{Stability}

Mechanical, fluid-structural, and neutronic stability is required. Aging effects on these characteristics (particularly irradiation induced aging) must be considered.

\subsubsection{Probabilistic Requirement}

The probability of unmitigated or unprotected core damage accidents should be as low as possible. All sources of core damage are carefully and adequately considered, using PRA techniques, and are limited to a frequency of less than $10^{-6}$ per year of operation.

\subsubsection{Passive Cooling}

In the event of an accident, designs should provide long-term passive cooling and maintenance of a coolable geometry at material temperatures that are sufficiently low to prevent further degradation of the core.

\subsubsection{Walk-Away Safety}

The design should ensure safe final states and outcomes from accidents, with no or minimal operator intervention. 


\subsubsection{Containment/Confinement}

The design should include containment or confinement of beam tubes or other such facilities. All reactor system pressure boundaries should be back-up protected with redundant barriers.

\subsection{Safety Considerations}

Loss of Coolant Accident (LOCA) proofing, in the sense of preventing a LOCA from occurring, is desirable. A ${ }^{3} \mathrm{He}$ or other fast scram system (a "reactor fuse") should be considered as a potential preventive for flow instability. Passive cooling design should be based on the recent Advisory Committee on Reactor Safety proposal: severe accidents should be considered in the containment design requirement.

\section{FACILITY USER NEEDS}

As a part of examining the need for and feasibility of a new Broad Applications Test Reactor, the Facility User Needs Team surveyed the various needs and possible uses of such a reactor.

A description of the basic experimental needs and wants are presented in a matrix form in Table 6 . Table 7 lists the essential facility user needs that are common among several disciplines. Table 8 summarizes the facility user needs and includes other design drivers. More extensive descriptions of the various needs are provided in the following sections. These sections are ranked in order of importance (as is Table 6).

\subsection{Fuels and Material Irradiation Testing}

This type of research and testing has been an important component of the work performed at ATR. The behavior and aging characteristics of 


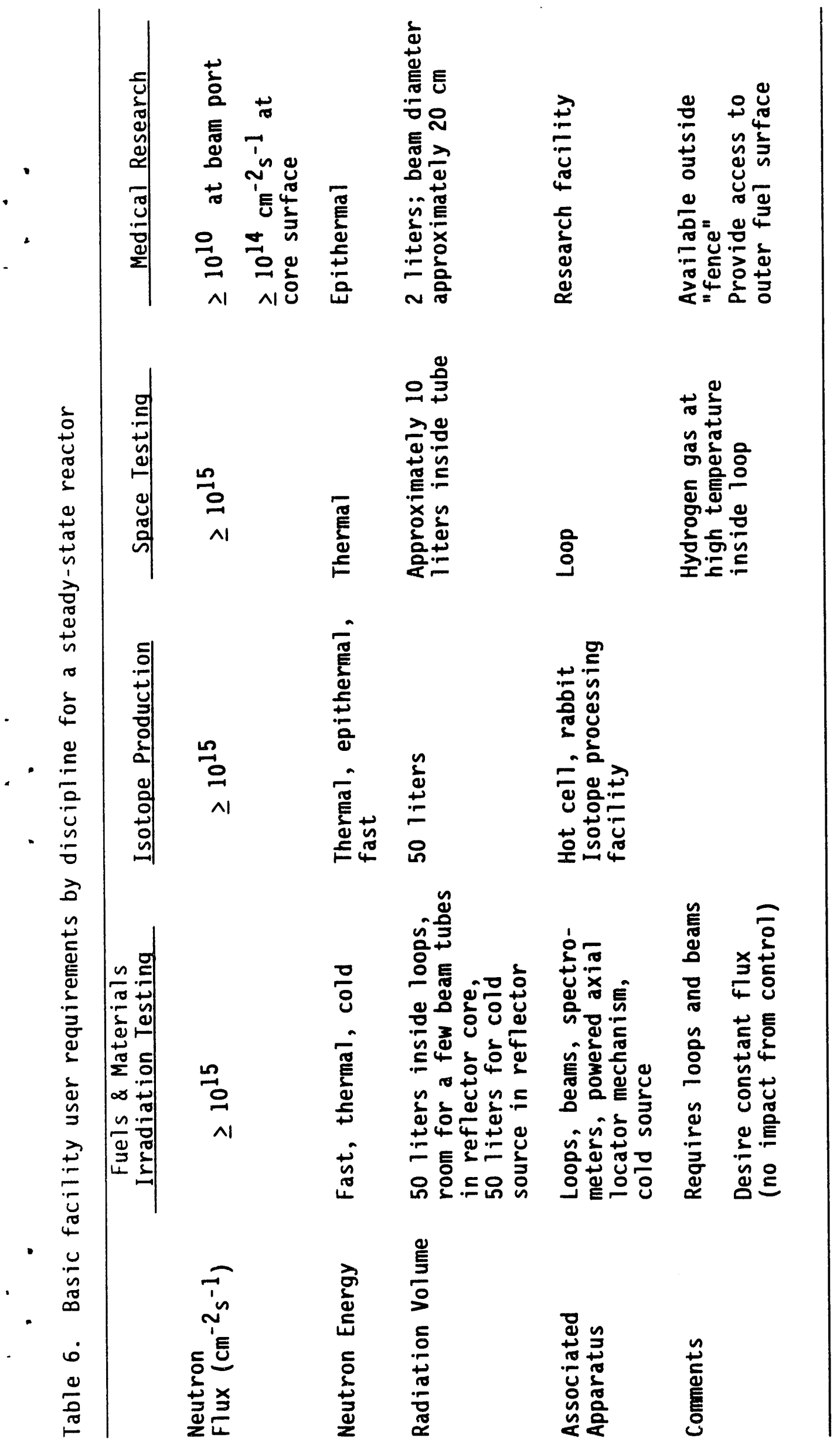




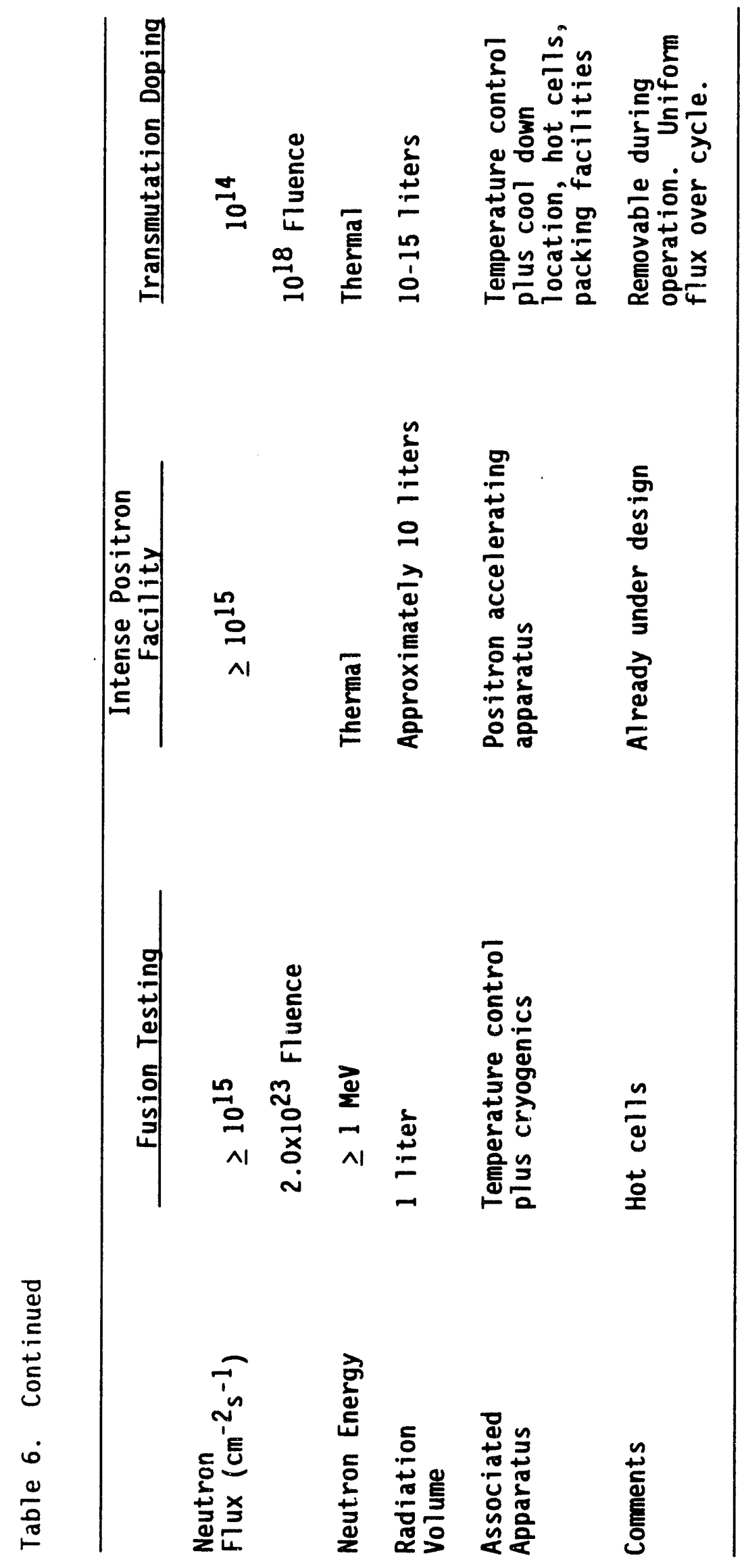


Table 7. Essential user needs

Need

Flux: $\geq 10^{15} \mathrm{~cm}^{-2} \mathrm{~s}^{-1}$

Energy:

Cold

Thermal

Epithermal

Fast

Volume: $\quad \frac{250 \text { liters a }}{\text { high flux }\left(10^{15}\right)}$

As much as possible

at lesser flux

Loops:

Beams:

Other: Rabbit and Powered Axial Locator Mechanism
Users

Radiation Testing, Isotope Production, Positron Facility, Materials, Medical

Materials, Magnetism

Irradiation Tests, Isotope Production, Fusion Transmutation, Positron Facility Medical, Isotope Production

Irradiation Tests, Isotope Production

Irradiation Tests, Isotope Production

Medical, Fusion Test, Fusion Transmutation, Positron Facility, Materials

Irradiation Tests, Fusion Tests, Positron Facility, Materials

Medical (20-cm diameter), Materials

Most Programs 
Table 8. Facility user needs and other design drivers

Priority User Needs/Design Drivers

Essential Must meet all applicable safety requirements

Must be licensable

High flux ( $\left.>10^{15} \mathrm{~cm}^{-2} \mathrm{~s}^{-1}\right)$, large sample volume, steady-state reactor

Multiple in-core loops required (variable dimensions)

Modular type core (reconformable, flexible)

Flexible core to accommodate changing missions

In-core rabbit tubes

Easy access to loops, rabbit tubes, neutron beams, etc.

High availability/capacity factor

Primarily thermal neutron flux spectrum, but some positions with fast and epithermal spectra

Isotope production capability and handling

Minimum operational cost

Minimum waste stream effluents/environmental impact

Desirable Minimum development risk (want evolutionary, not revolutionary, technology)

Neutron beam tubes in reflector

Cold source in reflector

Powered axial locator mechanism

Minimum impact of control system on the fluxes at 10op/beam/target locations

On-line experiment changes

On-line and/or easy refueling capability

On-line and/or easy maintenance/inspectability

Long operational lifetime 
Table 8. (Continued)

Priority

User Needs/Design Drivers

Beneficial Want participation from several outside users (DOE, DOD, Navy, NASA, universities, and industry, etc.)

Low-enrichment fuel to limit security issues

Design with loop and other target dimensions consistent with existing test reactors for phase-in of missions

Maximum power level of $500 \mathrm{MW}$

Minimum capital cost

Use of system heat to offset operations costs

Use of a standard fuel type to minimize operations costs

Core components and support structures that are easily replaced to respond to radiation embrittlement concerns

Size of containment hatches adequate for removal of any component

material used in reactors is of utmost importance. Studies at the ATR for the Navy and other customers have provided a considerable body of information on materials characteristics and behavior under irradiation. It is difficult to predict long-term effects produced by high-level radiation, although these effects can be inferred from the effects produced by yet higher radiation fluxes over shorter periods. With an increased interest in operating reactors for longer periods of time with higher fluxes and different fuels, these types of studies are becoming critical. The ATR is the only reactor in the U.S. currently that is capable of delivering high neutron flux levels inside experimental loops. This capability will continue to be needed after the ATR reaches the end of its operating life.

A requirement for this type of work is to attain as high of a steady-state flux as possible $\left(>10^{15} \mathrm{~cm}^{-2} \mathrm{~s}^{-1}\right)$ throughout an irradiation volume 
commensurate with the components under study. It is important to be able to insert and remove the samples at prescribed times for examination and perhaps reinsertion. For such operations, experimental loops within the reactor are essential. Constant fluxes are required throughout the irradiation period, and therefore the flux distributions inside the loops should be relatively free from outside perturbations.

Associated equipment will involve counting spectrometers and material degradation measurement apparatus. Well-equipped hot cells located close by will provide optimal ease and efficiency in the performance of fuels and materials irradiation testing.

Neutron scattering studies of materials provide one of the most powerful tools in nuclear and condensed-matter physics experimental analysis. The broad range of neutron energies available from a reactor can provide capabilities for studying nuclei and their cross sections and the dynamic behavior of atoms and molecules. The structure factor of a scattering body can be obtained as a function of the momentum and energy lost by the scattered neutron wave function. For very small energy loss, the structure factor is evaluated only as a function of the momentum 1oss, and the small momentum change is related to the small-angle neutron scatter. For highly-thermalized neutrons with large wavelength, the coherent neutron scattering intensity can probe structures of sizes inversely proportional to the momentum change. Thus polymer molecule sizes and morphologies of polymer crystals or other polymeric materials can be studied. When magnetically-polarized due to neutron spin, the highly-thermalized neutrons can be used to probe magnetic materials, magnetic domains, and phase transitions in critical phenomena. Such probes include studies on the atomic scale, such as strain and deformation, textures, surfaces, and structures. Much of the probing capabilities of neutron scattering cannot be replaced by lasers, electron microscopes, or any other tools. Worldwide, the reactors available for this work are few, and those currently available in the U. S., such as the University of Missouri Research Reactor, have intensities an order of magnitude lower than those available elsewhere, such as the Institut Laue-Langevin reactor at Grenoble, France. 


\subsection{Isotope Production}

Isotope production will be a valuable use of any new high flux reactor. Presently, it is not economically feasible to produce small quantities of exotic isotopes (highly asymmetric nuclei, long-lived metastable states, etc.). Nonetheless, there is a demand for a wide variety of radioactive isotopes for medicine, agriculture, materials, testing, and basic research. It would be useful to design a reactor with an "isotope production" region within its core. A high flux $\left(10^{15} \mathrm{~cm}^{-2} \mathrm{~s}^{-1}\right)$ is extremely valuable because the production rate is dependent on the total neutron availability, that is, the product of the flux intensity and irradiated volume. Activation is mainly due to thermal neutrons, (i.e., moderator) with a few cases requiring epithermal or fast neutrons. Because some nuclides in the chain decay quickly, a high flux is necessary to produce certain isotopes before the decay has a chance to occur. Thus a high flux reactor is often the only economical way to produce some isotopes. Ten liters of high flux radiation zone is considered adequate. Access loops and rabbit transfer mechanisms are also needed. Although the Advanced Neutron Source will replace the current isotope production capabilities of the High flux Isotope Reactor, more high flux capability will certainly be needed in the next century.

\subsection{Space Applications Testing}

The Space Exploration Initiative announced by President Bush in 1989 requires the development of both nuclear rocket propulsion and space nuclear power technologies. Both of these efforts involve extensive research and development efforts including test reactor irradiations to determine the effects of radiation on new high-temperature materials, nuclear fuels, and components. New reactor systems have been proposed to meet the unique requirements involived in providing electrical power on space ships and planets, and providing propulsion for space ships and planet rover vehicles. Reactor concepts cover the range from solid fueled 
types to liquid and gas-core options. Because of the high cost of transportation to space, essentially all concepts are pushing the limits of reactor core temperatures and power densities. The irradiation facility requirements include small capsules, loops, and larger volumes (for component testing) with both thermal and fast neutron fluxes of greater that $10^{15} \mathrm{~cm}^{-2} \mathrm{~s}^{-1}$.

\subsection{Medical Research}

Radiation therapy for cancer is now considered one of the standard techniques to combat the disease. Localized tumors have been treated with ${ }^{60} \mathrm{Co}$ and other radioisotopes for several decades. Unfortunately, the treatment of diffuse or filamented tumors has not experienced the same success. Research at the INEL in cooperation with other laboratories has shown the distinct possibility that a fibrous/filamenting tumor that occurs in the brain may be treated using Boron Neutron Capture Therapy (BNCT). This method uses "boron-loaded" bio-molecules that concentrate in these tumors. Neutrons of the appropriate energy are targeted to the diseased area, where they are preferentially captured by the boron. The resulting energetic fragments kill the cancer cells. In ore $r$ to carry on further studies and to possibly treat patients, a new high flux reactor is needed. A flux of $>10^{14} \mathrm{~cm}^{-2} \mathrm{~s}^{-1}$ in the reactor core would provide the desired $>10^{10} \mathrm{~cm}^{-2} \mathrm{~s}^{-1}$ neutron flux at the end of a beam port delivered into a medical unit. Epithermal neutrons produce the maximum efficiencies for treatment. A beam port with approximately a $20-\mathrm{cm}$ diameter is envisioned. This beam port would be used primarily to conduct research on animals. The BATR is not intended to be a dedicated medical therapy reactor. Other reactors have been proposed to fill that role. However, the BATR should have the flexibility to accomplish medical research if the DOE requests it. 


\subsection{Fusion Testing}

Fusion testing deals with the evaluation and understanding of materials in the hostile environment at a fusion energy production facility. Of particular interest is the damage and degradation of certain materials from the 14.1-MeV neutrons produced in the D-T reaction and the 2-MeV neutrons produced in the $D-D$ reaction. Additionally, the understanding and effects of nuclear activation processes is important for the development of economically viable fusion energy facilities. By increasing the neutron flux, one is able to shorten the time required to observe the effects of integrated fluence on components in a fusion environment. A neutron flux of $10^{15} \mathrm{~cm}^{-2} \mathrm{~s}^{-1}$ (or a total fluence of $2.0 \times 10^{23} \mathrm{~cm}^{-2}$ ) is needed. The energy of neutrons is in the range 1-15 MeV. A radiation volume compatible with the materials and components to be tested is required. A nominal one liter volume has been suggested. Associated apparatus requires temperature control and cryogenic equipment in order to perform temperature dependent studies. Hot cells for observation after irradiation are considered necessary as well.

\subsection{Intense Positron Facility}

The INEL is currently designing a high intensity positron beam (about $10^{11} \mathrm{e}^{+1} / \mathrm{s}$ on a $0.03 \mathrm{~cm}$ target) to be used as a facility for research and engineering studies for a variety of physical problems. One highly valuable use is as a positron microscope, the feasibility of which has already been demonstrated at the University of Michigan. The resolution obtained with an $\mathrm{e}^{+}$microscope scales with the intensity. At $10^{11}$ $\mathrm{e}^{+} / \mathrm{s}$, one can achieve about a 100-angstrom resolution. Several schemes have been proposed, all of which involve activation of $e^{+}$decay nuclei. Presently, the activation of copper is the first choice:

${ }_{29}^{63} \mathrm{Cu}+{ }_{0}^{1} \mathrm{n} \longrightarrow{ }_{29}^{64} \mathrm{Cu} \longrightarrow{ }_{28}^{64} \mathrm{Ni}+\underset{1}{0} \mathrm{e}^{+}$. 
The present geometry calls for a folded copper petal or umbrella configuration placed in a cylinder, which is then irradiated. When the "umbrella" is unfolded, a larger surface area will provide an extended $\mathrm{e}^{+}$source that will be focused. In BATR, a flux of about $10^{15}$ $\mathrm{cm}^{-2} \mathrm{~s}^{-1}$ would be desirable using thermal neutrons for activation. A cylindrical radiation volume of about 10 liters is needed. Associated apparatus would involve the positron accelerator and microscope; these must be near the source due to the short lifetime of the positrons.

\subsection{Transmutation Doping}

A process of potential economic reward that has been pursued at other reactors on a small scale is the process of "transmutation doping". Such a process at a BATR could be profitable. The primary product of value to date has been $p$-doped silicon for the semi-conductor industry. The process begins by obtaining very pure ${ }^{30} \mathrm{Si}$, then using neutron activation, such as:

$$
{ }^{30} S i+n \ldots{ }^{31} S i 2.5 \mathrm{hr} \ldots 31_{p}+\mathrm{e}^{+}
$$

to obtain ${ }^{31} \mathrm{p}$ as the desired product. A reactor such as a BATR with a high flux $\left(10^{14} \mathrm{~cm}^{-2} \mathrm{~s}^{-1}, 10^{18} \mathrm{~cm}^{-2}\right.$ fluence) could produce large amounts of the doped material. A large radiation volume (about 10-15 liters) with easy access is desirable. Lower flux levels exist further out in the reflector for large samples that require less fluence. Temperature control of the sample plus a spatially uniform thermal flux is required. Depending on the magnitude of product requested, up to tons per year could be produced. With an appropriate core access system, such as loops, insertion and removal of the material could be accomplished at any time. 


\subsection{Summary of Facility User Needs}

Tables 6,7 , and 8 summarize the generic and specific desires of potential users of a BATR. The most clear and consistent desire is to maximize flux and sample volume. A neutron flux of greater than $10^{15} \mathrm{~cm}^{-2} \mathrm{~s}^{-1}$ over a large volume is needed. A spectrum of neutron energies has been requested, but the majority of work can be done with thermal neutrons. Generally, a volume of several tens of liters of high flux is considered adequate. Other common essential requests are for the inclusion of experiment loops and rabbit capabilities.

The BATR design should be based on a thorough, unbiased market survey of the anticipated customer needs. The study conducted here was performed by INEL employees and does not represent the view of DOE or other national laboratories. The user needs must be clearly and thoroughly defined before detailed design begins. The BATR facility must be designed to achieve the best match to these needs within the constraints of safet, cost, and other design drivers.

\section{REACTOR CONCEPT EVALUATION AND CONFIGURATION DEVELOPMENT}

The Broad Application Test Reactor (BATR) safety requirements and facility user needs are discussed in Sections 2 and 3 , respectively. This section: (1) evaluates the capabilities of various facility concepts for meeting the BATR requirements and proposes concepts that best meet those requirements, (2) discusses general considerations for developing a BATR configuration, and (3) suggests preliminary configurations appropriate for a BATR.

\subsection{Neutron Source Concept Evaluations}

This section provides evaluations of candidate broad facility concepts for meeting the BATR safety and user requirements. The evaluations assume 
that the BATR neutron flux, spectra, and irradiation volume requirements may be met by a reactor operating with a power density from 1 to $2 \mathrm{MW} / 1$ iter, a judgement based on the capabilities of existing test reactors. A prior study ${ }^{2}$ evaluated a packed particle bed reactor, a reactor with rotating fuel rings, a cermet-fueled liquid-metal-cooled reactor, and an accelerator-driven spallation neutron source. These concepts were candidates during the selection process for the Advanced Neutron Source ${ }^{6}$. These concepts, plus the TRIGA, pebble bed, and conventional test reactor (water-cooled metallic fuel plates) concepts were considered as candidates for a BATR.

Concept evaluations were based on the following criteria: (1) the capability of the concept for attaining the required steady neutron flux, neutron spectra, and irradiation volume in test loops and beam tubes, (2) safety, (3) flexibility, (4) technological development risk, (5) licensability, (6) accessibility and inspectability, and (7) cost.

The ideal BATR concept would be one with a capability for exceeding the neutron flux, neutron spectra, and irradiation volume requirements in a reactor that poses minimum onsite and offsite safety concerns. The ideal concept would be flexible, providing a capability to accommodate changes in neutron flux and spectra, and in the test size and location. This flexibility extends from frequent changes (such as during the operation of a reactor cycle), to occasional changes (such as from one cycle to the next), to infrequent changes (such as a one-time reconfiguring of the reactor to follow long-term changes in experiment needs). The ideal concept would employ proven technology and involve a minimum of technical development risks; these features maximize the potential for the BATR to satisfy requirements for licensing and reduce research and development costs. Sufficient access would be provided such that all hardware could be inspected and maintained. Finally, the ideal concept would provide the most economical means for meeting the requirements.

Brief summaries of the facility concepts and evaluations of their suitability for a BATR are described in the following subsections. 


\subsubsection{Conventional Reactor}

The conventional reactor concept employs high surface-to-volume metallic fuel plates cooled by flowing light or heavy water. This concept is termed "conventional" because many of the currently operating and planned test reactors are of this type. Operating conventional concept reactors include the Advanced Test Reactor ${ }^{7}$ at the Idaho National Engineering Laboratory, the High Flux Beam Reactor 8 at the Brookhaven National Laboratory, the High Flux Isotope Reactor 9 at the Oak Ridge National Laboratory, and numerous others throughout the world. In addition, the Advanced Neutron Source ${ }^{6}$ planned for construction at Oak Ridge National Laboratory is of conventional design with extended technology.

The BATR user requirements appear to be achievable with the conventional concept. The BATR neutron flux, neutron spectra, irradiation volume, and total reactor power requirements likely can be met with an average power density of about 1-to-2 MW/1iter. This compares with power densities of about $1 \mathrm{MW} / 1$ iter for the Advanced Test Reactor and about $5 \mathrm{MW} / 1$ iter for the Advanced Neutron Source. The required BATR neutron spectrum can be met by appropriate selection of conventional design parameters. While existing conventional concept reactors may lack sufficient redundancy alid diversity to meet current licensing requirements, these issues can be resolved with a suitable BATR safety system design. Reactor operations are facilitated with the conventional concept because employing a water coolant enhances accessibility and inspectability during maintenance and refueling.

Negative features of a conventional concept for a BATR center on the use of aluminum, the most common conventional reactor fuel plate material. Aluminum is employed primarily because of its low neutron cross section. However, an aluminum oxide coating forms on the fuel plates during operation, increasing the effective thermal resistance and fuel operating temperatures. This, coupled with the low aluminum melting temperature and thermal capacity, can lead to a rapid melting of the fuel, 
should fuel plate dryout occur. Further, should a molten core result, steam explosions between molten aluminum and water can occur and appear to be particularly energetic. Finally, as compared with alternatives, the structural strength of aluminum is low, although experience with the mechanical integrity of Advanced Test Reactor fuel plates has been excellent.

\subsubsection{Packed Particle Bed Reactor}

The packed particle bed reactor concept ${ }^{10}$ is a compact reactor employing spherical graphite fuel particles packed into an annular region formed by two porous metallic frits. The core is cooled by heavy water flowing radially outward through an inner (cold) frit, fuel region, and an outer (hot) frit. A major advantage of this concept is the high neutron fluxes attainable. This flux capability may exceed that identified as required for BATR in Section 3. Packed particle bed designs with water flowing through them have never been tested and therefore have a high development risk and a high development cost. The associated safety and development risks limit the suitability of a packed particle bed reactor for a BATR.

\subsubsection{Pebble Bed Reactor}

The pebble bed reactor concept 11 is based on technology similar to certain German power reactors. For the German power reactors, pebble bed fuel is contained in graphite spheres of approximately $5-\mathrm{cm}(2-i n$. diameter. The fuel is cooled by flowing helium gas. Advantages of the pebble bed concept include a high degree of core geometric flexibility, the freedom to control the neutron spectra by altering the fuel/carbon ratio, and a minimum reactivity-insertion safety risk. The power density attainable with current (German) pebble bed technology is more than two orders of magnitude below that needed for BATR. Upgrading the power density capability would require significantly extending the current pebble bed fuel technology; a reduction in the pebble diameter to about 
2-to-4 $\mathrm{mm}$ (79-to-158 mil) would be needed. Fission products would be confined by pure carbide (for example, $\operatorname{ZrC}$ ) coatings of both the pebbles and the fuel particles within the pebbles. The pebble bed concept is not hampered by significant safety concerns, but upgrading the concept to meet BATR's needs would require significant development risk. For these reasons, the pebble bed concept is probably not appropriate for a BATR. Also, no clear advantage of the pebble bed reactor over a conventional reactor has been identified for a BATR.

\subsubsection{Reactor with Rotating Fuel Rings}

The rotating rings reactor concept ${ }^{12}$ features two stacks of flat annular fuel disks (or "rings"), constructed from conventional aluminum fuel plates and cooled by heavy water. Within each stack, the rings are separated by spaces slightly wider than the disk thicknesses. The stacks are aligned such that the disks on one stack correspond to the spaces on the other. The axes of the two stacks are offset, creating an intersecting region between the two stacks. Only the intersecting region is critical, providing a steady source of high flux neutrons. The rings rotate on their axes so that only fuel within the intersecting region experiences heating. Because fuel heating is transient, a very high power density is attainable locally within the intersecting region while the overall time-averaged core power density remains low. The rotating rings reactor concept involves substantial development risk, and its rotating fuel masses pose unique safety concerns regarding a dynamic core geometry, limiting its suitability for a BATR. In addition, this concept probably cannot meet the performance requirements such as several experiment loops in high neutron flux regions.

\subsubsection{Cermet-Fueled Liquid-Metal-Cooled Reactor}

The cermet-fueled, liquid-metal-cooled reactor ${ }^{12}$ employs cast fuel, fabricated from a stainless steel/uranium cermet. The fuel is cooled by liquid sodium flowing through passages within the fuel matrix. As compared with water, the thermal capacity of liquid sodium is low, 
reducing its effectiveness for limiting the fuel heat-up rate during an accident. This concept involves significant safety risks: the potential for reactions between the coolant and water, and between the coolant and air. This potential could be reduced through the use of double-walled vessels, however we believe that this approach would not adequately address the safety issues. These safety concerns limit the suitability of the cermet-fueled, liquid-metal-cooled concept for a BATR.

\subsubsection{IRIGA Reactor}

The TRIGA (Training Research Isotopes General Atomic) reactor concept ${ }^{13}$ is based on pool-type reactor technology in which a light-water pool serves as a moderator, reflector, shield, and coolant. Advanced TRIGA reactor designs include forced-convection, in addition to pool-cooling, of the reactor core. Fuel assemblies are constructed from aluminum- , or Incoloy-clad cylindrical rods fabricated from a mixture of enriched uranium and solid zirconium hydride. The hydrogen component in the fuel is an excellent moderator that provides a large prompt-negative fuel temperature reactivity coefficient. Because of this feature, TRIGA reactors are advantageous for applications requiring rapid pulsed operation. These reactors can operate at steady state, but their steady-state flux levels are significantly lower than those desired for the BATR. The TRIGA reactor concept is not considered suitable for a BATR because high levels of steady, rather than pulsed, neutron flux are needed.

\subsubsection{Accelerator-Driven Spallation Neutron Source}

An accelerator-driven spallation neutron source ${ }^{14}, 15,16$ produces an intense neutron flux by focusing a beam of protons or deuterons on a liquid lead-bismuth target. The flux spectrum includes neutrons of fission and higher energies. Thermal neutrons are produced within a beryllium or heavy-water moderator. The neutron flux is produced without involving nuclear fission and therefore dispersal of radioactive materials during accidents is not of concern. For neutron scattering experiments, 
accelerators may produce intense neutron pulses with much lower time-averaged heat removal load than produced with a reactor. The high energy neutron component produced with this concept poses special shielding problems, as compared with a reactor, as it affects the experiment environment. This concept is rejected for BATR on the basis of cost and development risk. No cost-effective spallation neutron source has, as yet, been built. Developing a large, reliable neutron source would involve significant technical risks as the neutron flux attainable with current technology is orders of magnitude below that required for a BATR. Possibly over $100 \mathrm{MW}$ of electrical power must be purchased to provide an acceleration with enough power to produce the required steady-state fluxes over the required volume.

\subsubsection{Comparison of Neutron Source Concepts}

Several existing and new neutron source concepts were evaluated as presented above. Table 9 summarizes the advantages and disadvantages of each concept.

Because the identified neutron flux and spectra requirements can be met with reasonable power densities, the conventional concept is the favored choice for a BATR. Further, these requirements can be met with technology that is well within the proven conventional reactor experience base. Large operational and experimental data bases are available from previous and currently-operating conventional concept reactors. A conventional concept BATR would: (1) involve a minimal of development risk, and thus have a minimal development cost, (2) encounter well understood safety issues, and therefore (3) rank high for licensability. Development of a conventional concept BATR could therefore concentrate on safety and operational improvements, through material selection and systems design. 
Table 9. Comparison of neutron source concepts for a BATR

\begin{tabular}{|c|c|c|}
\hline Concept & Advantages for BATR & Disadvantages for BATR \\
\hline Conventional & $\begin{array}{l}\text { Existing operating and } \\
\text { experimental experience } \\
\text { base, BATR flux can be } \\
\text { achieved with current } \\
\text { technology, licensability }\end{array}$ & $\begin{array}{l}\text { Aluminum (low melting } \\
\text { temperature, low strength, } \\
\text { low thermal-conductivity } \\
\text { oxide, steam explosions, } \\
\text { potential, chemical } \\
\text { reactions) }\end{array}$ \\
\hline $\begin{array}{l}\text { Packed Particle } \\
\text { Bed }\end{array}$ & Very high flux & Moderate development risk \\
\hline Pebble Bed & $\begin{array}{l}\text { Existing experience base, } \\
\text { geometric flexibility, } \\
\text { neutron spectra flexibility, } \\
\text { minimum reactivity } \\
\text { insertion risk }\end{array}$ & $\begin{array}{l}\text { Low flux with existing } \\
\text { technology, fuel } \\
\text { development risk }\end{array}$ \\
\hline Rotating Rings & $\begin{array}{l}\text { Very high flux, but over } \\
\text { a limited volume }\end{array}$ & $\begin{array}{l}\text { Substantial development } \\
\text { risk, safety concerns with } \\
\text { rotating fuel masses }\end{array}$ \\
\hline $\begin{array}{l}\text { Cermet-Fueled } \\
\text { Liquid-Metal } \\
\text { Cooled }\end{array}$ & High flux & $\begin{array}{l}\text { Significant safety risk } \\
\text { from coolant interactions } \\
\text { with in-core loop water }\end{array}$ \\
\hline TRIGA & $\begin{array}{l}\text { Existing experience } \\
\text { base, enhanced safety for } \\
\text { reactivity insertion events }\end{array}$ & $\begin{array}{l}\text { Suitable for pulsed, not } \\
\text { steady, operation, low } \\
\text { flux with existing } \\
\text { technology }\end{array}$ \\
\hline $\begin{array}{l}\text { Accelerator- } \\
\text { Driven } \\
\text { Spallation } \\
\text { Neutron Source }\end{array}$ & $\begin{array}{l}\text { Extremely high flux, but } \\
\text { over a small volume }\end{array}$ & $\begin{array}{l}\text { Cost, signiiicant } \\
\text { development risk, unique } \\
\text { problems for shielding } \\
\text { experimenters }\end{array}$ \\
\hline
\end{tabular}




\subsection{Conventional Reactor General Considerations}

This section discusses general considerations regarding the use of conventional reactor technology for a Broad Application Test Reactor. The discussions are separated into design/performance, safety, operational/flexibility, and reactur control topics.

\subsubsection{Design/Performance Topics}

In addition to future experimental needs, the BATR design should consider the needs (flux, spectra, diameter, volume, etc.) of current experimental programs in existing test reactors. Therefore, the BATR could readily satisfy these needs should unforeseen circumstances result in shutdown of one or more currently operating test reactors.

A conventional concept BATR should employ light water as a reactor coolant. The use of water enhances access to reactor components, thereby facilitating operations. Light-water coolant does not produce tritium, whose disposal must be considered, as does heavy-water coolant. The future availability of heavy water is uncertain, and heavy water is expensive (\$1000/liter). Requirements for a relatively large volume of high thermal neutron flux can be met by employing a heavy-water reflector tank surrounding the core region, as is featured in several existing test reactor designs. Thus, a reactor with light-water cooling and a heavy-water reflector probably achieves the best match with the requirements. Thus, we have concentrated on trade-off studies of reactors with these features.

The fast neutron flux needs associated with the materials irradiation objectives identified in Section 3 may be accommodated without employing a fast reactor. The BATR configuration could employ localized design features, such as regions of beryllium or nickel with thin hafnium shrouds, to tailor the flux spectrum as needed. 
Although for security reasons it would be advantageous to employ fuel enrichments below 20\%, it is unlikely the BATR neutron flux requirament can be met without resorting to higher enrichment fuels. In addition to use of standard (93.5\%) high-enrichment fuel, consideration will be given to potential safety benefits of the higher Doppler coefficient achievable with moderately-lower enrichments (for example, $80 \%$ ).

BATR core heat removal requires high surface area-to-volume ratios for the fuel region. A brief study indicates that core heat removal capabilities using heat pipes are not adequate at the expected BATR core power density. Four conventional types of fuel assemblies were considered for BATR: ATR-type (arcuate) with fuel plates, involute type with fuel plates, concentric-type with fuel plates, and fuel pins. In all cases the fuel assemblies are assumed to be constructed of a composite fuel "meat" region clad in a solid metal. The ATR-type fuel assembly consists of segments of concentric cylinders supported by side plates as currently employed in the Advanced Test Reactor. The involute fuel assembly consists of curved fuel plates supported by inner and outer cylindrical side plates. The involute design features a variable radius of fuel plate curvature that results in a constant-width coolant channel along the fuel plates from the inner to outer side plates. Full-annulus involute assemblies are currently employed in the High Flux Isotope Reactor (HFIR). The concentric-type fuel assembly consists of cylindrical tubes with a shape such as currently used in the Savannah River Laboratory (SRL) production reactors. Fuel pins are solid circular cylinders assembled in a regular pattern.

Fuel configurations considered for BATR are illustrated in Figure 4. Involute, concentric, and pin fuel assembly arrangements can be devised that provide performance parameters similar to those of the existing ATR fuel assemblies, whose operating history has been excellent. The ATR-type assembly features $1.27-\mathrm{mm}$-thick $(50-\mathrm{mil})$ plates with a $0.51-\mathrm{mm}(20-\mathrm{mil})$ meat and 1.98-mm (78-mil) coolant channels and would be appropriate for a BATR. 
The involute assembly (with dimensions similar to those of the ATR-type assembly) provides a small thermal-hydraulic performance advantage over the ATR-type assembly. However, involute assemblies in existing reactors are constructed using full annuli. For BATR this construction is considered acceptable only if the reactor configuration allows use of full annuli in which the resulting fuel assembly is subcritical under all foreseen conditions. This could readily be accomplished if the involute assembly is of relatively small size. However, if it does not prove possible to use full annuli, then segmentation of the annuli (for example into $45^{\circ}$ segments similar to that shown in Figure 4) would be needed. A satisfactory design for a segmented involute fuel assembly has not been demonstrated. Specifically of concern is the structural strength of the segmented assembly to withstand a load that compresses the inner and outer side plates. If this concern can be resolved, then an involute assembly may be appropriate for a BATR.

In the SRL reactors, the fuel assemblies possess the concentric cylindrical shape, but the assemblies are much larger (thicker plates, wider coolant channels, and longer lengths) than would be needed for a BATR. A possible concentric fuel assembly appropriate for BATR power densities might consist of concentric $1.27-\mathrm{mm}-(50-\mathrm{mil}-)$ thick plates separated by 1.98-mm (78-mil) fluid gaps and contained within a flow shroud. The thermal-hydraulic performance of such a fuel assembly would be similar to the ATR-type assemblies. The tubes of the concentric assembly could be supported transversely, with ribs between the tubes, and axially, with spider assemblies at the ends of the tubes. The concentric fuel assembly possesses a good performance history at SRL. Furthermore, this fuel assembly type has a strength advantage over the ATR-type and involute assemblies (see Appendix A) that makes it ideal for a BATR.

Fuel pins appeared to provide a promising alternative to the fuel plates that have most commonly been employed in existing test reactors. A pin design suitable for BATR might consist of 1.90-mm (75-mil) diameter pins with 1.27-mm (50-mil) fuel meat, and arranged on a 
ATR-Type

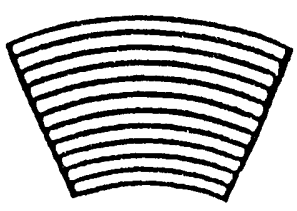

Involute

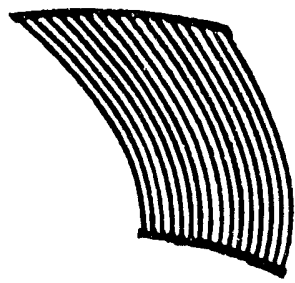

SRL-Type

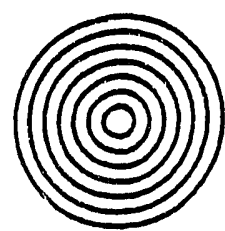

Fuel Pins

Figure 4. Fuel configurations considered for BATR. 
2.97-mm-(117-mil)-pitch square lattice. The challenge would be to design a sufficiently strong fuel assembly from such thin pins; a $7.6-\mathrm{cm}(3-\mathrm{in}$. diameter circular cross section would contain approximately 2,000 pins! The development risks associated with this challenge make the use of fuel pins inappropriate.

The selection of a BATR fuel assembly geometry must be made in concert with selection of the overall reactor configuration geometry. Some fuel assembly geometries are more suited than others for certain reactor configurations. The need for axial and/or radial grading of the $235 \mathrm{U}$ loading is dependent on reactor configuration, while the ability to provide suitable fuel grading varies with the type of fuel assembly. Therefore, specific fuel assembly recommendations are discussed as a part of the reactor configuration descriptions in Section 4.3.

The matrix and cladding metals considered for BATR fuel plates are aluminum, zirconium, stainless steel, and molybdenum. The studies of these metals are included in Appendixes $B, C$, and $D$. The significant trade-offs balance strength, thermal performance, and neutronic performance. Aluminum has the least neutronic penalty, but comparatively low strength, melting point, thermal capacity, and low-conductivity oxide. Zirconium has only a small neutronic penalty and a higher melting point. However, zirconium has a lower thermal conductivity, which will raise operating temperatures. Stainless steel provides a significantly higher melting point and thermal capacity. However, it has a significant neutronic penalty, which would require a higher fuel loading. The molybdenum neutronic penalty is extreme. Based on experience, the difficulties with aluminum fuel can be overcome, and $\mathrm{Al}^{-U A l_{3}}$ or a similar dispersed fuel appears to be best suited for this application. A second choice would be stainless steel- $\mathrm{UO}_{2}$ fuel. Uranium silicide fuels represent a distant third choice. An additional safety analysis should examine the potential for steam and chemical explosions assuming molten cores consisting of the various fuel plate materials. 
BATR pressure vessel design should consider use of stainless steel materials that are currently acceptable for Class 1 nuclear construction under the ASME Code. ORNL is currently developing a case for the use of aluminum as a pressure vessel, but the outcome is not certain. Regardless of the material used, the pressure vessel and other support structures must be designed considering the irradiation embrittlement environment.

\subsubsection{Safety Topics}

The BATR design should assure mechanical, neutronic, and thermal-hydraulic stability. Fuel assemblies should be designed for adequate static and dynamic loadings and a large safety margin to hydrodynamic instability. The design should consider the interactions of these stability concerns with neutronic feedback.

The BATR should feature upward flow through the core region. Many existing test reactors feature downward flow through the core, and this results in a safety issue regarding flow reversal. Should main coolant pumps fail (for example, as might occur during a station blackout event) then the core flow would transition from downward forced convection to upward flow resulting from buoyancy-driven natural circulation. The issue regards core cooling during the transition period when its flow is nearly stagnant. By using an upward core flow in BATR, a smooth transition from forced to natural circulation cooling is accomplished and a period of stagnant flow is avoided. When upward core flow is employed, core and irradiation targets must be restrained downward against the flow. The restraints designed for this purpose must preserve highly-uniform flow distributions. Further, the effects of upward-flowing coolant on downward-inserted control rods may be significant; a separate control rod cooling system or sophisticated fast-insertion system may be needed.

The BATR design should maximize the potential for natural circulation core cooling, for example by employing heat removal mechanisms that are elevated considerably above the core. This design will shorten the time 
required, following a loss of forced core flow, until core natural circulation is capable of maintaining core cooling. Similarly, mechanisms (for example, backup 'motors, and flywheels) should be evaluated for continuing a forced-convection core flow following a failure of the primary pumping capability.

The BATR should be designed for survivability during a loss-of-coolant accident. In addition to core flow continuation, this survivability will depend on employing rapid scram mechanisms, on limiting the depressurization rate following a primary system rupture, and on locating all large reactor vessel penetrations above the core.

The BATR needs for safety shutdown system redundancy and diversity should be directly addressed. For this purpose, a combination of shutdown rods and gas $\left({ }^{3} \mathrm{He}\right)$ injection systems appears to be promising. A ${ }^{3}$ He system would feature a high-cross-section, fast-moving gas, driven from accumulator tanks into evacuated tubes within the core. Use of separate accumulators could enhance redundancy. Possible problems with a ${ }^{3} \mathrm{He}$ system include difficulty in removing the poison after its use and transient expulsion of gas from the tubes due to heating effects.

A BATR design that minimizes the likelihood of a core damage accidents is needed. From Section 2.4.3, this likelihood should be limited to less than $10^{-6}$ per reactor year. However, should accidents that lead to molten cores need to be considered, we believe it is not possible to achieve a BATR design that completely eliminates the possibility for the occurrence of steam explosions. However, the design should minimize any secondary chemical reactions (for example, between a molten core and the coolant) with the potential for increasing the energy release or for releasing hydrogen. From safety and licensing viewpoints, the BATR design should consider accident mitigation and feature a containment that can withstand core melt, steam explosions, and hydrogen explosions. 


\subsubsection{Operational/Flexibility Topics}

The BATR design should feature capabilities for rearranging the core and experiment configuration. This capability starts with a modular changeable-grid core construction scheme (see Appendix E). Core and experiment features are contained in an interchangeable grid, facilitating reactor reconfiguration. Fixed penetrations through the reactor vessel upper and lower heads pose a problem that limits the possibilities for rearrangement. Specifically, with the changeable grid the core internals can be rearranged, but radial and azimuthal alignment of the rearranged core features may not match with the existing vessel head penetration openings. Two options may be used to circumvent this limitation. First, the vessel penetrations could remain fixed, and slant tubes (for example, with dog leg bends) could be employed to route piping as needed from rearranged core features to the existing vessel penetrations. Second, the vessel penetrations could be constructed on rotatable elliptic flanges that would effectively provide the capability for moving the vessel penetration locations, consistent with changes in the core and experiment geometry.

The BATR design should include the flexibility for conducting tests at different neutron flux levels and with different flux spectra. The capability for operating without insertion of a scheduled test is needed.

The BATR should allow changing of fuel and irradiation capsules without disturbing experimental 10op piping. A direct, unobstructed means for moving fuel and materials should be devised. These operations must consider the need for maintaining light-water coolant separate from a heavy-water reflector. Heavy water is preferred over beryllium for a thick reflector (such as would be needed for a large irradiation zone) because it sustains high thermal neutron flux over a larger volume. In addition, beryllium is toxic, brittle, expensive, and difficult to fabricate. A limited number of U.S. companies have the capability to fabricate a beryllium reflector. 
Considering flexibility, a heavy-water reflector needs to be confined in a vessel with horizontal and vertical tubes for access into the reflector region. Thus, changing the irradiation space layout requires changing these access ports. In contrast, a beryllium reflector can be water cooled (as, for example, in ATR) and thus allow access for changes within the core and primary system pressure boundary. One option that might be considered for a large heavy-water reflector would be to incorporate several relatively large light-water-cooled beryllium or graphite regions within a heavy-water tank. The size and shape of irradiation tubes within these regions could be changed more readily. The BATR design should allow access to all regions within the vessel and the capability for changing damaged internals.

The design should provide the capability for experiment changes on-line or with very short outages. The design should provide for long cycles, and the flexibility to vary the cycle length. The capability for on-line refueling should be considered, but seismic safety concerns may make this option infeasible. A large temporary irradiated fuel storage space is needed to permit maximum use of fuel. In general, the BATR design must optimize the management of fuel.

Relative to the identified medical facility need for boron neutron capture therapy and the desire to serve a wide spectrum of outside (university, foreign) users, consideration was given to the potential construction of more than a single integrated unit. A conventional reactor concept is amenable to the construction of single reactor units distributed in a common shield with common or separate cooling systems, but with the experimental facilities of each core in separate building areas subject to different personnel access requirements and permitting widely different types of research. More separation of the single units could be achieved by using completely separate shields, buildings, cooling systems, etc., at (in order of expense) a common site, adjacent sites, or widely-distributed sites. Reactors at a common site may be hampered by difficulties in having construction in progress during reactor operations, and such construction would necessarily proceed at a slow pace due to 
dependence on availability of incremental funding. A single integrated BATR can readily meet most of the potential user needs. The major potential exceptions include the treatment of patients at a cancer therapy facility, and the relatively complete freedom of access for outside users. While the relative merits of multiple reactors needs further assessment, the current plan is to proceed with studies of a single integrated BATR.

\subsubsection{Reactor Control Topics}

The BATR configuration should have multiple reactor control features that minimize perturbations to the whole reactor from the operation of any one control feature. This design would enhance capabilities for independently operating experiments in different regions of the reactor. The reactor control system needs to compensate for the reactivity loss due to fuel burnup, provide for adjusting the neutron flux distributions within the reactor, provide regulation of reactor power, and provide rapid shutdown upon signal from the plant protective system. The compensation for fuel burnup and adjustment of neutron flux distributions must be accomplished without producing undesirable neutron flux disturbances in the experimental positions.

The amount of shim control needed for countering fuel burnup is reduced by the incorporation of a burnable neutronic poison in the fuel assemblies. To minimize the effects on neutron fluxes in the experimental positions, it is desirable to also achieve the balance of reactivity adjustment by absorption of neutrons in or adjacent to the reactor fuel regions. This suggests that chemical shims with neutron absorbers in the primary coolant or a separate fluid system are options that should be evaluated. Also, shim blades or small rods adjacent to the fuel may be preferable to the use of rotating drums because the drums disturb the neutron fluxes in the reflector irradiation facilities. Individual adjustment of the neutron fluxes in the loop positions is highly desirable. The ability to meet this need without impacting other experimental positions is also enhanced by having shim capability adjacent to the fuel associated with each loop position. 
The ATR safety rods are cylindrical tubes concentric with the test loops. Since the major test facilities of the BATR are also the loop positions, the ATR safety rod arrangement can probably be appiied to the BATR. This safety rod afrangement would mesh well with a chemical shim system, if a suitable one can be devised. Alternatively, since the safety rod would be between the loop and the fuel region, the opposite side of the fuel regions would be a suitable candidate for multiple small-diameter shim rods to compensate for fuel burnup and/or adjust the neutron flux distribution. The locations of the regulating rods have relatively small reactivity effects, and their locations with respect to undesirable impact on irradiation position neutron fluxes is not very critical.

\subsection{Conventional Reactor Configuration Development}

This section describes two preliminary conventional reactor configurations that appear to be attractive for a Broad Application Test Reactor. The multiple-annular configuration is described in Section 4.3 .1 and the modular configuration is described in Section 4.3.2. For comparing the capabilities of these configurations with modest extensions of existing reactor capabilities, a postulated upgrade of the Advanced Test Reactor is described in Section 4.3.3.

\subsubsection{Multiple-Annular Configuration}

The multiple-annular configuration, shown in Figure 5 , features distributed separate annular core sections contained in their own pressure tubes. The spacious layout of the multiple-annular configuration aids operational accessibility and inspectability. Experimental loops 


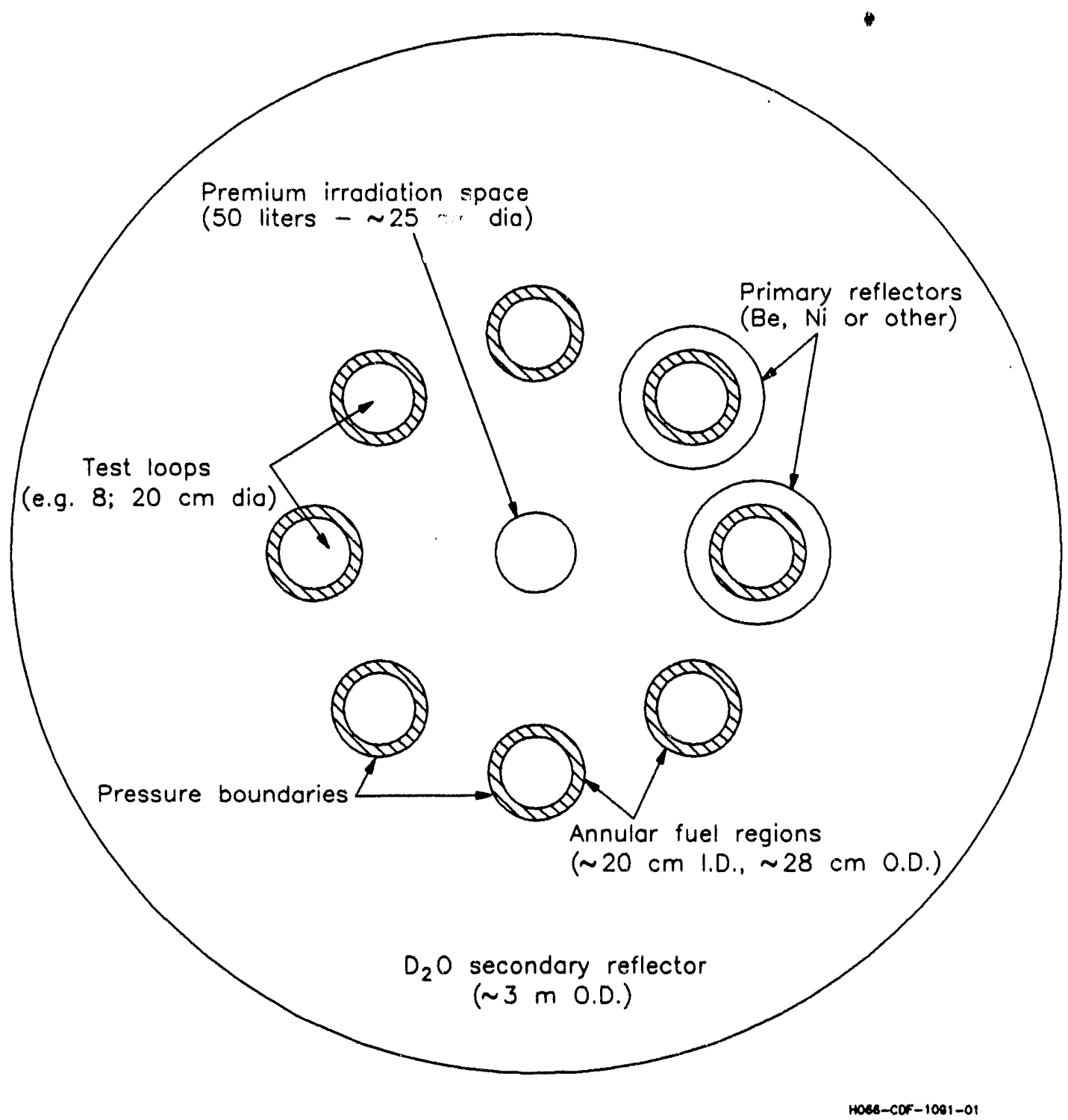

Figure 5. Multiple-Annular conventional reactor configuration. 
containing the test sections would be located in the centers of each annulus. The core sections would be assembled from ATR-type or possibly involute assemblies constructed of aluminum (or zirconium or stainless steel) fuel plates (see Section 4.2.1). The core regions would be about $1-m$ high and cooled with an upward flow of light water. This core height is short enough to provide adequate safety margins. Primary reflectors, if needed, could consist of sleeves of beryllium or nickel surrounding or within an annulus. The entire core assembly would be immersed within a large low-pressure heavy-water secondary reflector tank. The reactor with 8 annular core regions would operate at a thermal power of about 400 MW and a corresponding power density of about $2 \mathrm{MW} / 1$ iter.

The multiple-annular configuration features weak coupling among the separate core regions, allowing for operating the core regions somewhat independently. The core regions could be operated at widely varying powers and neutron fluxes, and the design has the potential for allowing operation with one or more of the core regions shut down. This independence enhances the flexibility of the reactor for supporting changing experimental needs.

The multiple pressure boundaries (i.e., surrounding each core region) provide a capability for operating core regions of significantly different heights. Thus, short, high-power-density experiments could be conducted in one region while long, low-power-density experiments could be conducted in others. The central location is particularly attractive for a short annular core region operating at a high power density or for a premium high-intensity target region with a fast neutron spectrum.

The multiple pressure boundary concept also provides a potential benefit for separating molten core regions during a severe accident; combining molten core regions poses possible coolability and criticality concerns.

The basic multiple-annular configuration features core regions cooled by light water flowing from a common inlet plenum, in parallel through the 
core sections, and into a common outlet plenum. However, the cooling systems for the separate core regions also could be separated. In this way, some of the core regions could be cooled with light water, others with heavy water, and perhaps others with a mixture of the two.

Separating the core region cooling systems provides additional flexibility for varying the neutron flux and spectra among the core regions; however, the complexity increases and the reliability may decrease.

Additional flexibility for tailoring loop flux and spectra is attained by (1) using different moderators between the experiment loop tubes and the inner faces of the core annuli, and (2) altering the compositions and thicknesses of the primary reflector sleeves around the outer faces of the core annuli. Another possibility for enhancing neutron flux and spectrum flexibility would be to employ offset fuel assemblies, such.as are featured in the Advanced Neutron Source design, around one or more of the experiment loops.

In summary, the capability for independent operation of differentgeometry core regions provides the multiple-annular configuration with considerable flexibility for following changing experimental needs.

\subsubsection{Modular-Hexagonal Configuration}

The modular-hexagonal configuration, shown in Figure 6, features a core layout in a uniform pattern; a hexagonal pattern has been suggested. Although the core is close-packed, provision for operational accessibility and inspectability could be included. Experimental loops containing the test sections and surrounding core fuel assemblies would be located within modules. The core is contained within a single pressure boundary and this construction simplifies the design and facilitates reconfiguring of the reactor.

The concentric SRL-type fuel assembly, constructed from aluminum (or zirconium or stainless steel) fuel plates (see Section 4.2.1), is 


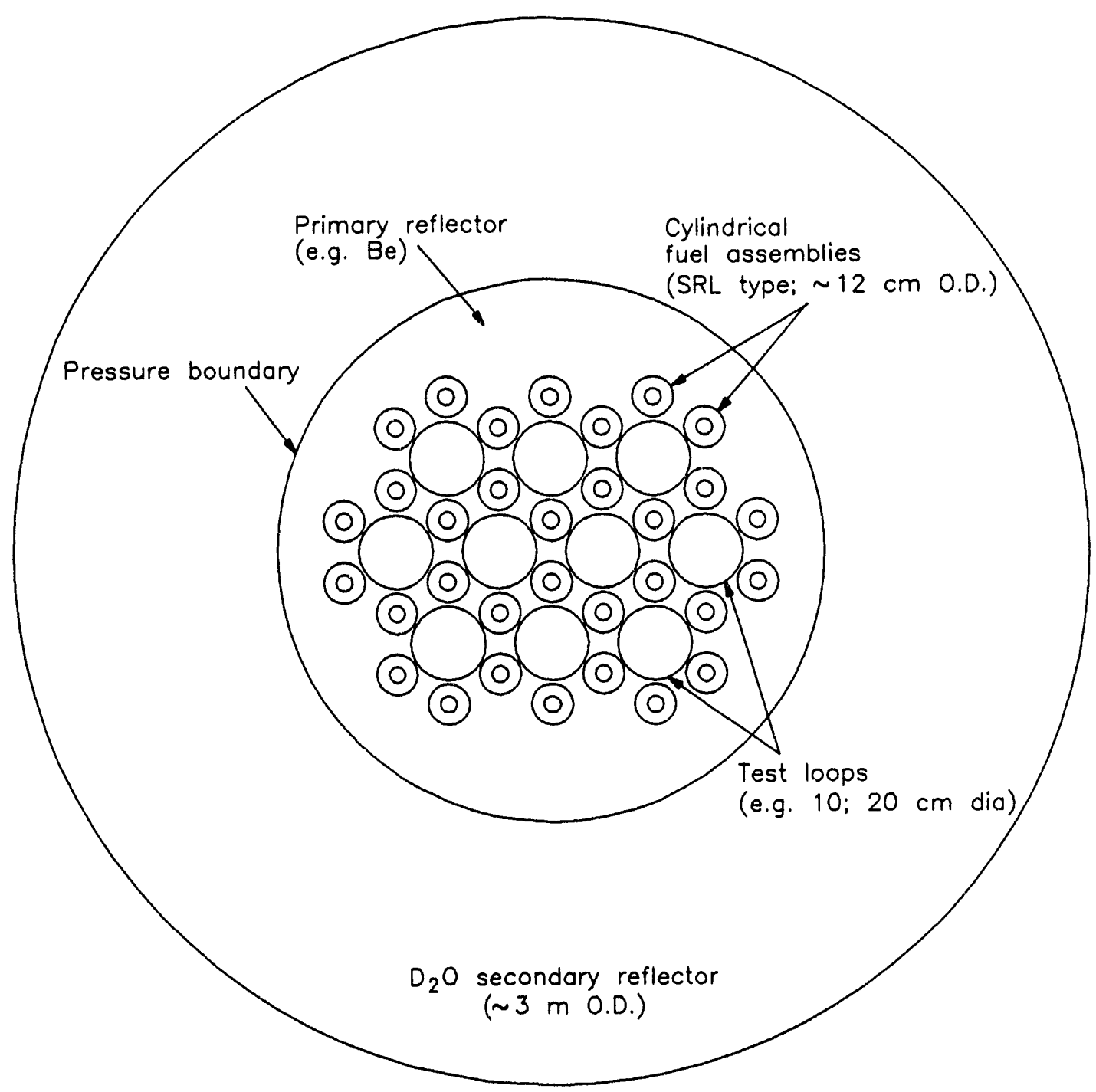

Ho6e-COF-1001-02

Figure 6. Modular-hexagonal conventional reactor configuration. 
recommended. A design consideration with this fuel arrangement would be azimuthal variations in the neutron flux and spectrum around the experiment loops. The central hole, within the fuel assembly, provides a region that is particularly favorable for a fast neutron spectra irradiation.

The core regions would be about $1-m$ high, contained within a pressure boundary, and cooled with an upward flow of light water. This core height is short enough to provide adequate safety margins. A beryllium primary reflector surrounds the core modules. The entire core assembly would be immersed within a large low-pressure heavy-water secondary reflector tank. The reactor shown in Figure 6 might operate at a thermal power of about $500 \mathrm{MW}$ and a corresponding power density of about $2 \mathrm{MW} / 1$ iter.

The modular-hexagonal configuration features tight coupling across the cross section of the core. Because of its single pressure boundary, all regions of the reactor would need to be cooled with the same fluid. These features would limit the capability for separately operating the different core regions. This is not to say that different core regions could not be operated at different neutron fluxes and spectra, but only that altering the operation of one core region would affect the other regions as well. However, the tight coupling of the core would provide the advantage of limiting the flux attenuation resulting from insertion of a particularly absorbent test in one location.

Flexibility for tailoring loop flux and spectra is attained using different moderators between the experiment loop tubes and the fuel assemblies and by altering the compositions and thicknesses of moderating materials embedded within the reactor modules.

A major advantage of the modular-hexagonal configuration is its particular compatibility with a changeable grid construction scheme, such as described in Section 4.2.3. This compatibility results from the single pressure boundary concept; reactor rearrangement takes place within the boundary and reconfiguring of the boundary (except for pressure vessel penetrations) is not needed. 
The modular-hexagonal configuration also appears to be particularly suitable for developing a layered reactor design, such as the 2-1ayer checkerboard layout illustrated in Figure 7 . A layered reactor design provides additional flexibility (axial variation) for laying out the reactor features; it also allows maintaining neutron flux while using shorter core flow paths, resulting in improved safety margins.

In summary, the replaceable and interchangeable grid construction of the modular-hexagonal reactor configuration provides considerable flexibility for following changing experimental needs.

\subsubsection{Upgraded ATR Configuration}

The capabilities of a new BATR configuration need to be compared to some reference configuration that represents the capabilities of current reactors, as might be extended through modest future improvements. For this purpose, this section describes one such reference based on an upgrading of the Advanced Test Reactor, as shown in Figure 8 . The configuration is based on the current ATR design with the following changes:

(1) the maximum experiment loop dianeter is increased by enlarging the flux trap size to $20-\mathrm{cm}(8-i n$.$) inner diameter, 30-\mathrm{cm}(12-i n$.$) outer$ diameter,

(2) the core height is reduced to about $1 \mathrm{~m}$, and the core flow direction is changed from downward to upward,

(3) the core power density is increased from 1 to about $2 \mathrm{MW} / 1$ iter and the power is increased to about $400 \mathrm{MW}_{\mathrm{t}}$,

(4) a large (about 3-m (10-ft) diameter) heavy water secondary reflector tank is added to increase the available irradiation space, 


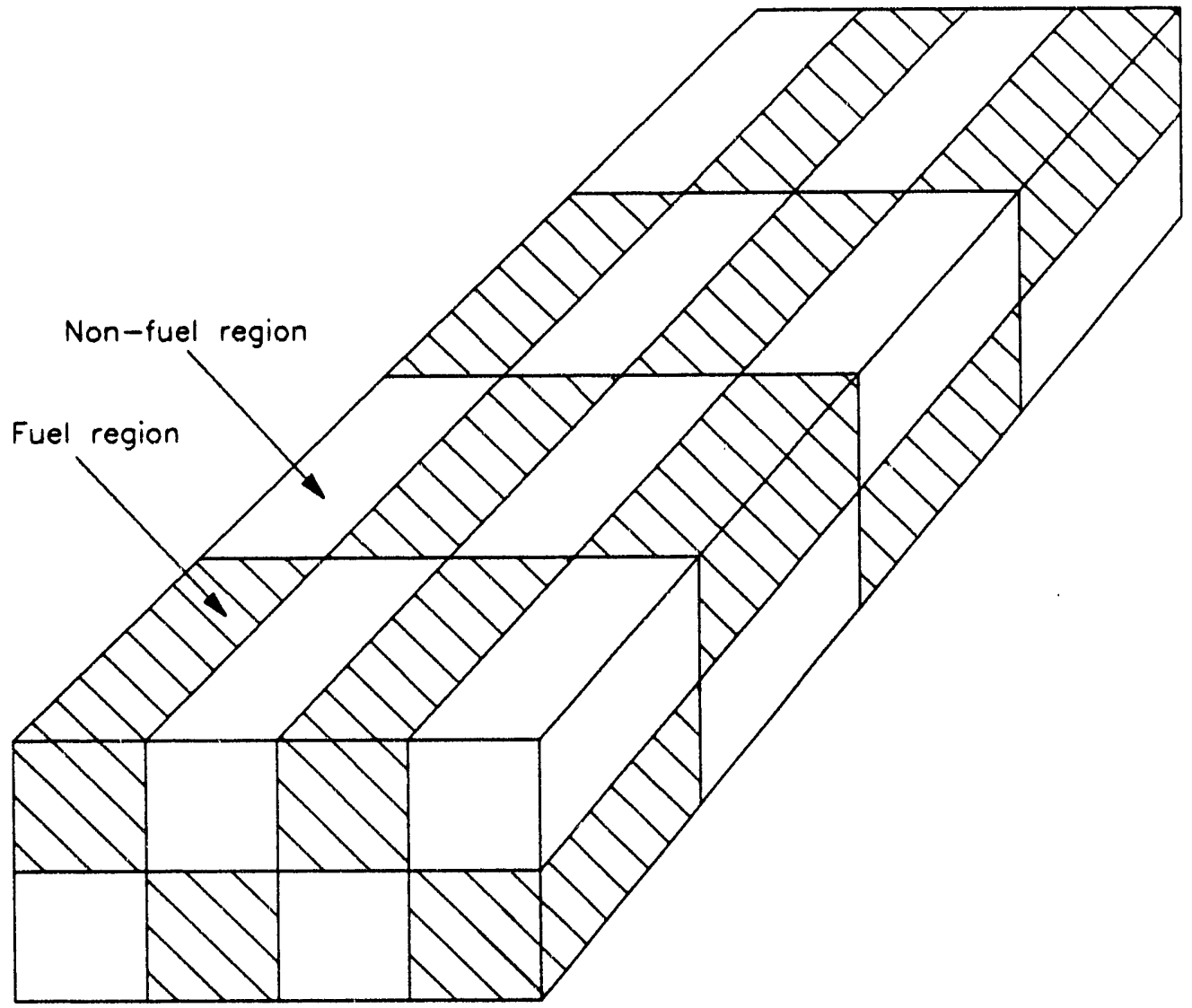

$4068-\operatorname{cof}-1001-03$

Figure 7. A two-layer checkerboard reactor configuration. 


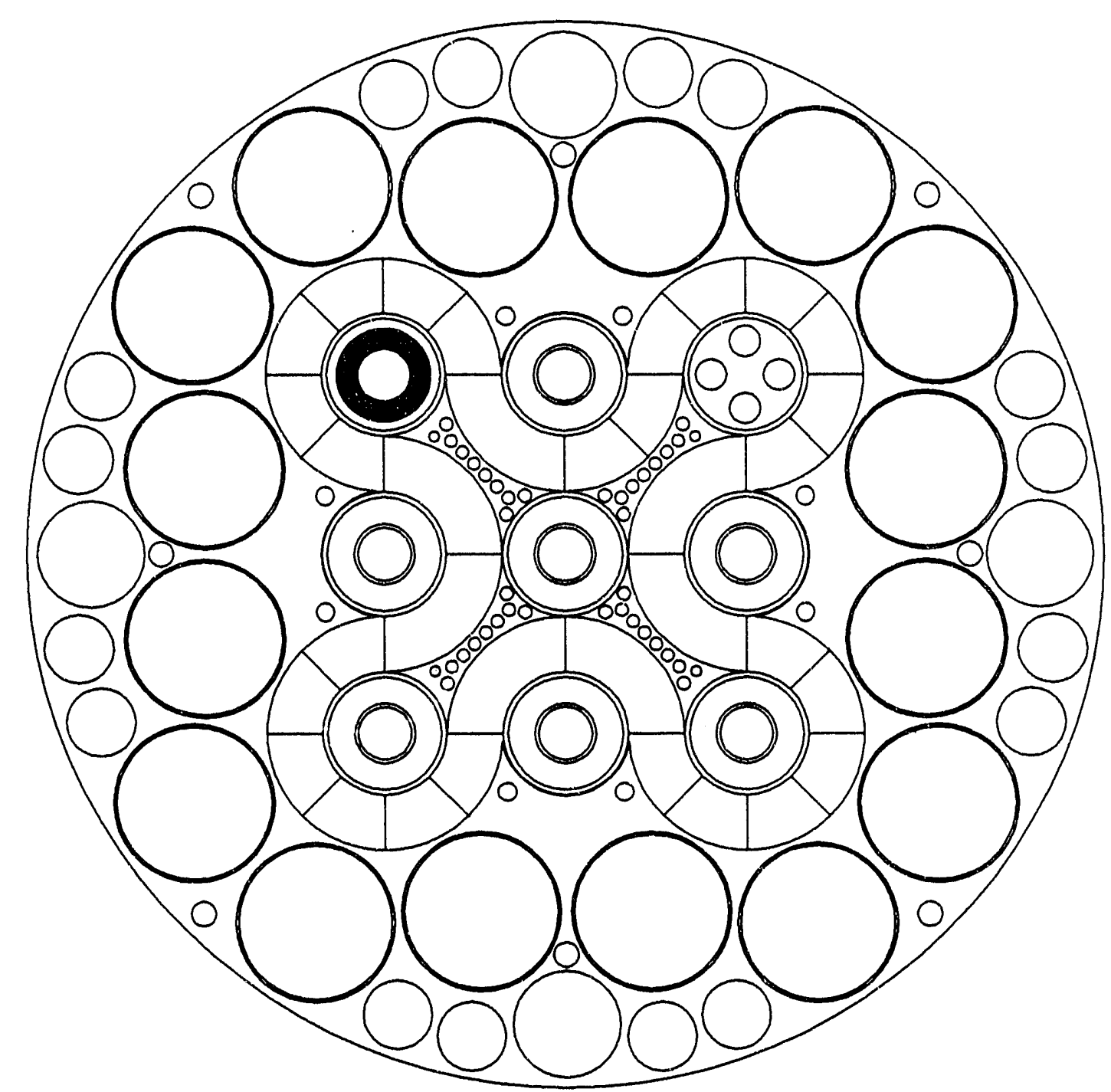

$1086-C D F-1091-00$

Figure 8. Upgraded Advanced Test Reactor configuration. 
(5) the thickness of the beryllium primary reflector thickness is reduced, and

(6) the rotatable reactor shim control drums are replaced with a system designed for less impact on reflector neutron fluxes and on accessibility to all reactor regions.

\subsection{Comparison of Conventional Reactor Configurations}

The BATR neutron flux, neutron spectra, and irradiation volume requirements can probably be achieved with an upgraded ATR or reactors of either the multiple-annular or modular-hexagonal configurations described in Sections 4.3.1 and 4.3.2, respectively. In addition to meeting the design requirements as initially formulated, the ideal BATR reactor configuration would provide an economical capability for modifying the reactor to keep pace with changing experimental needs. Therefore, comparison of reactor configurations should be made primarily on the basis of flexibility considerations. Table 10 presents a qualitative flexibility comparison of the multiple-annular and modular-hexagonal BATR configurations along with the upgraded ATR configuration.

As indicated in Table 10, the flexibility for both of the configurations suggested for BATR generally exceeds that afforded with the upgraded ATR configuration. The flexibility advantages of the two BATR configurations over the upgraded ATR configuration result from: (1) the provision for increasing the diameter of the experiment loops without modifying a beryllium reflector, and (2) the ease with which neutron flux intensityand spectra-modifying features can be incorporated.

The comparison between the flexibility of the multiple-annular and modular/hexagonal configurations indicates that the multiple-annular configuration ranks higher because of its capability for independently operating reactor core regions of different lengths. As a result of its interchangeable grid construction scheme, the modular-hexagonal configuration ranks higher for ease of reconfiguring. 
Table 10. Comparison of reactor configuration flexibility

\begin{tabular}{lcccc}
\hline & \multicolumn{3}{c}{ Flexibility Ratings } \\
Parameter & Multiple-Annular & Modular/Hex & ATR Upgrade \\
Neutron Flux & & High & Moderate & Moderate \\
Neutron Spectrum & High & High & Moderate \\
Loop Diameter & Moderate & Moderate & Low \\
Loop In-Core Length & High & Low & Low \\
Reconfigurability & Moderate & High & Low \\
& & & \\
\hline
\end{tabular}

Detailed design comparisons should eventually be performed for reactor performance, safety, flexibility, technological development risk, licensability, accessibility and inspectability, and cost. As the designs evolve, the best features of each design should be incorporated, where possible, into the design that is finally selected.

\subsection{Summary of Findings and Recommendations}

In summary, the BATR neutron flux, neutron spectra, and irradiation volume requirements appear to be achievable with reactors of either the multiple-annular or modular-hexagonal configurations. Each of these configurations possesses unique features that enhance the flexibility for altering the reactor in response to changing experiment needs or regulatory concerns.

The following studies are recommended for the next phase of BATR development: (1) evaluate the viability of the multiple-annular and modular-hexagonal configurations for attaining the required neutron flux, neutron spectra, and irradiation volume, (2) assess alternatives to 
aluminum fuel plate materials, (3) perform neutronic, thermal-hydraulic, and structural comparisons between the ATR-type and SRL-type fue 1 assemblies, (4) develop a preliminary layout for the core, vessel, and reflector tank, and perform operations and maintenance studies, (5) develop a preliminary layout for the reactor coolant system, and perform heat balance and safety system studies.

\section{CONCLUSIONS AND RECOMMENDATIONS}

This report presents the need for a new test reactor, the project process definition, a set of current and projected regulatory compliance and safety requirements, a set of facility users needs for a broad range of projected testing missions, and a set of reactor concepts that meets these requirements. The information contained here can be used for strategic planning to provide the Department of Energy with management options. The INEL should assist the Department of Energy in organizing a new initiative to provide the United States with a comprehensive Broad Application Test Reactor for the next century.

This report summarizes the FY-91 effort of nearly 50 scientists and engineers working part-time on this LDRD project. A similar LDRD effort is being conducted in FY-92: detailed trade-off and preconceptual design studies are proposed to (1) explore the reactor concepts that best meet the user and safety requirements, and (2) identify the key technologies for supporting the government's long-term strategic and programmatic planning. The study findings will provide a basis for recommending one or more candidate reactor designs for a new broad application test reactor.

The following specific studies are recommended for FY-92:

1. Evaluate the viability of the multiple-annular and modular-hexagonal reactor configurations for attaining desired flux and irradiation volume: neutronics, thermal-hydraulics. 
2. Assess alternatives to aluminum for the fuel plates: neutronics, steam explosion, fuel/coolant heat transfer, fuel material smear density, irradiation performance, fuel/water interactions, fuel fabrication, shipping, lifetime, and disposal issues.

3. Evaluate the relative merits of arcuate, involute, and concentric fuel elements: neutronics, thermal-hydraulics, static strength, dynamic stability.

4. Examine core, reflector tank, and vessel layout, develop changeable-grid schemes, and conduct flexibility enhancement studies.

5. Prepare a general layout of the fluid systems, compute the heat balances, and perform operations/maintenance studies.

6. Examine redundancy/diversity issues, determine passive safety features, and find ways to minimize reactivity insertion and loss-of-coolant accident potentials.

7. Perform a market survey to identify future customers and their projected needs. This may strengthen the justification for proceeding with the BATR design.

Some of these studies were performed in FY-92 with Laboratory Directed Research and Development funding and are reported in Reference 17. 


\section{REFERENCES}

1. International Nuclear Safety Advisory Group, "Basic Safety Principles for Nuclear Power Plants", Safety Series No. 75-INSAG-3, International Atomic Energy Agency, Vienna, Austria, 1988.

2. J. A. Lake and C. D. West, "Report on Working Group on 'Critique of Source Concepts', " Nuclear Instruments and Methods in Physics Research, A249, 1986, pp. 125-131.

3. "Nuclear Research Reactors in the World," International Atomic Energy Agency, July 1990.

4. J. M. Ryskamp, D. L. Selby, and R. T. Primm III, "Reactor Design of the Advanced Neutron Source," Nuclear Technology, 93, 1991, pp. 330-349.

5. A. N. Goland, Review of the Advanced Neutron Source (ANS) Materials Irradiation Facilities, ORNL/CONF-901276, Oak Ridge National Laboratory, March 1991.

6. C. D. West, "The Advanced Neutron Source: A New Reactor-Based Facility for Neutron Research, "Iransactions of the American Nuclear Society, 61, 1990, p. 375.

7. D. R. deBoisblanc and S. Cohen, Safety Analys is Report Advanced Test Reactor, Volumes 1 \& 2, IDO-17012, National Reactor Testing Station, U. S. Atomic Energy Commission, April 1965.

8. S. Shapiro, D. C. Rorer, and H. Kuper, HFBR Handbook, BNL-24182, Brookhaven National Laboratory, August 1983.

9. F. T. Binford and E. N. Cramer, The High-Flux Isotope Reactor, A Functional Description, Volumes 1 \& 2, ORNL-3572, Oak Ridge National Laboratory, May 1964.

10. J. R. Powe11, H. Takahashi, and F. L. Horn, "High Flux Research Reactors Based on Particulate Fuel, "Nuclear Instruments and Methods in Physics Research, A249, 1986, pp. 66-76.

11. M. S. El-Genk and N. Morley, "Thermal-Hydraulic Study of Pellet Bed Reactor Concept for Nuclear Thermal Propulsion, " Conference on Advanced SEI Technologies, Cleveland, Ohio, September 3-6, 1991, AIAA-91-3510.

12. A. P. 01 son, "Very-High-Flux Research Reactor Concepts, " Nuclear Instruments and Methods in Physics Research, A249, 1986, pp. 77-90.

13. General Dynamics' TRIGA Reactors - for Research, Training, and Isotope Production, General Dynamics, General Atomic Division, August 1964. 
14. R. J. Burke and D. L. Johnson, "An Accelerator Based Steady State Neutron Source," Nuclear Instruments and Methods in Physics Research, A249, 1986, pp. 91-101.

15. B. G. Chidley, "CW Accelerators Suitable for Spallation Neutron Sources," Nuclear Instruments and Methods in Physics Research, A249, 1986, pp. $102-115$.

16. W. E. Fischer, "On The Neutronics of SINQ, A Continuous Spallation Neutron Source," Nuclear Instruments and Methods in Physics Research, A249, 1986, pp. 116-124.

17. W. K. Terry, J. M. Ryskamp, S. N. Jahshan, C. D. Fletcher, R. L. Moore, C. F. Leyse, C. G. Motloch, E. H. Ottewitte, and J. M. Lacy, "Preliminary Design Studies on the Broad Application Test Reactor," EGG-NRRT-10350, Idaho National Engineering Laboratory, July 1992. 
APPENDIX A

FUEL ASSEMBLY STRUCTURAL STUDIES

G. L. Thinnes 


\section{A. 1 INTRODUCTION}

The fuel assembly structural requirements for BATR center around maintaining a coolable geometry under a variety of normal operating conditions as well as a number of accident conditions. Because the structural capacity of the fuel depends on a large variety of design details that are unknown at this time, only general design statements can be made with the understanding that a variety of fuel configurations could be made to function structurally in the required environment. However, some configurations are more susceptible to structural failure than others.

The combination of fuel design requirements, evolutionary concepts instead of revolutionary concepts, and a high flux density per unit volume have effectively narrowed the choice of fuel type to the plate geometry. Given this subset of fuel configurations, some general observations of structural capacity can be made. Since these plates are quite thin compared to their width, width-to-thickness $(w / t)$ ratios might realistically range between 10 and 80 . The structural response (stresses and deformations) of these fuel plates are very sensitive to the mechanical boundary conditions imposed on the plates.

Differential temperatures between the hotter fuel matrix region of a single plate and the cooler supporting structure of the fuel assembly offer considerable possibilities for thermal distortion. The fuel assembly design is required to hold the fuel plates together during fuel loading and unloading procedures, to maintain inter-fuel-plate spacing for cooling and neutronics purposes during operation, and yet not overly constrain them and cause severe thermal distortions that would cause flow blockage. Obviously, some intermediate mechanical attachment condition must be achieved, accompanied with additional design concepts that cause any distortions among the fuel plates to uniformly deform and, thus, 
maintain the needed coolant flow channel cross sections. One such example of this type of mechanical attachment is joint swaging, and the use of fuel plate end combs has proven successful for maintaining uniform spacing of curved fuel plates under thermal-hydraulic loads.

Flow-induced vibrations are also a major consideration in plate-type fuel design. The phenomenon stems from non-laminar flow through the coolant flow channel entry causing random differential pressures across fuel plates. When the shell-mode natural frequencies of the plates are sympathetic with the broad-banded frequency content of the forcing pressures, and the material and hydrodynamic damping are low enough, dynamic instability of the plates becomes a concern. Differential pressure can also occur from a Bernoulli effect when adjacent flow channels have different steady-flow velocities. This results in a static differential pressure across the fuel plates.

Structural capacity is primarily a function of the plate width, thickness, curvature, and the temperature dependent stress-strain characteristics of the plate cladding material. Generally, at fuel plate temperatures above four tenths of the absolute melting point of the plate material, the time-temperature-stress dependent phenomenon of "thermal creep" is also a significant stress reliever, but causes strains to rapidly increase if they are not self-limiting in nature.

Several materials have been investigated for fuel cladding. The cladding provides the majority of the bending strength for the fuel plates. Zircaloy-4 is presently used in many commercial light-water applications, $\mathrm{Zr}-2.5 \mathrm{Nb}$ is used in the CANDU reactor fuels, and 6061 Aluminum is currently used in a number of research and test reactors. Stainless steel is also a possible candidate in these investigations. Table A-1 summarizes some mechanical and physical properties for these materials.

Other aluminum series were also considered. However, years of test reactor experience have indicated that high fluence causes greater 
activation problems in some series than in others. The best performers have been the 1000,5000 , and 6000 series of aluminum. The copper $(2000$ series) and zinc (7000 series) alloying elements are particularly unstable.

Table A-1. Mechanical and physical material properties

\begin{tabular}{|c|c|c|c|c|}
\hline Material Property & $\underline{\text { Zircaloy }-4}$ & $\underline{\mathrm{Zr}-2.5 \mathrm{Nb}}$ & $6061-\mathrm{TO}$ Al & $\begin{array}{c}\text { Annealed } \\
304 \text { Stainless } \\
\end{array}$ \\
\hline $\begin{array}{l}\text { Yield Strength } \\
\text { (MPa) }\end{array}$ & 241 & 310 & 55 & 165 \\
\hline $\begin{array}{l}\text { U1timate Strength } \\
\text { (MPa) }\end{array}$ & 413 & 448 & 125 & 483 \\
\hline Total Elongation (\%) & 20 & 20 & 25 & 40 \\
\hline Melting Point (K) & 2123 & 2113 & $853-923$ & 1789 \\
\hline $\begin{array}{l}\text { Thermal } \\
\text { Conductivity } \\
\text { (W/m-K) }\end{array}$ & 21.5 & 17.1 & 167 & 16 \\
\hline $\begin{array}{l}\text { Coefficient of } \\
\text { Linear Thermal } \\
\text { Expansign } \\
\left(\times 10^{-6} / \mathrm{K}\right)\end{array}$ & 6.0 & 6.3 & 23.6 & 15.8 \\
\hline
\end{tabular}

The strength properties for the materials listed above are at room temperature. The aluminum melting point is considerably below that of the other materials. The yield strength of aluminum reduces rapidly for heat treated materials such as 6061-T6, which reduces from $276 \mathrm{MPa}$ to $12 \mathrm{MPa}$ in the 298-to-593 K range. Because of the high temperature of fuel blister tests, which can anneal most of the strength out of any heat treatment of aluminum, and the existence of higher ductility for accommodating fuel swelling, the To, or annealed, condition of the material, is usually selected for fuel cladding. 
Based on these structural concerns for plate-type fuel, three configurations have been considered for BATR: the arcuate fuel cross section of ATR, the involute section of ANS and HFIR, and the concentric circular plate section of SRL. See Figure 4 in the main report. The following is a brief discussion of the structural merits of each cross section.

\section{A.2 SEGMENTED INVOLUTE FUE! ASSEMBLIES}

Fuel assemblies consisting of full annuli may be critical when immersed in light or heavy water if the fuel loading is high enough, thus requiring the presence of poisons to assure subcriticality. This safety characteristic complicates transportation and fuel handling operations. An annular core constructed from full-annular fuel assemblies also does not provide the flexibility for rearranging the core in response to varying needs. A modification of this configuration considered sectioning the side plates to form arched sections of inner and outer side plates bounding a group of fuel plates (See Figure A-1). This sectioning results in eccentric side plates, with respect to the fuel cross section, which would result in eccentric loading on the fuel plates. Any transverse loads on the cross section transmitted through the side plates would have to be resisted by bending stiffness in the involute plates near the attachment point to the outer side plate because of the shallow attachment angle. This is considerably different from the ATR type cross section, which attaches fuel plates to side plates at right angles. This perpendicular attachment allows the transverse loads on the fuel cross section to be resisted in the fuel plates by membrane stiffness that is much higher than the bending stiffness of the plates. For this reason the involute plate configuration, when sectioned in this fashion, is structurally a weaker fuel assembly cross section than those of the ATR or SRL types. 


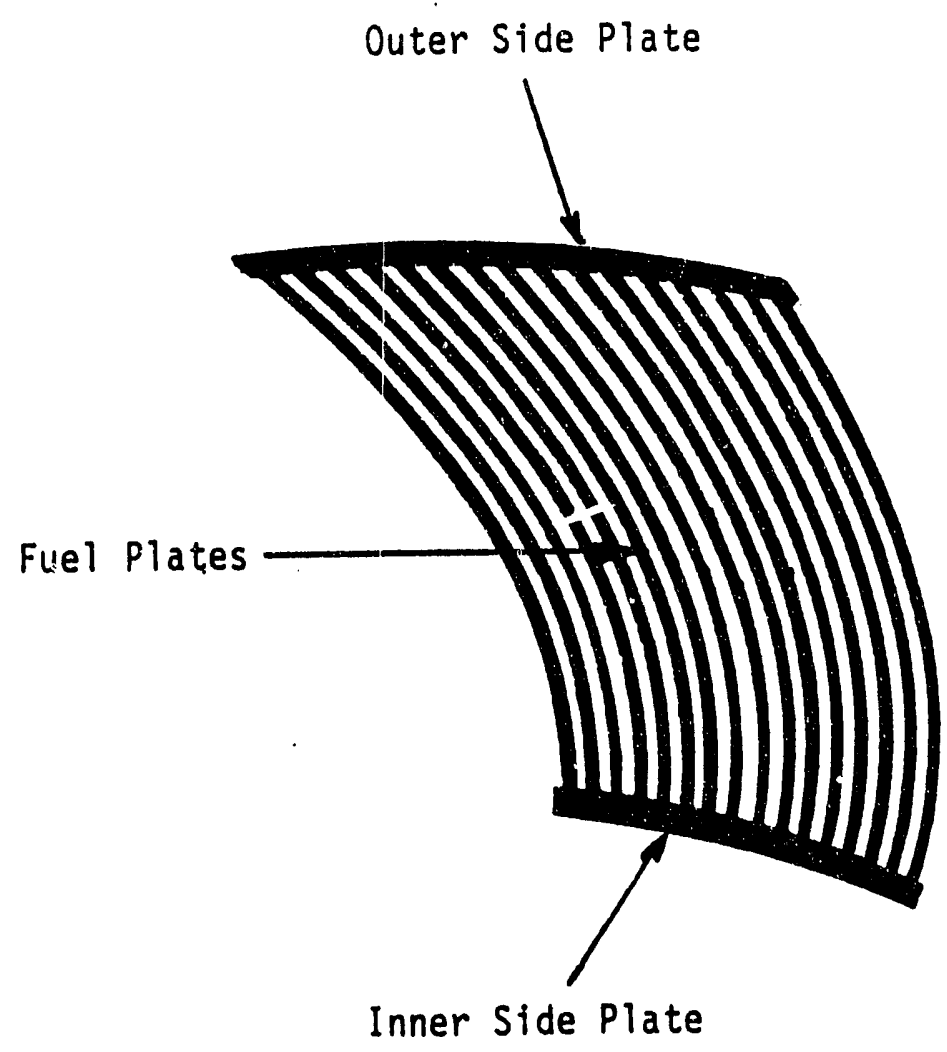

Figure A-1. Segmented involute fuel assembly. 


\section{A.3 CONCENTRIC AND ARCUATE FUEL ASSEMBLIES}

An evaluation of structural capacity of concentric and arcuate fuel cross sections has been based upon several assumptions. The comparison was made between the current ATR assembiy and a nine-plate SRL cross section that fits within the perimeter of the ATR fuel cross section. It was also assumed that spacer ridges would be placed at $45^{\circ}$ intervals in the concentric fuel, that all fuel plates were $1.27-\mathrm{mm}(50-\mathrm{mils})$ thick, and the material had properties of aluminum. This reduces the problem to a strength evaluation of ATR Plate 18, the outermost plate with this thickness, having a plate mean radius of $13.32 \mathrm{~cm}(5.246 \mathrm{in.})$, and the outer plate of the SRL type with a $2.86 \mathrm{~cm}$ (1.127-in.) radius. Obviously, the smaller radius of the SRL type will offer more structural stiffness and strength than that of the ATR-type assembly cross section. When an external radial pressure is applied to both fuel types, the minimum pressures at which elastic buckling would occur, $p^{\prime}$, are related as:

$$
p^{\prime}(A T R) / p^{\prime}(S R L)=(r(S R L) / r(A T R))^{3}=0.01 \text {. }
$$

Elastic axial buckling loads, oriented down the length of the plates, were also investigated for these cross sections. The SRL-type assembly axial plate buckling load is approximately five times that of the ATR section. Column buckling of whole fuel assemblies has not been addressed here because this buckling mode can be addressed in the design, and its effect is not a primary contributor to possible flow channel blockage.

The smaller radius of the SRL-type assembly also provides higher natural frequencies, which affects flow-induced vibration in the plates. The first circumferential modal frequency in the SRL-type assembly is estimated at $7813 \mathrm{~Hz}$, while the corresponding mode in the ATR type is $369 \mathrm{~Hz}$. Thus, it would be expected that much higher flow rates would be allowed in the SRL-type assembly than the ATR-type assembly. 


\section{A.4. INVOLUTE SIDE PLATE SPACING}

Involute plates do not lend themselves to such simple direct comparisons. However, some insights from these studies can be made concerning involute plates. Fuel plate curvature tends to increase the plate stiffness and structural capacity for axial and transverse loads on the fuel assembly cross-section. Since the radius of curvature for an involute varies over its span (width), the stiffress and buckling are dependent upon the plate span and initial radius. If the involute was bounded by inner and outer annular cylinders (see Figure A-1), such as is found in ANS, the outer-to-inner cylinder radius ratio should be less than that of the curves shown in Figure A-2. This would maintain a maximum radius of curvature less than that of the outer fuel plate on the ATR fuel assembly $(13.32 \mathrm{~cm}, 5.246$ inches) and the SRL-type fuel cross section $(2.86 \mathrm{~cm}$, 1.127 inches) investigated above.

\section{A.5. HEXAgONAL FUEL PLATES}

While flat plates are not the equal of curved sections of the same dimensions in axial buckling stability, narrow segments, such as those found in a hexagonal shape, cannot necessarily be ruled out. As an example, a hexagonal fuel plate section circumscribing the outer SRL plate discussed above $(2.86 \mathrm{~cm}, 1.127$ inches across the flats of the hexagonal) has an axial critical buckling load on the flat segments that is $33 \%$ of the circular section and $154 \%$ of the ATR plate investigated.

\section{A.6. SUMMARY}

Based upon the assumptions stated above, the structural comparison of fuel cross sections indicates that the SRL-type fuel assembly is stronger than the others for the purpose of maintaining open coolant flow channels. 


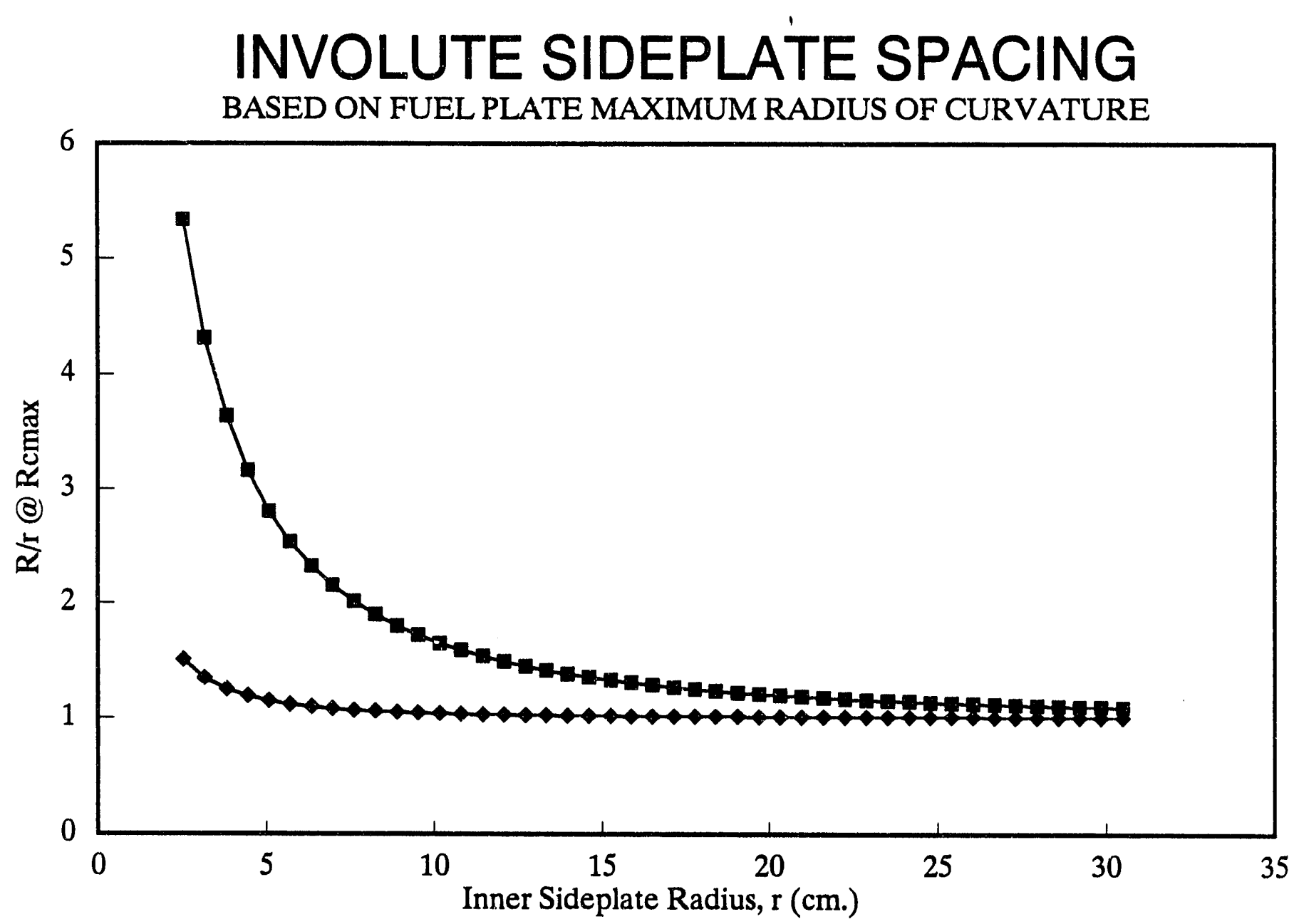

$\rightarrow$ ATR plate with $13.325 \mathrm{~cm}$. radius $\rightarrow$ SRL type with $2.863 \mathrm{~cm}$. radius

Figure A-2. Involute side plate spacing based on maximum curvature (largest radius of curvature for ATR plates is $13.325 \mathrm{~cm}$ ). 


\section{APPENDIX B}

FUEL STUDIES

L. B. Lundberg 


\section{B.1. FUEL REQUIREMENTS}

Fuel to be used in a Broad Application Test Reactor (BATR) must be in a form that can successfully deliver a very high heat flux. The reactor core must produce between 1 and $2 \mathrm{MW} / 1$ iter to achieve the desired peak neutron flux levels. This means that the fuel "form" and fuel assembly geometry must be able to deliver its fission heat to the core coolant without significant impedance. The term fuel "form" encompasses the material chemical composition, manufacturing methods, and local geometry of a fuel element. The coolant of choice will probably be light water moving at very high velocity $(10-30 \mathrm{~m} / \mathrm{s})$.

Fuel elements for prior high neutron flux reactors have been characterized by thin plates in which there is a continuous, solid-state bond between a uranium-bearing fuel material and a solid heat transfer medium that provides for maximum heat transfer within the element. These fuel assemblies have been designed with high surface-to-volume ratios to provide maximum heat transfer rates to flowing, liquid water. A typical example is the ATR fuel plates, which consist of uranium aluminide particles bonded into an aluminum matrix. ${ }^{B-1}$ These fuel forms, which are usually called dispersion fuels, ${ }^{B-2}$ are typically coated or clad with a metallurgically bonded, compatible layer whose purpose is to prevent fission product release and corrosion of the fuel by the coolant.

In order to reduce quantities of enriched uranium in the fuel, the non-fissile, matrix materials in dispersion fuels preferably should have low neutron capture cross sections. For example, aluminum, with its low cross section ( 0.2 to 0.4 barns/atom) is a better choice than stainless steel, with its relatively high cross section (about 12 barns/atom).

The fuel form chosen for BATR must perform well in the reactor environment, with retention of fission products being of utmost importance. Radiation induced swelling and distortions must be minimal as should those effects that can be produced by overheating irradiated fuels 
such as plate blistering. Radiation enhanced corrosion must also be minimal. The burnup limits of the fuel must be as high as possible to keep operating and recycling or disposal costs down.

The BATR fuel form must be fabricate into the shapes required by the reactor design. In order to meet the heat transfer requirement, production of thin-section structures from the fuel form must be possible. Costs of fabrication must also be as low as possible, which usually means reducing the number of fuel plates and employing a conventional fuel type.

Safety in all reactor operation and accident situations will be a dominant fuel requirement. Performance of the BATR fuel form in all severe accident scenarios must not significantly add to or compound the accident problems. For example, a severe core overheat must not lead to the development of uncontrollable burning resulting from fuel ignition.

\section{B-2. FUEL CANDIDATES}

The final choice of a BATR fuel material will probably come from the list of fuel forms that have a demonstrated record of performance in high flux reactors. A major fuel development effort would probably not te acceptable for BATR development because of the requirement to reduce technical development risk. The candidate fuel forms that are seriously considered in the following discussion are listed in Table B-1. The three fuel forms include two aluminum matrix dispersion fuel forms and a $\mathrm{UO}_{2}$-stainless steel cermet. The advantages and disadvantages of these three fuel forms are discussed below.

Several other fuel forms were considered but were not included in the list of candidates because of one or more deficiencies. For example, a $\mathrm{UO}_{2}$-zirconium cermet was considered, but it was rejected on the basis of concerns such as excessive operating temperatures, fuel-matrix chemical reactions, metal-water reactions, and lack of reactor operating experience. 
Table B-1. BATR fuel candidates

\begin{tabular}{|c|c|c|c|c|}
\hline Fuel Form & $\begin{array}{c}\text { Reactor } \\
\text { Experience }\end{array}$ & $\begin{array}{l}\text { Maximum Fuel } \\
\text { Assembly Power } \\
\text { Density (MW/L) }\end{array}$ & $\begin{array}{c}\text { Solidus } \\
\text { Temperature(K) }\end{array}$ & $\begin{array}{l}\text { Peak Burnup } \\
\text { (fissions } / \mathrm{m}^{3} \text { ) }\end{array}$ \\
\hline$A 1-U A I_{3}$ & ATR, HIFR, etc. & $1.1 *$ & 915 & $2.3 \times 10^{27}$ \\
\hline $\mathrm{Al}-\mathrm{U}_{3} \mathrm{Si}_{2}$ & ANS & $8.0 * \star$ & 850 & $2.0 \times 10^{27}$ \\
\hline $\mathrm{SS}-\mathrm{UO}_{2}$ & OMRE & $2.7 *$ & 1675 & $1.2 \times 10^{27}$ \\
\hline
\end{tabular}

All of these fuel forms have been fabricated into thin-plate geometries, and the ATR/HIFR fuel is in current production. The fabrication development for the Advanced Neutron Source plate fuel form is currently in progress. All of these fuel forms can also be produced in pin geometry.

\section{B.2.1 Aluminum Matrix Fuels}

\section{B.2.1.1 Uranium Aluminide Dispersion Fuels}

The most popular fuel form for high flux research reactors has been a metastable composite that consists of uranium aluminide particles dispersed in aluminum. Due to fabrication restraints and the need for a continuous aluminum matrix, the fuel loading of the aluminide dispersions appears to be 1 imited to about $6 \times 10^{27}$ atoms $\mathrm{U} / \mathrm{m}^{3}$. B-3 The most common fuel matrix material has been 1100 grade aluminum. Aluminum alloys have been used for cladding the composite structure (sometimes referred to as the fuel 'meat') to provide better water corrosion resistance. Alloy 6061 is being used on the ATR fuel plates, and alloy 5052 is being used on the European high flux reactor plates. 
A great deal is known about the behavior of this type of fuel, and much of what is known about its reactor operating performance is documented in reference B-1. Property and engineering data are currently being compiled for the ATR fuel, and these data should be available for use in BATR final design efforts. The burnup limit indicated in Table B-1 is for ATR fuel.

Irradiation swelling of the aluminide dispersion fuels appears to be well controlled with the intentional incorporation of porosity into the composite structure. ${ }^{B-1}$ Generally, the porosity is mostly filled by the fission products before bulk swelling proceeds. However, the irradiation performance of the aluminide dispersion fuels is not well known at the fission rates expected for BATR (about twice that of ATR). Accumulated fission gases can cause the surfaces of plate-form aluminide dispersion fuel elements to blister when heated to temperatures sufficiently high to cause the fission gases to start releasing from the fuel particles. The blistering temperature reduces with burnup to about $1.2 \times 10^{27}$ fissions $/ \mathrm{m}^{3}$, where it reaches a plateau at about $700 \mathrm{~K}$. Fission product release from fuel plates appears to coincide with the blistering process. B-4 $^{-4}$

There is also data to indicate the performance of the aluminide dispersion fuels in severe accident situations. ${ }^{B-5}$ The low melting temperature of the $A 1-6061$ and the matrix aluminum represents a weakness in this fuel form for over-temperature excursions. A1-6061 starts melting around 860 $K$. The solidus temperature listed in Table $B-1$ for the $A l_{-U A l_{3}}$ fuel form represents the temperature at which the aluminum matrix forms an eutectic with the $\mathrm{UAl}_{4}$-phase that forms as a diffusion layer between the $\mathrm{UAl}_{3}$ particles and the aluminum matrix. This melting appears to represent a major fission product release mechanism. ${ }^{B-5}$ The $\mathrm{UAl}_{4}$-phase decomposes to aluminum and $\mathrm{UAl}_{3}$ above $1005 \mathrm{~K}$, and $\mathrm{UAl}_{3}$ does not melt until it is heated to about $1625 \mathrm{~K} .^{\mathrm{B}-6}$ Formation of molten phases in the $\mathrm{Al}^{-U A l_{3}}$ dispersion fuel in a water-cooled reactor can cause rapid steam generation and chemical reaction with the water. Fortunately, the UAl 4 -phase appears to be quite stable and does not appear to react with water chemically, even at the melting temperature of al uminum and to temperatures as high as $1100 \mathrm{~K} .{ }^{\mathrm{B}-7}$ 
The data on the oxidation of molten aluminum-uranium alloys in steam indicates that the oxidation rates are comparable to pure aluminum for alloys with uranium contents up to $17 \mathrm{wt} \%$ and to temperatures as high as $1873 \mathrm{~K}$. Even though the oxidation rates were rapid at this temperature, the rates were not at explosive levels. However, the effects of fission products on the potential for violent reactions with water is not well known.

The current fabrication costs of aluminide fuels are well known. For example, an ATR fuel assembly costs about $\$ 25,000$ to fabricate. However, this figure does not include the costs of the uranium, shipping, safeguards and security, inspection and pre-operation proof testing. The $235 \mathrm{U}$ enrichment level is certain to be a cost driver for BATR fuel even if the direct costs of the $235 \mathrm{U}$ are not applied.

The disposal of spent, highly-enriched aluminide fuel is based on the recovery of residual ${ }^{235} \mathrm{U}$, which has been performed at the Chemical Processing Plant (CPP) at the INEL. The current costs of spent aluminide fuel disposal are not known, but they are expected to be high enough to strive for the highest possible fuel burnup in BATR.

\section{B.2.1.2 Uranium Silicide Dispersion Fuels}

The uranium silicides dispersed in aluminum have been studied extensively $y^{B-3}$ but have only recently been proposed for use in fuel assemblies for high flux reactors. ${ }^{B-8}$ This fuel form can also be characterized as $\mathrm{U}_{3} \mathrm{Si}_{2}$ particles bonded into an aluminum matrix to form a metastable mixture. Studies are currently underway to develop an $\mathrm{Al}-\mathrm{U}_{3} \mathrm{Si}_{2}$ dispersion fuel for use in the ANS. This fuel is being considered for high flux reactors because of its potential for higher uranium densities.

The silicide dispersion fuels can be more heavily loaded with uranium in an aluminum matrix on a volumetric basis than the aluminide fuels. It 
is estimated that silicide dispersion fuels can be fabricated and operated successfully with uranium concentrations up to $12 \times 10^{27}$ atoms $\mathrm{U} / \mathrm{m}^{3}$. The ANS fuel will contain up to $6 \times 10^{27}$ atoms $\mathrm{U} / \mathrm{m}^{3}$.

Outside of the higher uranium density potential, silicide dispersion fuels appear to be very similar to aluminide dispersion fuels. However, reactor experience with the silicide fuel forms is limited when compared to the aluminide fuels. Much of the property data on $\mathrm{Al}_{-} \mathrm{U}_{3} \mathrm{Si}_{2}$ dispersion fuel materials and forms relative to reactor design can be found in reference B-3. These data indicate that the silicide dispersion fuels possess irradiation swelling behavior similar to that observed for the aluminide fuels. However, much of the irradiation behavior data is based on samples with low uranium-235 enrichment (less than $20 \%{ }^{235} \mathrm{U}$ ), and fission rate is usually an important swelling parameter. Plate blistering also occurs at the same temperatures as for the aluminide dispersion fuels, but the effects of burnup are not well defined for the silicides.

One major difference between the silicide and aluminide dispersion fuels is the chemical stability of the fuel form relative to the aluminum matrix. The silicide form reacts rapidly and exothermically with the the aluminum matrix above about $865 \mathrm{~K}$. In the aluminide form reactions between the $\mathrm{UAl}_{3}$ and the aluminum matrix proceed by diffusion and do not generate significant heat. The heats of reaction are somewhat higher than has been observed for the reaction between $\mathrm{U}_{3} \mathrm{O}_{8}$ and aluminum. ${ }^{\mathrm{B}-3}$ The $\mathrm{U}_{3} \mathrm{Si}_{2}$ fuel form reacts with the aluminum matrix to form $U(A 1, S i)_{3}$, which is less dense than the pure silicide. This reaction can also proceed at lower temperatures but at much slower rates because the rate is diffusion controlled. Volumetric swelling of the silicide-aluminum dispersion fuels is observed as a result of the interdiffusion reaction process and a concurrent release of impurity hydrogen. B-9

The behavior of the silicide dispersion fuels during extreme overheating in water cooled nuclear reactor environments is not well defined. Also, 
it appears that only cursory studies of the water corrosion behavior of the silicide dispersion fuels have been performed. ${ }^{B-3}$ The data are limited on the lifetime and accident behavior of the silicide dispersion fuels.

Fabrication of the silicide dispersion fuels is very similar to that for the aluminide dispersion fuels. Consequently, it is estimated that the fabrication costs of silicide plate fuel elements will be close to those already mentioned for the aluminide fuel plates. Fuel plate fabrication development efforts are currently underway in preparation for the production of ANS fuel.

The disposal of spent, highly-enriched silicide fuel will be based on the recovery of residual $235 \mathrm{U}$, which has been performed at the Savannah River Plant. ${ }^{B-3}$ The costs of spent silicide fuel disposal are not known, but as with the aluminide fuel, they are expected to be high enough to strive for the highest possible fuel burnup.

\section{B.2.2 Stainless Steel- $-\mathrm{UO}_{2}$ Dispersion Fuels}

Fuel plates containing $\mathrm{UO}_{2}$ dispersed in an austenitic stainless steel have been considered for use in high flux research reactors. Most of the following discussion is based on data presented in reference B-10. Fuel behavior studies have been performed on plates that contained up to $40 \mathrm{wt} \%$ $\mathrm{UO}_{2}$. This translates to a uranium density of about $7.5 \times 10^{27}$ atoms $/ \mathrm{m}^{3}$ in a dispersion that contains a void fraction sufficient to accommodate most of the irradiation swelling. Higher fuel loadings may be possible. The burnup 1 imit 1 isted in Table B-1 for the SS- $\mathrm{UO}_{2}$ dispersion fuel is based on the fuel swelling data $B-10$ and a volumetric irradiation swelling limit of about $3 \%$.

The SS- $\mathrm{UO}_{2}$ dispersion fuel is usually clad with a similar, compatible stainless steel for fission product containment and additional protection against water corrosion. Cladding thicknesses in the vicinity of $0.127 \mathrm{~mm}$ on 1-mm-thick plates have been demonstrated to be fabricable and fission- 
-product tight in radiation tests. inis cladding thickness is significantly less than that used on lluminum matrix fuels.

The $\mathrm{UO}_{2}$ particles are relatively unreactive with the stainless steel matrix during fabrication or operation, even when the particles contain significant quantities of fission product elements. Only fission recoil contamination of the stainless steel matrix is observed at the relatively low operating temperatures expected for high flux test reactors.

The plate-blistering behavior of $\mathrm{SS}^{-\mathrm{UO}_{2}}$ dispersion fuel is similar to that observed for the aluminum matrix dispersion fuels. Porous $\mathrm{UO}_{2}$ releases fission gases at temperatures similar to those for both the aluminide and silicide fuel forms.

Even though austenitic stainless steel matrix fuels have high neutron cross sections, the $\mathrm{SS}-\mathrm{UO}_{2}$ dispersion fuel form may offer a significant safety advantage over the aluminum matrix fuels by virtue of their high melting points and heat capacities. The total amount of thermal energy required to melt the matrix material is proportional to both of these properties. Violent reactions with water should also be mitigated by the high thermal energy required for melting. However, experimental data were not found to support these hypotheses, so it will probably be necessary to perform accident simulation studies on these fuels in support of BATR design studies.

Historically, the meat of this fuel form has been fabricated by standard cermet production methods. In general, spherical $\mathrm{UO}_{2}$ particles are blended with 300-series (austenitic) stainless steel powder, cold pressed, and sintered to produce a rolling billet. The sintered dispersion is clad with Type 347 stainless steel plate, and the resultant plate is rolled to reduce the total thickness and bond the cladding to the fuel meat. $\mathrm{SS}-\mathrm{UO}_{2}$ dispersion fuels are not currently in production, so some development would be required to fabricate BATR fuel assemblies. Fabrication costs are expected to be slightly higher than for the ATR fuel assemblies because of process differences such as high temperature 
sintering of the fuel meat rolling billet. Fabrication costs could be much higher if BATR is the only reactor using this fuel type in the future.

It is not known whether reprocessing methods were ever fully developed for the $\mathrm{SS}-\mathrm{UO}_{2}$ dispersion fuels. Any previously developed reprocessing or disposal processes for $\mathrm{SS}_{-} \mathrm{UO}_{2}$ dispersion fuels would probably require modification in order to meet current environmental standards. The activation of the stainless steel in $\mathrm{SS}-\mathrm{UO}_{2}$ dispersion fuels is certain to add to the difficulties of reprocessing or disposal.

\section{B.3. CONCLUSIONS AND RECOMMENDATIONS}

Aluminide dispersion fuels $\left(\mathrm{Al}^{-U A 1_{3}}\right)$ are the first choice for BATR fuel. The $\mathrm{SS}^{-\mathrm{UO}_{2}}$ dispersion fuels are a reasonable second choice, while the silicide forms are third. Even the aluminide dispersion fuel forms do not represent a perfect choice, primarily because of the relatively small amount of thermal energy required to form molten phases.

Some work indicates the feasibility of producing higher performance aluminide fuels primarily in the area of higher burnup. ${ }^{B-11}$ A $30 \%$ increase in useful life has been indicated for ATR operating conditions, but further studies are required to indicate fuel performance expectations for a BATR that might operate at a higher burnup rate.

\section{B.4. REFERENCES}

B-1. J. M. Beeston, R. R. Hobbins, G. W. Gibson, and W. C. Francis, "Development and Irradiation Performance of Uranium Aluminide Fuels in Test Reactors, " Nuclear Technology, 49, 1980, pp. 136-149.

B-2. D. L. Keller, "Dispersion Fuels, "Chapter 13 in Reactor Handbook, Vol. I, Materials, 2nd Ed., Interscience Publishers, Inc., 1960, pp. 304-330. 
B-3. J. L. Snelgrove, R. F. Domagala, G. L. Hofman, T. C. Wiencek, G. L. Copeland, R. W. Hobbs, and R. L. Senn, The Use of $U_{3} \underline{S i}_{2}$ Dispersed in Aluminum in Plate-Type Fuel Elements for Research Reactors, ANL/RERTR/TM-11, Argonne National Laboratory, October 1987.

B-4. T. Shibata, T. Tamai, M. Hayashi, J. C. Posey, and J. L. Snelgrove, "Release of Fission Products from Irradiated Aluminide Fuel at High Temperatures," Nuclear Science and Engirieering, 87, 1984, pp. 405-417.

B-5. P. G. Ellison, M. L. Hyder, C. L. Angerman, and J. P. Morin, A Phenomenological Assessment of Nuclear Metallic Fuel Melt Behavior During Severe Accidents, WSRC-RP-90-1130, Westinghouse Savannah River Co., October 1990.

B-6. T. B. Massalski (Ed.), Binary Alloy Phase Diagrams, Vol.1, 2nd edition, Metals Park, OH: ASM International, 1990.

B-7. J. P. Adams and D. L. Hagrman, An Analytical Assessment of the Chemical Form of Fission Products During Postulated Severe Accidents. in the SRS Production Reactors, WSRC-RP-1365, Westinghouse Savannah River Co., December 1990.

B-8. J. M. Ryskamp, D. L. Selby, and R. T. Primm III, "Reactor Design of the Advanced Neutron Source," Nuclear Technology, 93, 1991 pp. $330-349$.

B-9. T. C. Wiencek, R. F. Domagala, and H. R. Thresh, "Thermal Compatibility Studies of Unirradiated Uranium Silicide Dispersed in Aluminum," Nuclear Technology, 71, 1985, pp. 608-616.

B-10. M. J. Graber and G. W. Gibson, Irradiation Testing of Fuel for the Mark I Core of the Argonne Advanced Research Reactor, IN-1160, Idaho Nuclear Corporation, April 1968.

B-11. L. G. Miller and J. M. Beeston, Extended Life Aluminide Fuel, Final Report, EGG-2441, Idaho National Engineering Laboratory, June 1986. 
APPENDIX C

\section{THERMAL-HYDRAULIC STUDIES}

C. D. Fletcher

I. M. Blasch 


\section{C.1. INTRODUCTION}

The following thermal-hydraulic trade-off studies were performed to support the development of the Broad Application Test Reactor. The studies were performed using a one-dimensional model representing the cross section of a fuel plate with the RELAP5/MOD3 computer code. The base model uses $0.51-\mathrm{mm}$-thick $(20-\mathrm{mil})$ fuel meat, $0.38-\mathrm{mm}$-thick $(15-\mathrm{mil})$ cladding, 0.02-mm-thick (0.7-mil) oxide, 1.98-mm-wide (78-mil) coolant channel, and the fluid conditions of the Advanced Test Reactor operating at $250 \mathrm{MW}_{t}$ with three reactor coolant pumps powered. The equivalent power density for the base model is $1 \mathrm{MW} / \mathrm{liter}$.

\section{C.2. PLATE MATERIAL THERMAL LIMIT}

Starting with the base model that employs aluminum alloy fuel plate material properties, the fuel centerline operating temperatures for various power densities were calculated. Then the calculations were repeated using material properties representing two alternate fuel plate alloy materials: zirconium, and stainless steel. For zirconium, the aluminum fuel plate geometry was retained; however, for the stronger stainless steel it was assumed that thinner fuel plates could be employed. The input assumptions and calculation results for this study are given in Table $\mathrm{C}-1$.

The results indicate that the low thermal conductivity of zirconium and its oxide cause fuel centerline temperatures to exceed the long term blistering temperature at power densities greater than $2 \mathrm{MW} / \mathrm{liter}$. Thus zirconium may not be an appropriate fuel material for a BATR where local power densities above $2 \mathrm{MW} / \mathrm{liter}$ may be experienced. However, this finding is very sensitive to the assumptions made on zirconium oxide thermal conductivity and thickness; further confirmatory work is needed. 
Table C-1. Assumptions and results for the plate material thermal limit study

Assumptions

\begin{tabular}{l} 
Alloy Material \\
\hline Aluminum Zirconium Stainless Steel
\end{tabular}

Thermal Conductivity $(\mathrm{W} / \mathrm{m}-\mathrm{K})$

Meat

Cladding

Oxide

Thermal Capącitance

$\left(\times 10^{6} \mathrm{~J} / \mathrm{m}^{3}-\mathrm{K}\right)$

Meat

Cladding

Oxide

Thicknesses (mm)

Plate

Meat

Cladding

Oxide

Coolant Channel

Solidus Temperature (K)

Blistering Temperature (K)

\section{Results}

Power Density (MW/liter)
1.0
2.0
3.0
4.0
5.0

147.0

237.4

2.243

9.096

12.34

2.243

14.95

14.95

14.95
2.404

2.668

3.099

1.270

0.508

0.381

0.018

1.981

858

673
2.502

1.934

3.099

1.270

0.508

0.381

0.018

1.981

2125

673
4.037

4.111

4.111

1.270

0.762

0.127

0.018

1.981 *

1726

673

Fuel Plate Centerline Temperature (K)

$\begin{array}{rrr}404 & 487 & 419 \\ 475 & 644 & 507 \\ 542 & 796 & 592 \\ 593 & 931 & 667 \\ 631 & 1052 & 722\end{array}$

* For stainless steel, the coolant channel width and core flow velocity were maintained, and the core power was reduced by a multiplier of 0.922 to maintain the same core power density. 
The results also indicate that stainless steel is superior to aluminum as a fuel plate material in several respects. While its thermal conductivity is lower than for aluminum, its oxide thermal conductivity is greater. Further, its greater strength allows the use of thinner plates.

These combined effects cause the stainless plate operating temperatures required for removing the fission heat to only moderately exceed those of the aluminum plates. This thermal penalty is therefore quite small in comparison with safety benefits of stainless steel: mechanical strength, high melting temperature, and lower concerns for reactions between molten cores and coolants.

\section{C.3. PLATE MATERIAL HEAT-UP RATE}

The base model and variations described in Table $C-1$ were used to determine the time required for the fuel plates to reach the solidus temperature following a departure from nucleate boiling. The calculations assume continuation of full core power. The results provide an indication of the time available prior to the occurrence of fuel damage for reactor trip actuation. Calculation results are shown in Table C-2. Comparison of results for the different fuel plate materials also provides an indication of the relative time available for operators to control an accident following a reactor trip and prior to the occurrence of fuel damage. The results indicate that the time required to reach the fuel plate melting temperature is significantly longer with zirconium and stainless steel than with aluminum. These findings are due to the higher melting temperatures for zirconium and stainless steel, and due to the larger thermal capacity of stainiess steel.

Table C-2. Time to reach fuel plate solidus temperature at full reactor power

Power Density (MW/Iiter)

1.0

2.0
Time (Seconds) to Reach Solidus Temperature Aluminum Zirconium Stainless Steel

0.78

0.32
2.07

0.76
2.18

0.95 


\section{C.4. COOLANT SELECTION}

The base model described in the plate material was employed to compare the thermal-hydraulic effects of using light and heavy water coolants. Parallel, steady-state calculations were performed using the properties of the two fluids and assuming the core flow velocities are the same. The study indicates that there are only minor differences in the thermal-hydraulic performances of the two fluids. Coolant and fuel plate temperatures are slightly $(2-3 \mathrm{~K})$ cooler with heavy water, due to its higher density and mass flow rate. The core differential pressure with heavy water was about $12 \%$ higher than with light water, also as a result of the density difference. The fuel plate heat transfer coefficient with heavy water was about $4 \%$ lower than with light water, due to differences in fluid transport properties.

\section{C.5. EFFECT OF METAL/WATER RATIO ON SAFETY MARGIN}

The metal-to-water ratio within the reactor affects the reactor safety margin because it relates the fuel plate heat flux and the coolant channel width. A short study was performed to show this relationship.

The base case selected used ATR geometry and 250-MW full-power conditions. The ATR employs $1.27-\mathrm{mm}$-thick (50-mil) fuel plates and 1.98-mm-thick (78-mil) coolant channels at an average power density of $1 \mathrm{MW} / \mathrm{liter}$. The ATR metal/water ratio is 0.641 . For ATR, the limiting safety margin is flow instability resulting from saturation of the fluid at the core exit. Based on a core inlet temperature of $325 \mathrm{~K}\left(125^{\circ} \mathrm{F}\right)$, a core exit pressure of $1.86 \mathrm{MPa}$ (270 psia), and a core flow velocity of $14.3 \mathrm{~m} / \mathrm{s}(47 \mathrm{ft} / \mathrm{s})$, flow instability is predicted to occur at an average core power density of $4.71 \mathrm{MW} / 1$ iter.

Next, it was assumed that the coolant channels were narrowed from 1.98 to $1.27 \mathrm{~mm}$ ( 78 to $50 \mathrm{mils}$ ), resulting in a metal/water ratio of 1.00 . Assuming the same core power density and core outlet fluid temperature 
results in a core flow velocity of $17.5 \mathrm{~m} / \mathrm{s}(57.3 \mathrm{ft} / \mathrm{s})$ and a lowering of the core exit pressure to $0.91 \mathrm{MPa}(137.2 \mathrm{psia})$. Under these conditions, flow instability was predicted to occur at an average core power density of $3.73 \mathrm{MW} / \mathrm{liter}$.

A final case was studied with the base case assumptions alterec by widening the coolant channel from $1.98 \mathrm{~mm}$ to $3.18 \mathrm{~mm}$ ( 78 to $125 \mathrm{mils}$ ), resulting in a metal/water ratio of 0.400 . Using the same method as in the previous paragraph, flow instability was calculated to occur at a core power density of $5.01 \mathrm{MW} / \mathrm{liter}$.

In summary, this study shows that the margin to flow instability decreases from 5.01 at a metal/water ratio of 0.400 , to 4.71 at a metal water ratio of 0.641 , to 3.73 at a metal/water ratio of 1.00 . The safety margin therefore is shown to be quite sensitive to the selection of the metal/water ratio and this ratio should be considered a significant design parameter. 
Appendix D

REACTOR PHYSICS STUDIES

S. N. Jahshan

R. C. Thayer 


\title{
D.1. INTRODUCTION
}

The safety requirements and user needs evaluations in Sections 2 and 3 led to a selection process of the available reactor concept types. This process led to narrowing down the selection to that of a conventional, evolutionary (as opposed to revolutionary) test reactor concept of the ANS/ATR type. This concept type contains plate fuel and is moderated and cooled by some combination of $\mathrm{D}_{2} \mathrm{O}$ and $\mathrm{H}_{2} \mathrm{O}$. This reactor concept should meet the safety and performance requirements defined by the safety and user needs committees. The operational requirements are essentially: (a) a thermal flux intensity of approximately $10^{15} \mathrm{~cm}^{-2} \mathrm{~s}^{-1}$ and (b) a fast flux intensity of approximately $10^{14} \mathrm{~cm}^{-2} \mathrm{~s}^{-1}$ in an irradiation volume of at least 50 liters. The reactor is to operate at less than about $500 \mathrm{MW}_{\mathrm{t}}$ power with the longest cycles possible.

As identified in the main report, a reactor concept composed of several fuel assemblies cooled by light water and contained in one large heavy water reactor tank was selected for further study. The specific arrangement of the assemblies and their design details are investigated here from a reactor physics standpoint. The BATR reactor physics development work centers on the selection of the following three design elements: (1) fuel type, (2) materials (fuel, reflector, and internal components), and (3) core module arrangement.

Terminology:

\begin{abstract}
"Reactor" is a system encompassing all space and characterized by one multiplication factor (k-effective), which is a measure of the system state: critical, subcritical, or supercritical.
\end{abstract}

\footnotetext{
"Module" is a subsegment of the reactor, characterized by being an active as compared to a passive (load) component.
} 
These three elements were considered simultaneously (or interactively). Early analysis considered items (1) and (2) above. These centered on selection of fuel type: ATR, involute, concentric, or other. Also, fuel material substitutions were considered in terms of their effects on the value of the multiplication factor, neutron spectrum, and mechanical properties such as strength at elevated temperatures, stability and chemical reactivity with other components.

Starting with the standard aluminum plate fuel, zircaloy substitution in ATR and ANS models (MCNPD-1 and $P D Q^{D-2}$ ) resulted in very small adverse effects on the multiplication factors. The substitution of stainless steel with corresponding $\mathrm{plate}$ thickness changes to account for realistic densities and strength of materials deployed, yielded large adverse effects in the multiplication factors. Substitution of molybdenum also yielded very poor multiplication factors for these systems. Thus, the use of stainless steel as a cladding would require a significantly higher fuel loading than for Al-6061 or zircaloy. This increases fuel cost, reduces the neutron flux in different regions, and may affect safety margins.

The effects of fuel assembly type selection (concentric, arcuate, involute) on the neutronics is minimal for this highly-enriched (93\%) system. These considerations are important for heat removal analysis. Thus, an average homogenized fuel was chosen. This reflects a composition with a density less than that of the average ANS fuel, in which light water has been substituted for heavy water. Thus, the fuel type became a parameter to be fixed later. The fuel plate material was set as A1-6061 for this study. The fuel meat is like the ANS fuel meat ${ }^{\mathrm{D}-3}, A \mathrm{Al}-\mathrm{U}_{3} \mathrm{Si}_{2}$, with $\mathrm{Al}-\mathrm{UA} \mathrm{I}^{\mathrm{D}-3}$ as a possible substitute. The fuel meat may be changed to yet another composition depending on the final dispersion fuel to be chosen.

This work was performed based on the following outline:

(1) Single module (cylinder) studies

- Search for base case

- Fuel clad substitution

- Primary reflector substitution 
In each job run obtain the multiplication factor and the thermal and fast flux distributions (relative to a module power of $100 \mathrm{MW}_{\mathrm{t}}$ ).

(2) Two module studies

Parametric analyses for optimization of fast and thermal fluxes and the multiplication factor due to the interaction of modules.

(3) Full core studies

- 6 modules in a circular core

- $4 \times 4$ modules in a hexagonal grid

- 4 × 4 modules in a rectangular grid.

\section{D.2 SINGLE MODULE STUDIES}

A cylindrical fuel assembly with a height of $95 \mathrm{~cm}$ and inner and outer diameters of 21 and $34 \mathrm{~cm}$, respectively, was selected after several MCNP2 Monte Carlo simulation iterations over the inner and outer diameters and height. The cylinder is centered in a 3-m high cylindrical $\mathrm{D}_{2} \mathrm{O}$ reflector with a diameter of $3 \mathrm{~m}$, as shown in Figure $\mathrm{D}-\mathrm{i}$. The coolant flow through the cylinder and within its inner radius is $\mathrm{H}_{2} \mathrm{O}$. The fuel material is a homogenized region of $93 \%$ enriched $\mathrm{Al}^{-} \mathrm{U}_{3} \mathrm{Si}_{2}$ fuel with Al-6061 plates. This corresponds to the ANS fuel material with a fuel density below the ANS average. This fuel was then homogenized with the $\mathrm{H}_{2} \mathrm{O}$ coolant, keeping the same water-to-metal ratio as in ANS.

The effects of dispersion fuel substitution, in particular, $\mathrm{UAl}_{3}$ in place of $\mathrm{U}_{3} \mathrm{Si}_{2}$ is not important for criticality evaluations or flux level values but rather for burnup and manufacturing considerations. Replacing $\mathrm{U}_{3} \mathrm{Si}_{2}$ with $\mathrm{UAl}_{3}$ in the ANS design has a negligible effect on core reactivity.

The effects of "primary" reflector substitutions are outlined in Tables D-1 through D-4. This is the case where a reflector cylinder of $7-\mathrm{cm}$ thickness is substituted immediately outside the fuel in place of the $\mathrm{D}_{2} \mathrm{O}$, or a "primary" reflector cylinder of $5-\mathrm{cm}$ thickness is substituted immediately inside the fuel in place of the $\mathrm{H}_{2} \mathrm{O}$. In the last entry of 


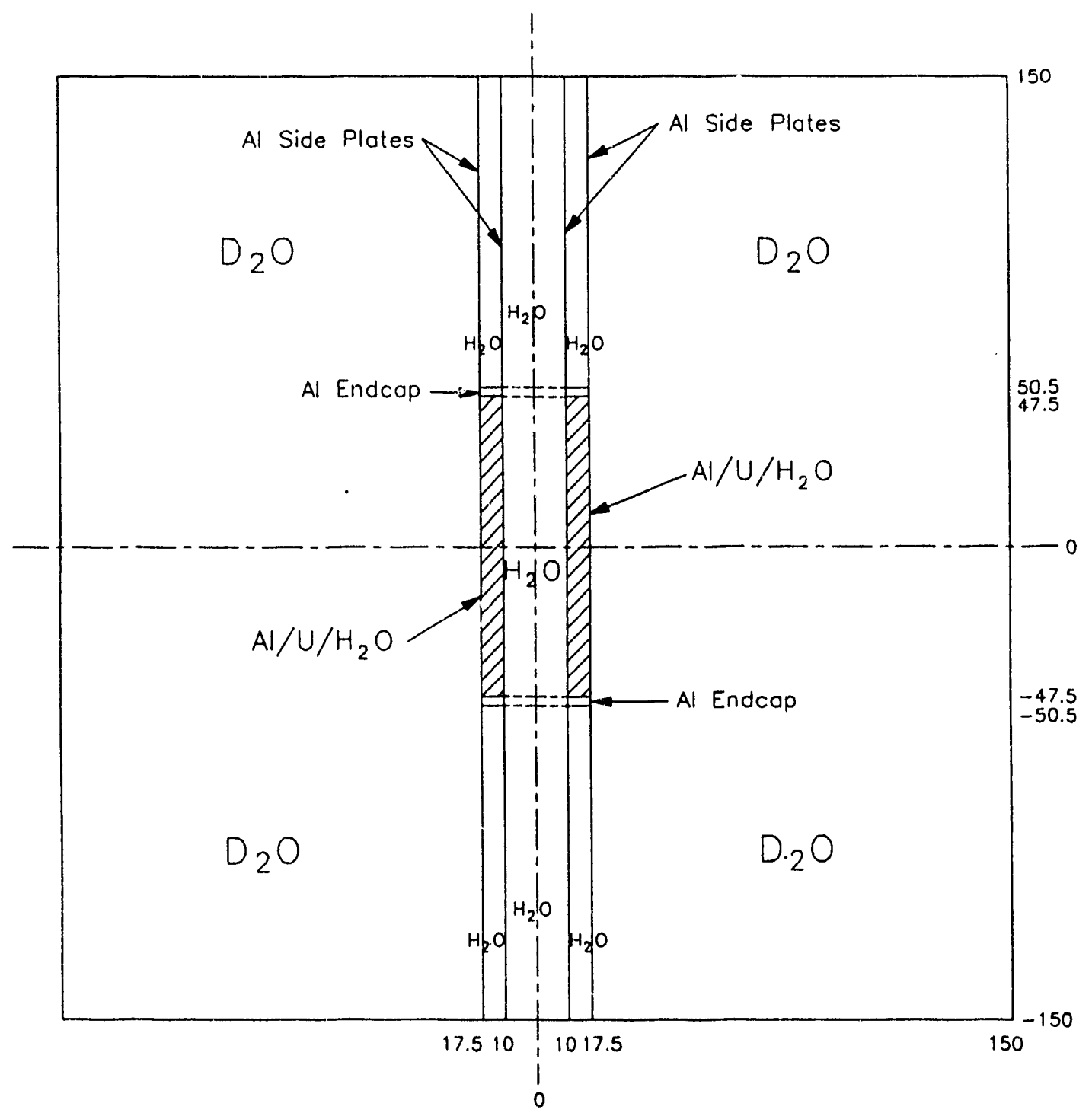

Radial Region Dimensions (cm)

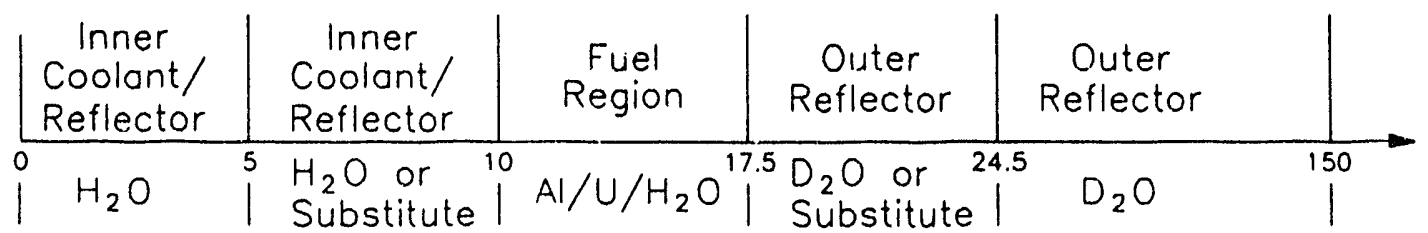

HO62-SN-0891-01

Figure D-1. BATR single base module and dimensions. 
Tables $\mathrm{D}-1$ through $\mathrm{D}-4$, the $\mathrm{D}_{2} \mathrm{O}$ substitution represents $\mathrm{placing} \mathrm{D}_{2} \mathrm{O}$ in the entire inner reflector. The relative dimensions of 5 and $7 \mathrm{~cm}$ were obtained by inspection from several runs but are not opiimized dimensions.

The primary conclusions obtained from this set of single-module simulations in MCNP are the following:

1. Ni has the highest effect on flux shaping among the primary reflectors. A primary outer $\mathrm{Ni}$ reflector increases the thermal and fast fluxes in the inner reflector. A primary $\mathrm{Ni}$ reflector inside the fuel shell increases the thermal flux in the outer reflector. However, there is a large penalty in the core multiplication factor when nickel is used as the primary reflector.

2. Be greatly increases the core multiplication factor when used as the primary inner reflector. This also increases the fast flux in the inner reflector.

3. Heavy water in the central hole provides the greatest increase in the core multiplication factor. Thus, light water in the fuel with inner and outer heavy-water reflectors is a great combination to achieve a long fuel cycle. This could be achieved by operating the experiment loops with heavy water. Heavy water in the coolant channe?s decreases the core reactivity. Accident scenarios of light or heavy water ingress into various regions are important and must be analyzed in the conceptual reactor design.

4. A void channel within the $\mathrm{H}_{2} \mathrm{O}$ inner reflector increases the thermal and fast fluxes without significantly reducing the multiplication factor. However, a positive reactivity insertion could occur upon reflooding of this central void. 


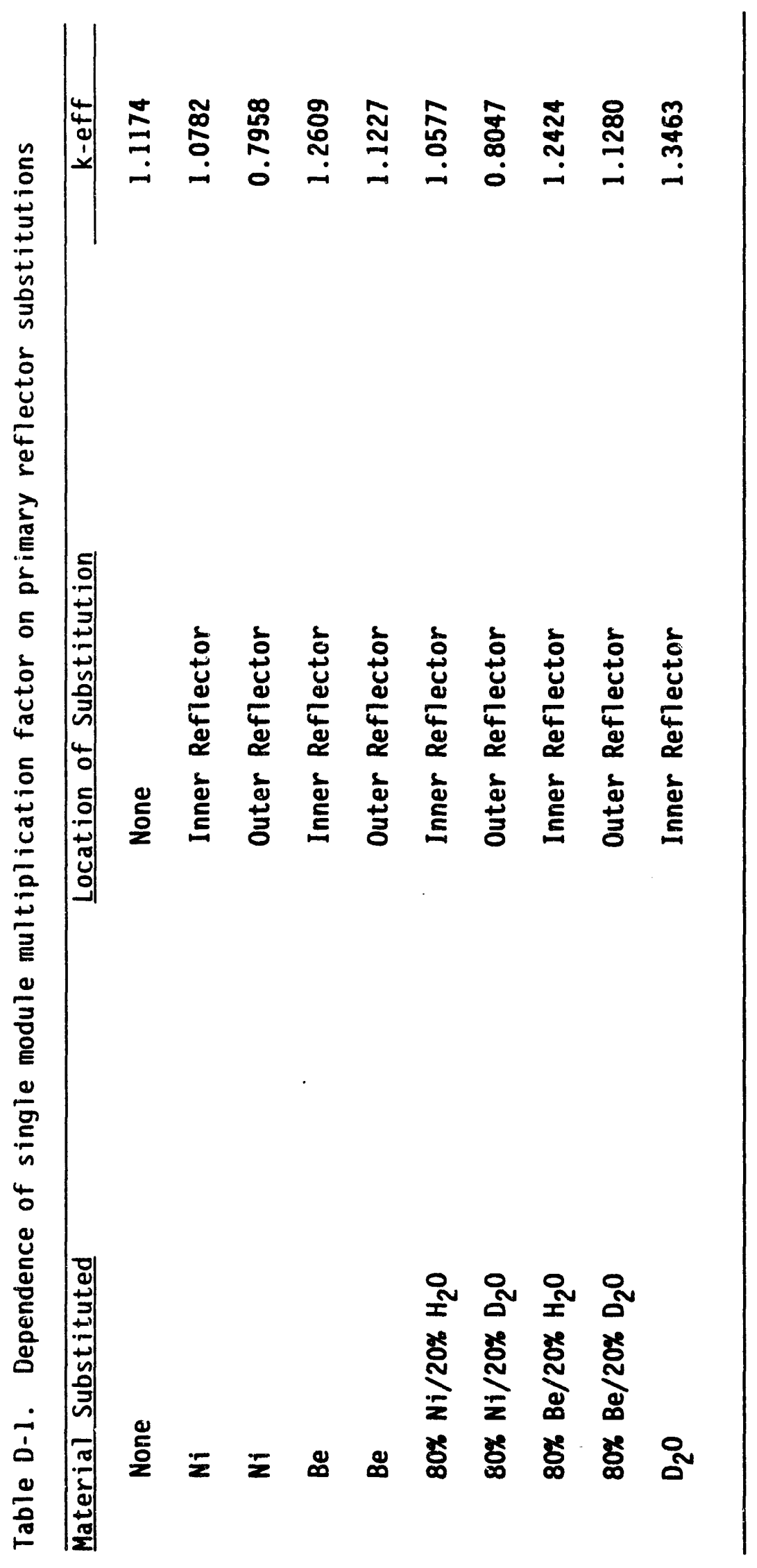




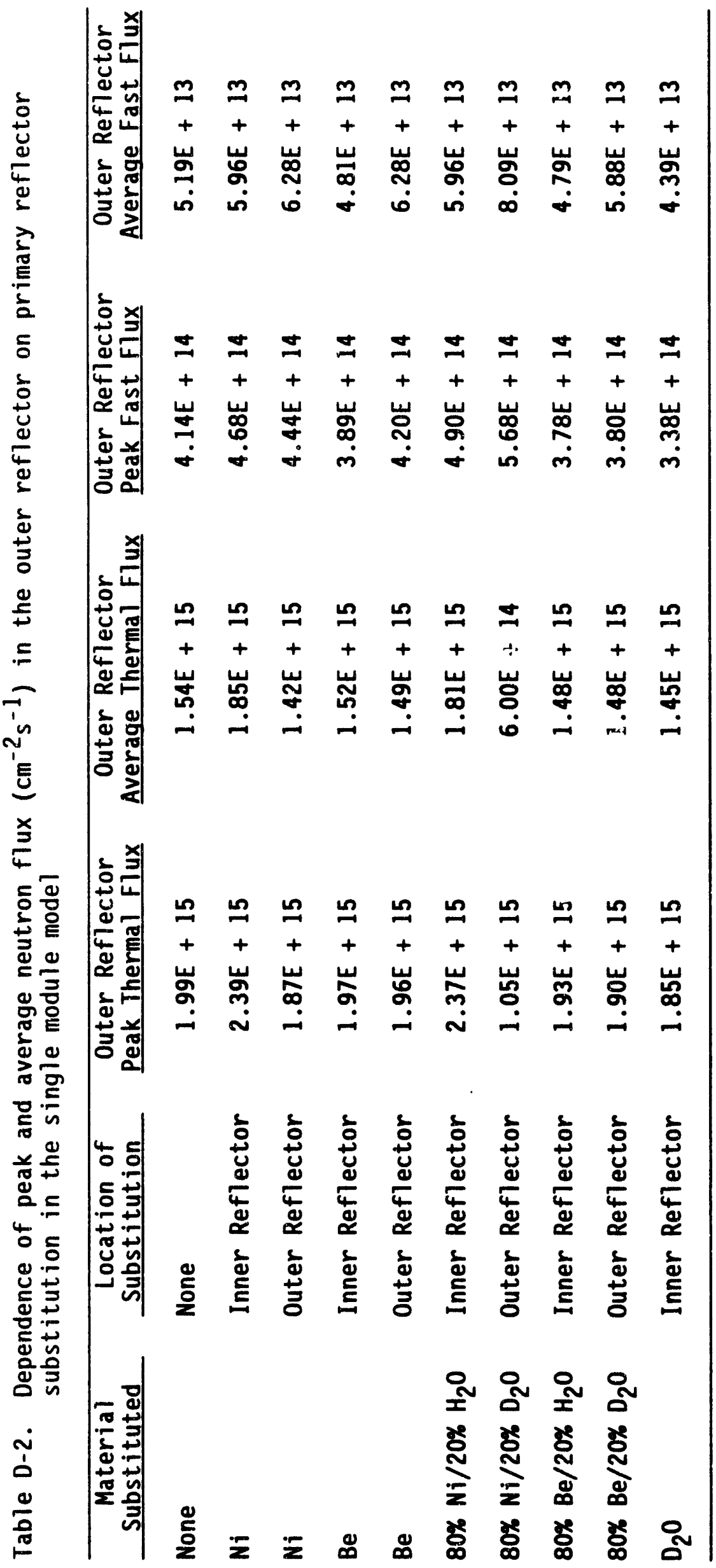




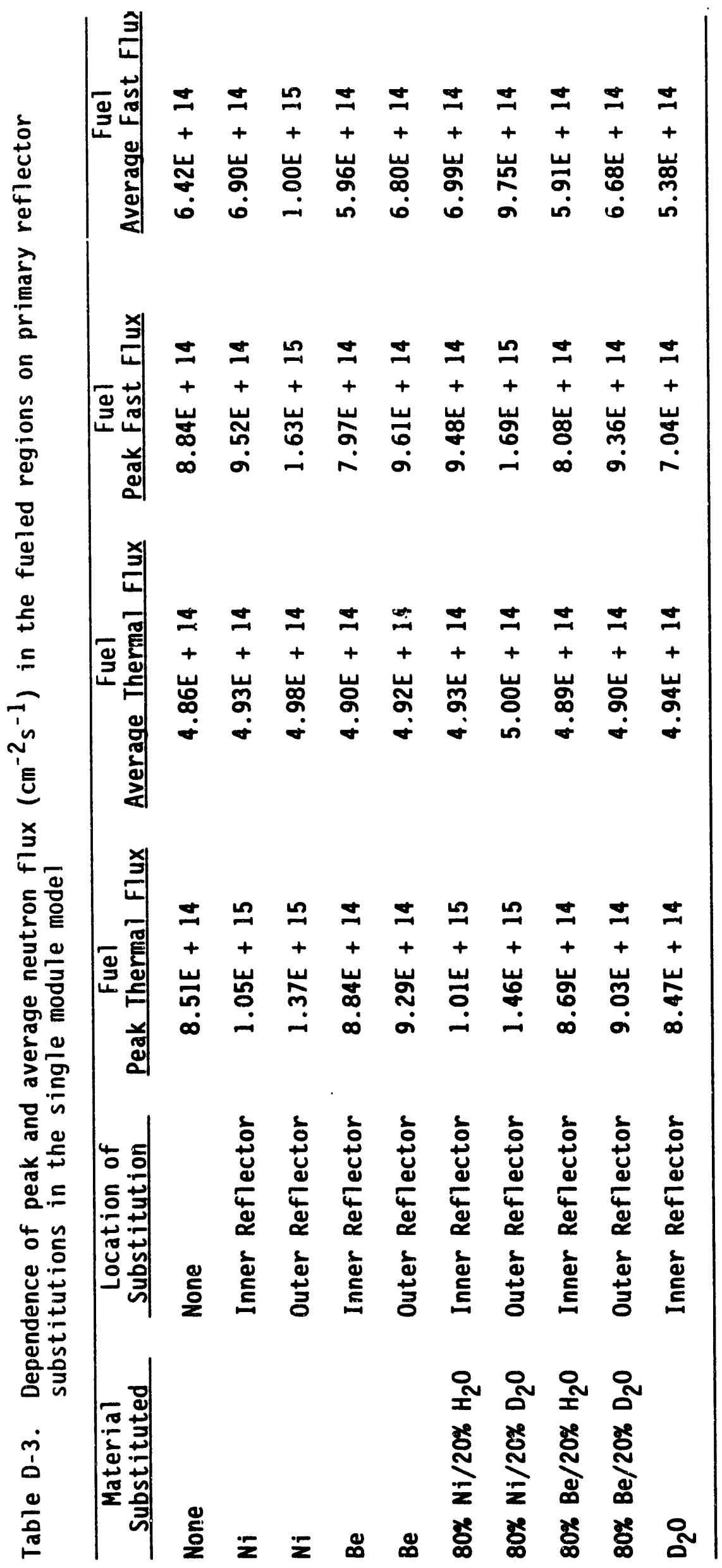




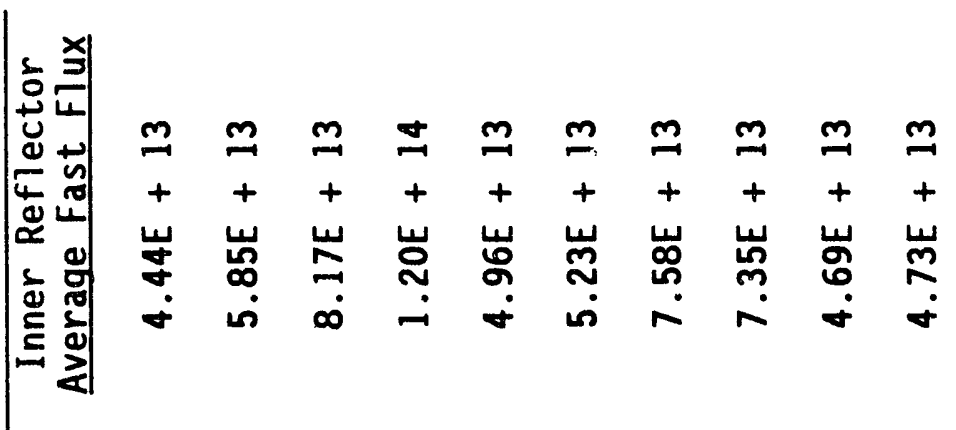

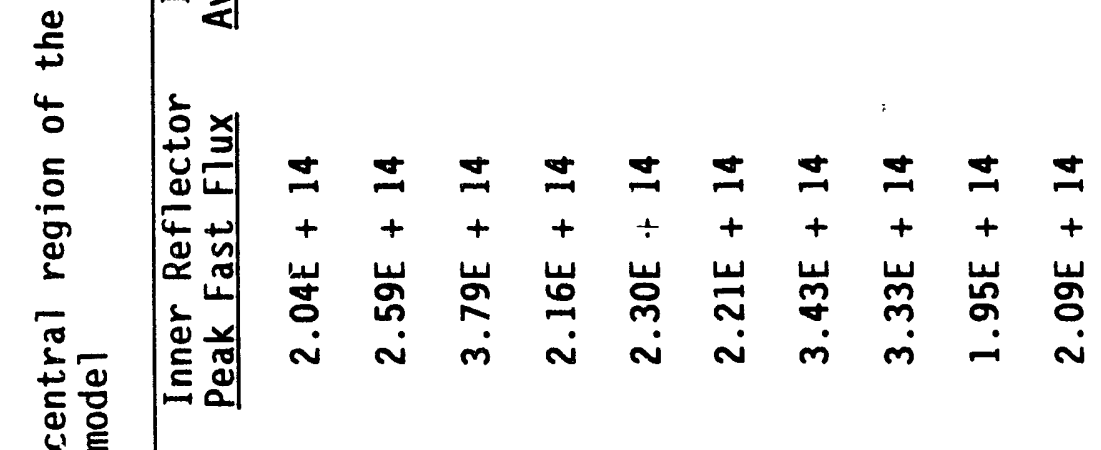

$$
\begin{aligned}
& \text { 岳焉 }
\end{aligned}
$$

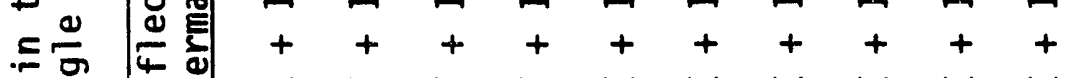

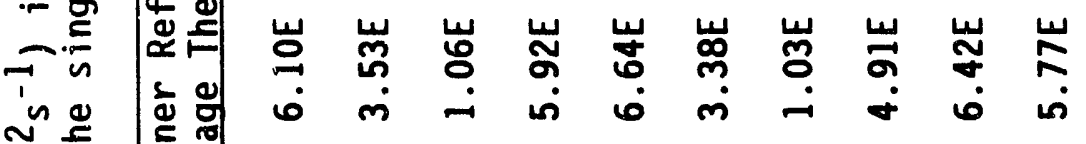

$$
\begin{aligned}
& \sim \text { s } \\
& \text { 'E } \\
& \text { 동 } \\
& \text { 전 } \\
& \text { ธำ } \\
& \text { 站苔 }
\end{aligned}
$$

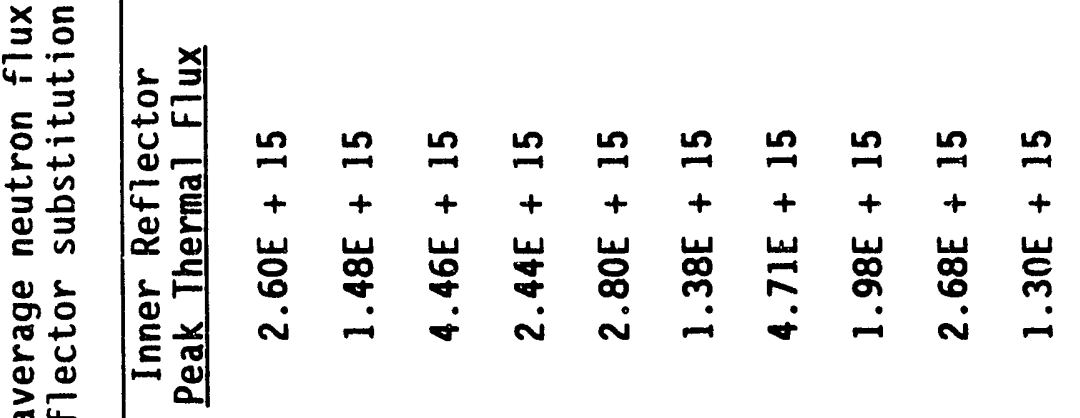

$$
\begin{aligned}
& \text { त }
\end{aligned}
$$

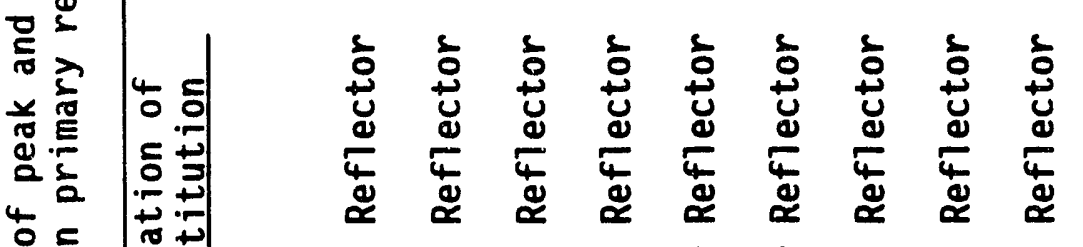

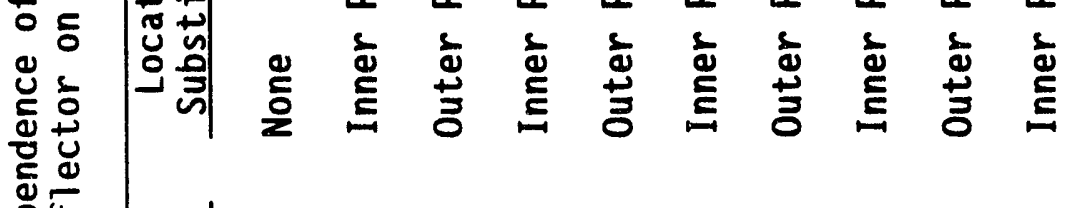

$$
\begin{aligned}
& \text { 高㐫 } \\
& \text { 安 }
\end{aligned}
$$

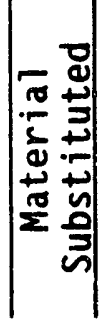

$$
\begin{aligned}
& \text { 옹 요 }
\end{aligned}
$$

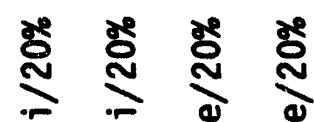

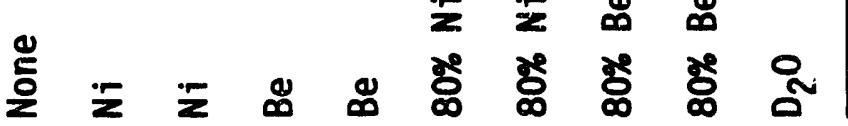




\section{D.3. TWO MODULE STUDIES}

4 two module prototype core has been studied to examine the effects of intermodule separation distance on the fast and thermal neutron fluxes and on the multiplication factor. Table D-5 shows a comparison of the multiplication factor and the peak thermal flux attainable as the separation between the two modules is varied from $0.5 \mathrm{D}$, to $1 \mathrm{D}$, to $2 \mathrm{D}$, where $D$ is the outer fuel module diameter $(=17.5 \mathrm{~cm})$. As expected, the multiplication factor increases with decreasing module separation, but the peak thermal flux reaches a maximum for module separation between 2.0 and $0.5 \mathrm{D}$. For reference, the single-module unperturbed core has a $k$-effective of 1.1174 (from Table D-1). These results can be used to help select the optimum spacing of modules in the multiple-annular reactor concept.

Table D-5. Variation in the multiplication factor and the peak thermal flux with the two module separation

\begin{tabular}{llc}
\hline $\begin{array}{c}\text { Module } \\
\text { Separation }\end{array}$ & k-effective & $\begin{array}{c}\text { Peak Therma }) \text { Flux } \\
\left(\mathrm{cm}^{-2} \underline{s}^{-1} L^{\text {Flux }}\right.\end{array}$ \\
\cline { 2 - 2 } Infinite* & 1.1174 & $1.99 \times 10^{15}$ \\
$2 D=35.0 \mathrm{~cm}$ & $1.1354 \pm 0.0027$ & $2.13 \times 10^{15}$ \\
$1 D=17.5 \mathrm{~cm}$ & $1.1515 \pm 0.0018$ & $5.35 \times 10^{15}$ \\
$0.5 D=8.75 \mathrm{~cm}$ & $1.1827 \pm 0.0025$ & $1.21 \times 10^{15}$
\end{tabular}

* This case is for a single module at $100 \mathrm{MW}$, while for the other cases the total power is $200 \mathrm{MW}$ ( $100 \mathrm{MW} /$ module).

\section{D.4. FULL CORE STUDIES}

\section{D.4.1 Six Module Ring Full Core}

A base case of 6 modules, each identical to the single base module, arranged in a circular ring in one large $D_{2} 0$ reflector tank, has been modeled. A base multiplication factor, $k=1.2714 \pm 0.0018$, was obtained for an intermodule separaition of $2 D=35 \mathrm{~cm}$ (twice the outer module 
diameter). Figure $D-2$ is a drawing to scale of this 6 -module reactor arrangement. The many surfaces shown are the flux tally (edit) regioris. The modules are identical to the base cases discussed above and the coolant is light water flowing through the fueled region and inside the inner fuel side plates. The reflector outside the fuel sideplates is heavy water. As expected, the core multiplication factor is higher with more modules present.

\section{D.4.2 Sixteen Module Full Core}

Hexagonal and rectangular arrays of 16 modules ( 4 by 4 ), each identical to the singla base module in a large $D_{2} 0$ reflector tank, have been modeled. The base model multiplication factors are $k=1.3115 \pm 0.0017$ and $k=$ $1.3076 \pm 0.0022$, respectively. These are shown in Figures $D-3$ and $D-4$, respectively. Again, the modules are identical to the base case module with inter-module separation of 20 and the reflecior outside the outer fuel side plates is heavy water.

\section{D.5. REFERENCES}

D-1. J. Briesmeister, ed., MCNP, A General Monte Carlo Code for Neutron and Photon Transport (Version 3A), LA-7396-M, Rev. 2, Los Alamos National Laboratory, 1986.

D-2. C. J. Pfeifer, PDO-7 Reference Manual II, WAPD-TM-947(2), Westinghouse Atomic Power Division, 1971.

D-3. J. M. Ryskamp, D. L. Selby, and R. T. Primm III, "Reactor Design of the Advanced Neutron Source," Nuciear Technology, 93, 1991, pp. $330-349$. 


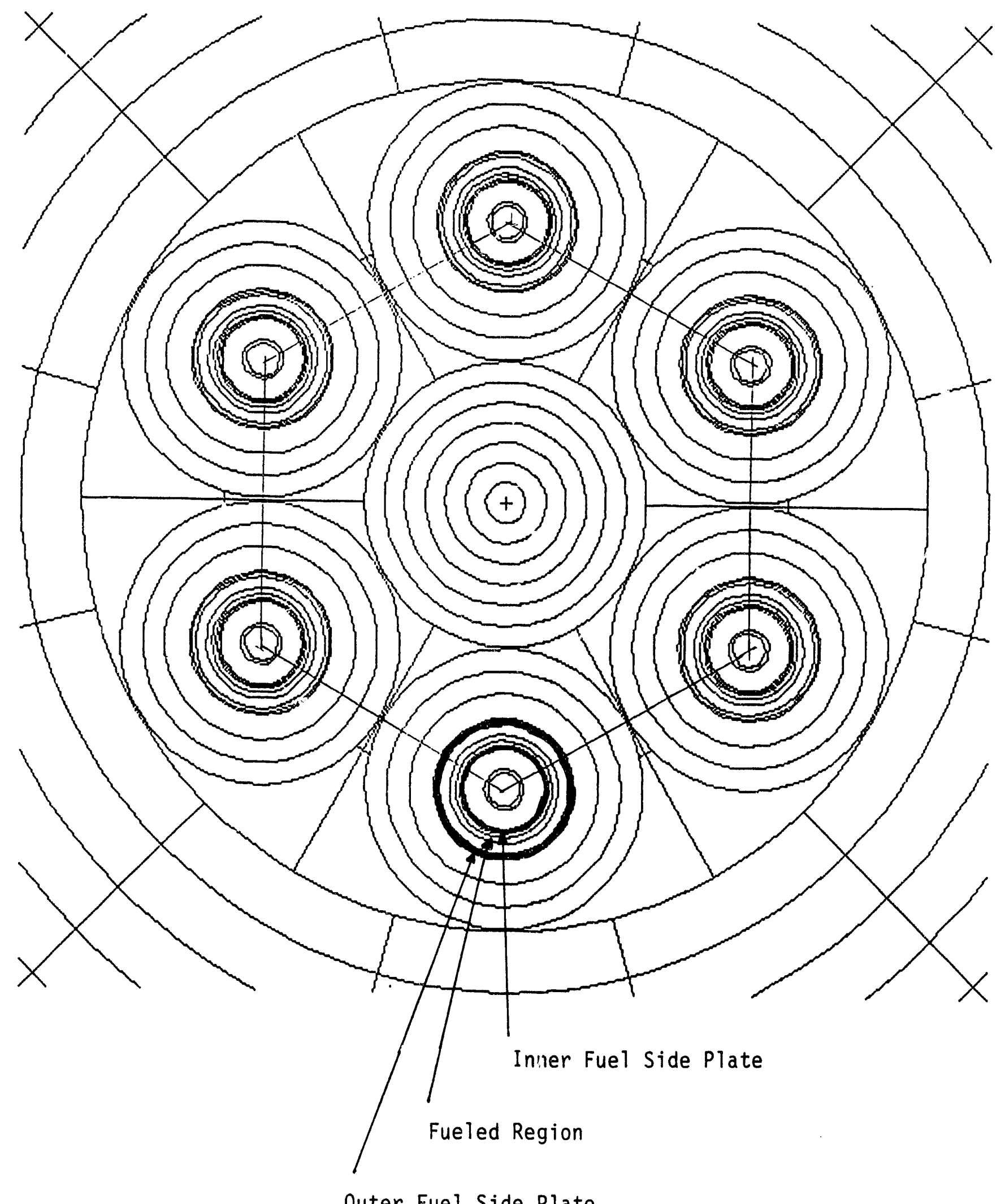

Outer Fuel Side Plate

Figure D-2. Six modules in a circular layout core. The intermodule separation is 2D, twice the diameter of the fuel side plate of a module. Tally (edit) surfaces are shown. Drawing is to scale. Cuter reflector tank is outside range of this figure. 

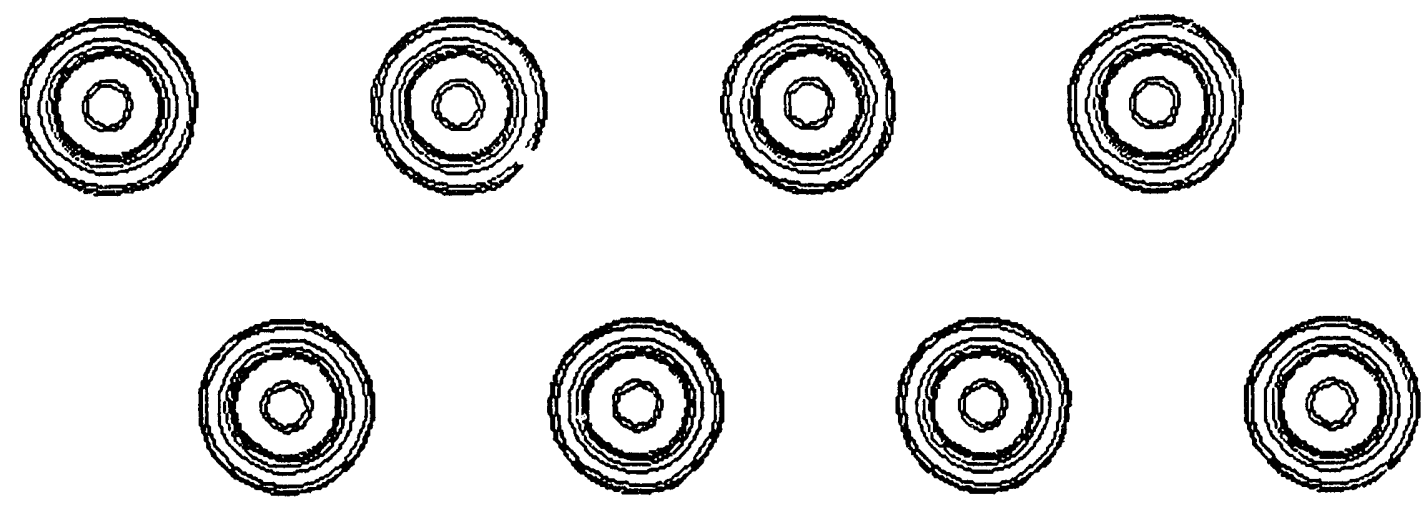

$+$

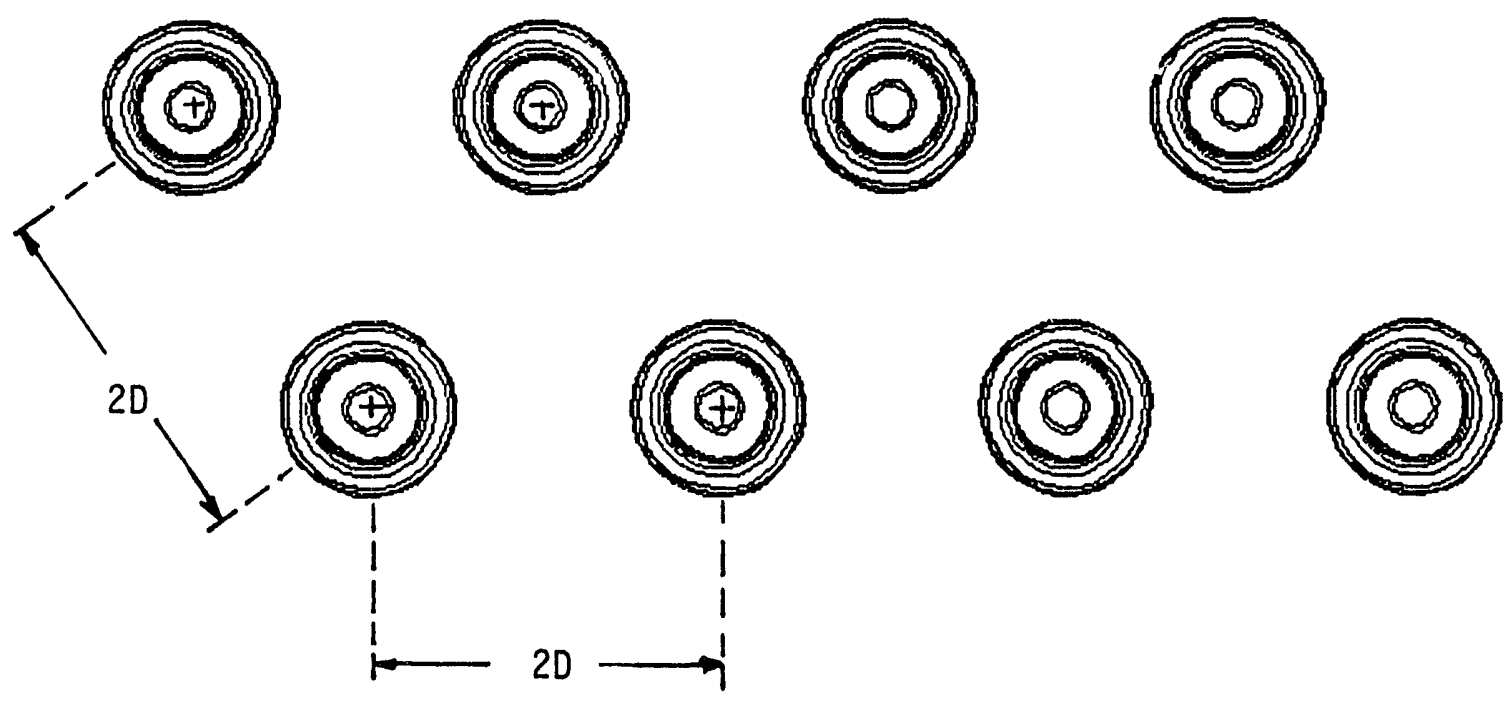

Figure D-3. Hexagonal layout of $4 \times 4$ modules. The intermodule separation is 20 , twice the outer fuel side plate. diameter of a module. 

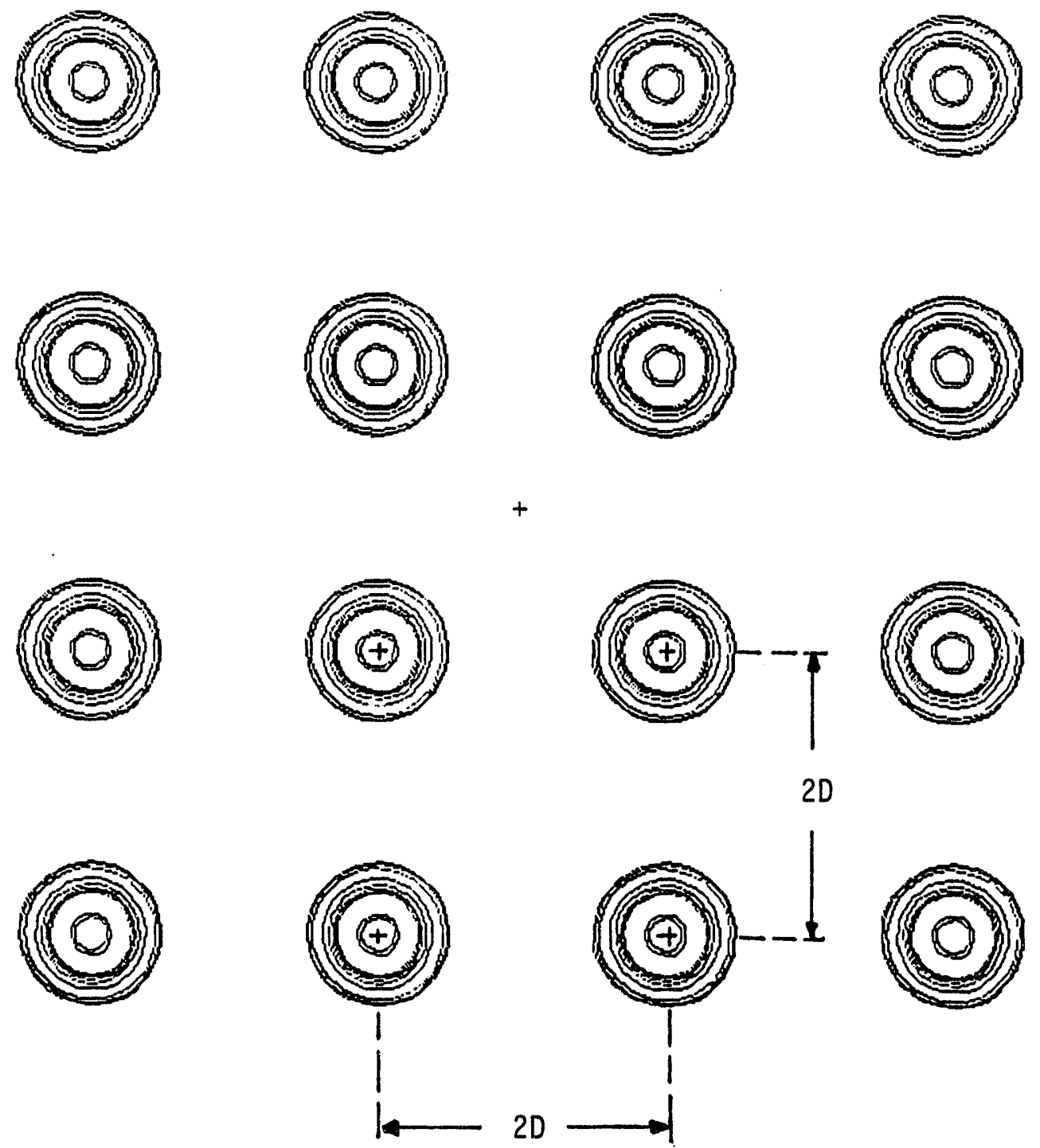

Figure D-4. Rectangular layout of $4 \times 4$ modules. The intermodule separation is $2 D$, twice the outer fuel side plate diameter of a module. The reflector outer perimeter is beyond the figure. 
APPENDIX E

MECHANICAL DESIGN STUDIES

R. L. Drexler 


\section{E.1. DESIGN INPUT BASED ON ATR FEATURES}

The Advanced Test Reactor, designed in the 1960s, has been a very successiul test reactor, and has a record of thousands of successful radiation exposures. The ATR is a third generation reactor, having been preceded by the Materials Test Reactor (MTR) and Engineering Test Reactor (ETR). From the operations of ATR and its predecessors over many years, there is a wealth of design and operating experience that should be factored into the design of any new test reactor.

A number of engineering personnel familiar with the ATR facility and procedures have made suggestions regarding certain design features and characteristics that a new test reactor should incorporate, and other areas where experience dictates changes. Most of the recommendations are intended to simplify or improve procedures during fuel or experiment handling operations.

\section{E.1.1 General Arrangement}

The general arrangement of the ATR and its operating systems has proven to be very satisfactory. One of the ideal arrangements, from an experimenter's standpoint, is the capability to leave the experiment loop piping and seals undisturbed while changing or manipulating irradiation capsules or reactor fuel. Access ports in the reactor vessel head allow in-vessel operations without removal of the vessel head. The region above and around the vessel head is kept clear for experiments and access for in-vessel operations. Control element drives and penetrations are located in the sides and bottom of the vessel.

While the specific core configuration selected for the BATR will determine the mechanical arrangement details, the general arrangement of the ATR has proven very satisfactory and could be advantageous for the BATR. Current safety criteria would dictate location of all major nozzles in the vessel at elevations above the top of the core. 


\section{E.1.2 Fuel Handling Within the Reactor Vessel}

The ATR reactor vessel head remains in place during fuel relocation or replacement operations. Fuel handling is done through five elliptical ports in the vessel head, leaving the experiment loop tubes in the central portion of the head undisturbed. While this is an excellent arrangement from the experimental standpoint, fuel handling is somewhat difficult. Fuel and other core and experimental items are removed from the vessel by moving them with long handled tools to a discharge port, located in the side of the vessel at an elevation near the top of the core.

A number of experiment 1000 tube supports and other structures above the core level interfere with movement of fuel and other radioactive materials within the vessel.

A much improved means of moving fuel and other items inside the vessel should be developed for the BATR. A direct, unobstructed path for moving fuel and materials to the discharge port and a procedure to reduce operating time and personnel exposures is essential. The procedures need to consider the possible effects of mixing light water with heavy water, if the latter is employed in the BATR.

\section{E.1.3 Internal Components}

The ATR reactor uses beryllium extensively for reflector material throughout the core. Certain beryllium components are large, difficult to fabricate, and are prone to damage from extended radiation exposure.

BATR internals, particularly beryllium components, should be designed to be less prone to failure from material radiation damage. Coniponents should be replaceable with a minimum of effort, downtime, and expense. Modular construction should be utilized where practical to simplify reactor system service. 


\section{E.1.4 Lower Plenum Access}

Access to the lower plenum region of the ATR reactor vessel is quite difficult due to the general arrangement and configuration of internal components. The BATR vessel and internals should be designed with a means of access to all regions where inspection or retrieval of loose hardware may be necessary.

\section{E.1.5 Cable Shim Drives}

Shim rods, inserted from below, are pushed up into position in the reactor by a flexible cable inside a curved guide tube. High resistance from friction and pressure differential of these drives should be addressed if drives of this type are used in the BATR.

\section{E.1.6 Fuel Hatch}

Irradiated fuel and capsules are removed from the ATR reactor vessel through an underwater discharge port in the side of the vessel. This system has functioned very well; however, for the BATR a similar system should have greater operating clearance with the items to be discharged.

\section{E.2. CHANGEABLE GRID CONCEPT}

Greater flexibility to accommodate larger or other special test loops could be achieved by incorporating a changeable grid structure reactor system. The grid, or core support and fuel configuration, would be changeable, such that reactor fuel could be repositioned to accommodate larger or special test loops. Alternate configurations could involve changes to only a part of the reactor core, or possibly a revised arrangement of the entire reactor. 


\section{E.2.1 Reactor Core}

Alternate configurations of the core and experiment loops is primarily dependent on the fuel assembly configuration. Optional loop locations would probably be limited to multiples of the standard fuel assembly pitch, or possibiy to other arrangements with slightly-modified fuel assemblies.

\section{E.2.2 Fuel and Core Support}

Fuel assembly end fittings can be designed to engage the core support structures in both the primary and alternate configurations. If there is an interference between nominal and alternate fuel locations, fuel assemblies with special end fittings could be used in the alternate locations.

Core support structures for the BATR are necessarily more complex than for the ATR in that additional core support structure is needed to restrain the fuel against the upward-directed coolant flow. Designing removable upper core support structures to fit into the crowded space around and between the flow loops may be a design challenge for any core configuration. Support and positioning structures could be designed with "insert" sections if needed to accommodate special or al ternate fuel configurations. Flow control and distribution elements for the core inlet region can be designed to operate with the core in more than one configuration. Fuel locations not in use can be filled with reflector elements, capsule racks, or can otherwise be blocked. Removable core inlet orifices can be used where needed for uniform flow distribution for all configurations.

\section{E.2.3 Pressure Vessel and Head}

Alternate locations of the test loops in the core must be compatible with the fuel, with linitations imposed by available space in the vessel, and with space for penetrations through the vessel top head. 
Test loops with a straight top tube entry are preferred from an experiment design and installation standpoint, and so the top penetration should be aligned with the test loop section in the core. However the tube below the core test section could be curved without inhibiting the test article or its installation and removal operations. It seems then that test loops with an offset below the core could be rotated about the lower head penetration to move the test section to alternate locations in the core region without changing the location of the penetration in the lower head.

Top head penetrations could be through off-center locations in port flanges. The flanges could be rotated on the ports to reposition the penetrations. A relocation of a few centimeters would be possible with this system, limited primarily by space requirements of the other loops and nozzle size requirements. Displacements of more than a few centimeters would probably require a vessel head with a large replaceable intermediate flange or a complete new replacement vessel head.

Space limitations on the vessel top head can be managed to an extent by design variations in the vessel head configuration. All of the standard and expected alternate configurations should be integrated into the initial vessel and head design so that ASME code compliance can be designed into all of the expected configurations. The size and location of the experiment loop tube penetrations will determine the degree of difficulty with the vessel head design. Generally, the larger core with more widely spaced loop penetrations will ease the problems with the vessel head design. A very thick vessel head design could be necessary if the experiment loop penetrations are large and are closely spaced.

\section{E.2.4 Control Elements}

Another limitation on the space available fur alternate test loop locations is the envelope established by the peripheral control elements. While it is not desirable to remove or relocate control elements in the 
core, with adequate design and safety analysis, alternate arrangements involving relocated control elements are possible.

The sidewall penetrations for the peripheral control element drives and lower head penetrations for central core element drives, as used in ATR, have a minimum impact on test loops and fuel handling operations. This type of radial drive for the peripheral control elements can easily accommodate radial relocation of those elements inside the vessel for alternate core and experiment loop configurations. 

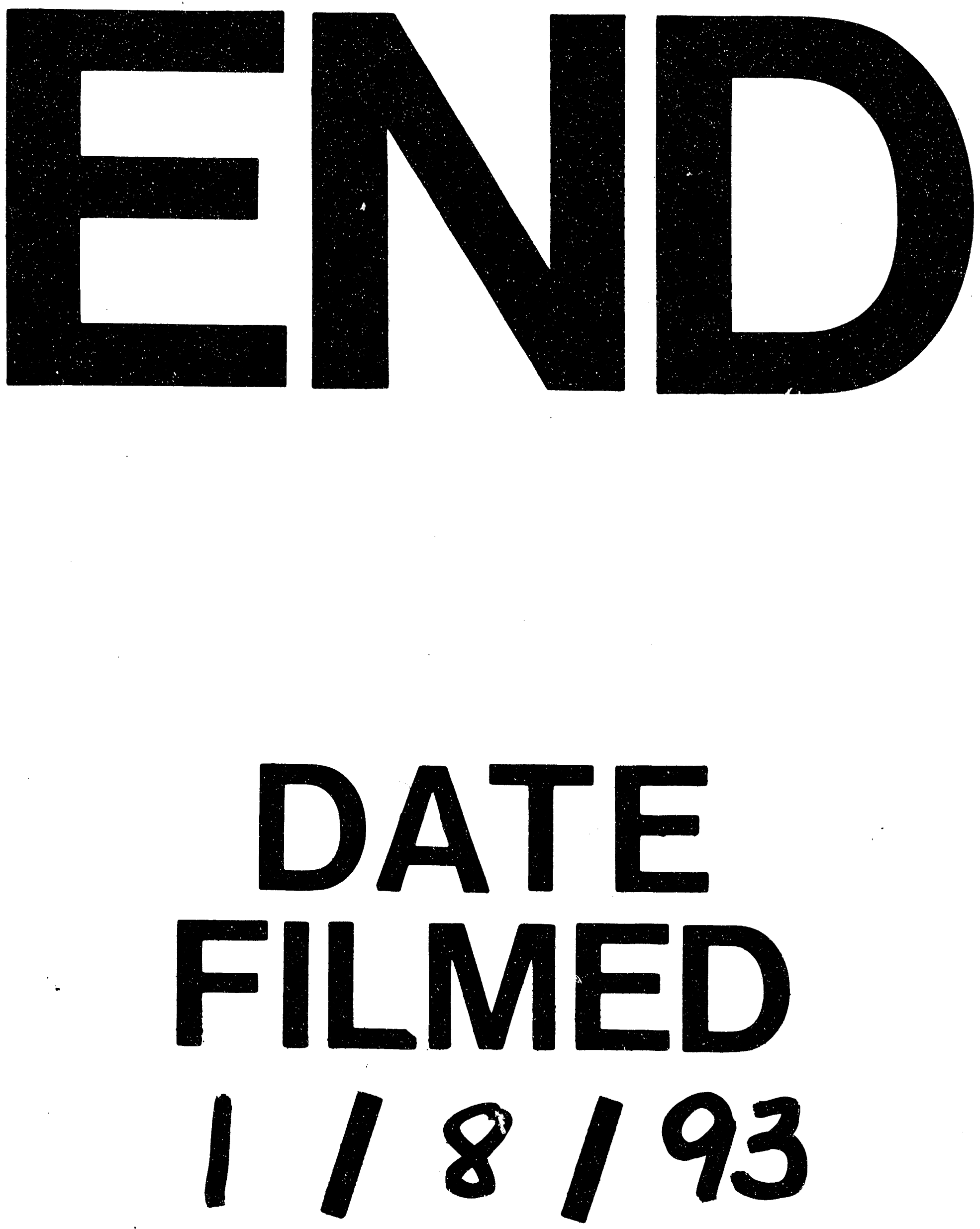
